\title{
Hemifacial Microsomia (HFM) and Treacher Collins Syndrome
}

\author{
Manikandhan Ramanathan
}

\subsection{Introduction}

Hemifacial microsomia (HFM) is a three-dimensional congenital deformity of the craniofacial region characterized by abnormal and underdevelopment of the first and second pharyngeal arches. Due to involvement of multiple structures, this disorder has a broad spectrum of involvement with diverse clinical features [1].

The highly variable phenotypes have probably led to variation in its nomenclature as well, alternatives used being craniofacial microsomia (CFM), otomandibular dysostosis, facio-auriculo-vertebral spectrum, oculo-auriculo-vertebral spectrum, first and second branchial arch syndrome, otomandibular-facial dysmorphogenesis, and lateral facial dysplasia [2].

This disorder is characteristically unilateral; however, incidence of bilateral cases is 10-15\%. Although this disorder was described first by Carl Ferdinand von Arlt, a German physician in 1881, "hemifacial microsomia" got its name from Gorlin and Pindborg in the early 1960s. Converse et al. proposed the name, craniofacial microsomia, in cases of coexisting cranial deformities where HFM is also associated with vertebral, cardiac, and renal defects, in a condition called as Goldenhar syndrome. It was termed "oculoauriculovertebral dysplasia" (OAVD) by Gorlin. It is also associated with epibulbar dermoids and ear deformities [2, 3].

\subsubsection{Epidemiology and Etiopathogenesis}

HFM is the second most common congenital anomaly of the face, with a male predilection and which is more common in

M. Ramanathan $(\bowtie)$

Department of OMFS, Meenakshi Ammal Dental College and Hospital, MAHER University, Chennai, India

Meenakshi Cleft and Craniofacial Centre, Meenakshi Ammal Dental College and Hospital, Chennai, India the right than the left side. The incidence of HFM ranges between 1 in 3500 and 1 in 26,000 live births [4-7].

The cause of HFM remains largely unknown. Poswillo in 1973 reported that hematomas resulting from disruption of embryonic arteries (stapedial artery) in utero produce abnormalities in the development of the structures derived from the first and second pharyngeal arches. The extent of the hematoma and consequent tissue damage during the first 6 weeks of gestation determines the severities of deformities. He was able to produce the CFM phenotype in mice, thus proving his theory. He administered teratogens to produce a hematoma of the stapedial artery and the artery of the second arch which resulted in regional necrosis [4] (Fig. 78.1a, b).

The second widely accepted hypothesis is a change in the migration of neural crest cells (Fig. 78.2). Retinoic acid is believed to influence and alter the migration and distribution of neural crest cells, which may predispose to abnormalities in the pharyngeal arch derivatives. The intake of retinoic acid in humans during the early stages of pregnancy may cause multiple disorders collectively known as "retinoic acid embryopathies" (RAEs); these include variable defects of the jaws and the middle and external ear [3-5]. Apart from retinoic acid, thalidomide, primidone, ethanol and isotretinoin have also been studied as causative agents in HFM through their teratogenic effects [6, 7].

More recent studies have demonstrated an association between HFM and multiple gestations, along with other maternal risk factors such as assisted reproduction, smoking, maternal diabetes mellitus and vasoactive drugs. Moreover, HFM may demonstrate autosomal dominant and recessive Mendelian patterns in families. Positive family history accounts for $50 \%$ occurrence of features [8].

Genetic events like duplication of the OTX2 gene (chromosome 14q22.3) have also been researched upon. OTX2 encodes a transcription factor, essential for craniofacial development and anterior brain morphogenesis. Heterogeneity in aetiology along with variable penetrance 
Fig. 78.1 (a, b) Anatomy of the stapedial artery during embryonic development

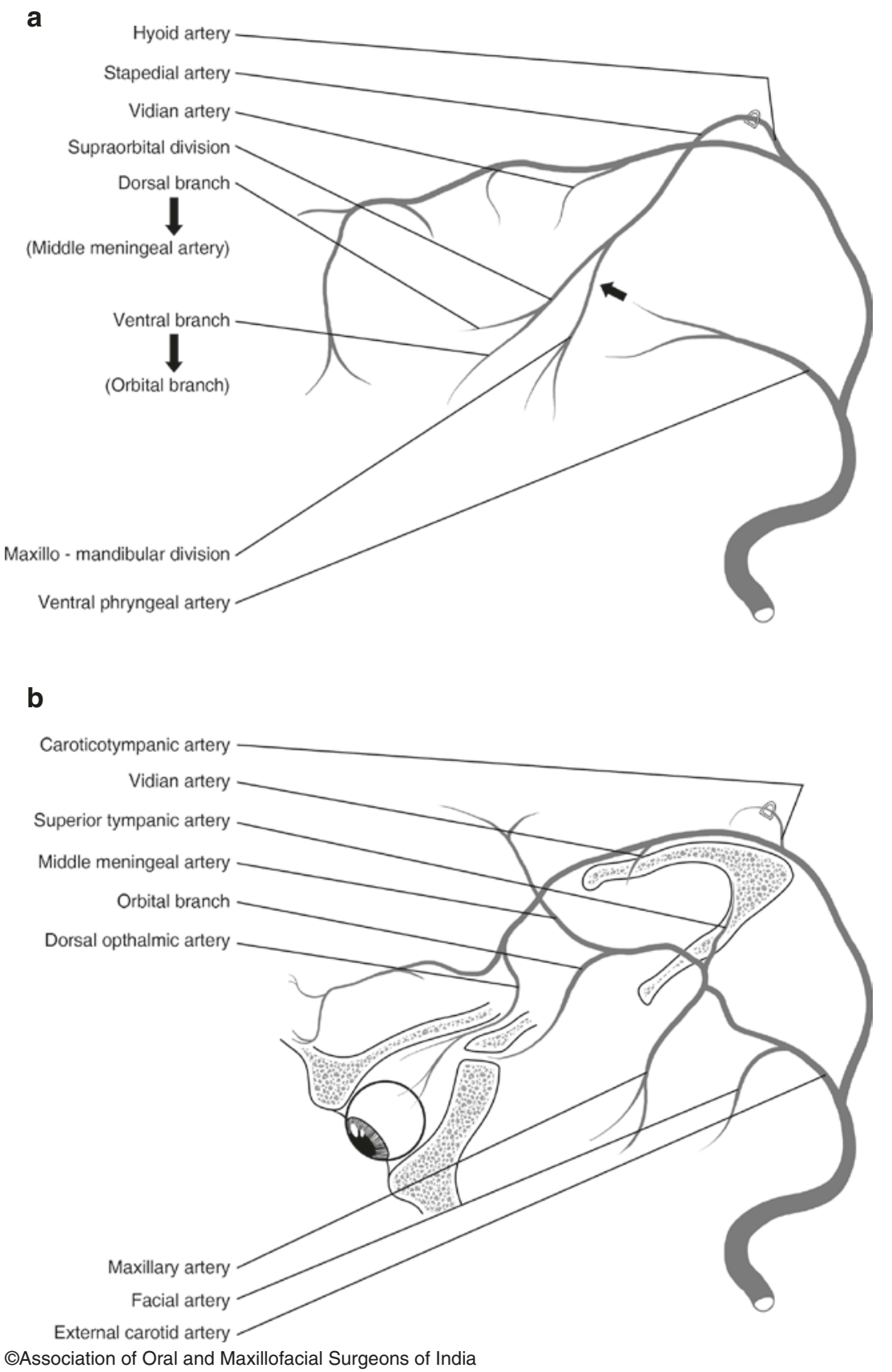

and expression is postulated to account for the widely variable phenotypic spectrum of HFM $[9,10]$.

\subsubsection{Classification Systems}

Various classifications have attempted to categorize various features of HFM as enumerated below [11-13]:

1. SAT classification.

2. OMENS classification.

3. Kaban-Pruzansky classification.

\subsubsection{SAT Classification}

The skeletal, auricle, and soft tissue (SAT) classification.

The SAT and the OMENS (Tables 78.1 and 78.2) classifications provide an elaborate system covering simple to complex skeletal, soft tissue and neurological involvement. On the other hand, the Kaban-Pruzansky classification explains malformations involving the mandible, masticatory muscles, and TMJ. Therefore, it is more useful for orthodontists and maxillofacial surgeons in reconstruction of the mandible and TMJ. Thus, this classification has become the gold standard. It involves four classes- 


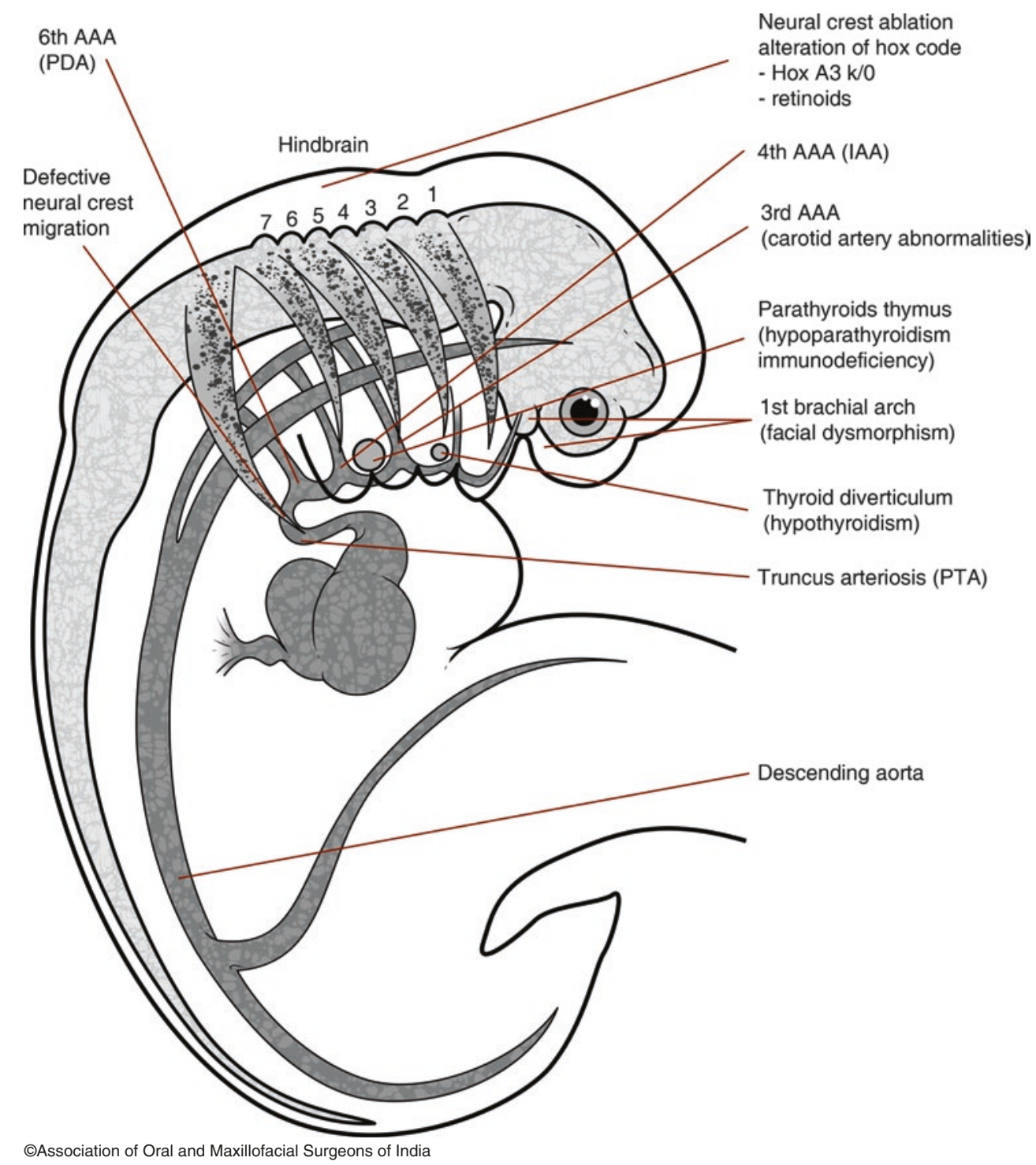

Fig. 78.2 Migration of neural crest cells during embryonic development

Table 78.1 SAT classification of HFM

\section{Skeletal categories (S)}

$\mathrm{S} 1=$ small mandible - Normal shape

S2 = condyle, ramus, sigmoid notch discernible, distorted; mandible remarkably different in size and shape S3 = severe mandibular deformity, poorly discernible, to agenesis of ramus

S4 = an S3 mandible with orbital involvement, lateral and inferior orbital rims displaced posteriorly

S5 = the S4 defects plus orbital dystopia, hypoplastic, asymmetric, neurocranium and a flat temporal fossa

\section{Auricle categories (A)}

A0 $=$ Normal

A1 = small, malformed auricle - With characteristic features

A2 $=$ rudimentary auricle with hook at cranial end corresponding to the helix A3 = malformed lobule, pinna absent
Soft tissue categories (T)

$\mathrm{T} 1$ = contour defect minimal - No cranial nerve involvement $\mathrm{T} 2=$ moderate defect 
Table 78.2 OMENS classification

\begin{tabular}{|c|c|c|c|c|}
\hline Orbit & Mandible & Ear & Nerve (cranial nerve VII) & Soft tissue \\
\hline $0=$ Normal & Type I & Type I = small ear, the normal structure & $0=$ Normal & $0=$ Normal \\
\hline 1 = small size & Type IIA & $\begin{array}{l}\text { Type } \mathrm{II}=\text { severe external ear deformity with a } \\
\text { rudimentary auricle }\end{array}$ & $1=$ upper branches impaired & $1=$ mild hypoplasia \\
\hline $2=$ poor position & Type IIB & $\begin{array}{l}\text { Type III = small rudiment of external ear with no } \\
\text { pinna }\end{array}$ & $2=$ lower branches impaired & $\begin{array}{l}2=\text { moderate } \\
\text { hypoplasia }\end{array}$ \\
\hline $\begin{array}{l}3=\text { small size and } \\
\text { poor position }\end{array}$ & Type III & Type IV = Anotia & $\begin{array}{l}3=\text { upper and lower branches } \\
\text { impaired }\end{array}$ & $\begin{array}{l}3=\text { severe } \\
\text { hypoplasia }\end{array}$ \\
\hline
\end{tabular}

the Type 1, Type 2A, Type 2B, and Type 3 (Fig. 78.3a-d).

\section{Type 1}

In this category, the TMJ morphology is normal with adequate bulk and function of masticatory muscles. The mandible is slightly hypoplastic and retruded which may project as a mild asymmetry with deviation of the chin to the affected side (Fig. 78.4a, b).

\section{Type 2A}

In this type, the affected side TMJ is shifted anteriorly and medially than its counterpart, but the overall morphology of the condyle and glenoid fossa remains unchanged. The joint is functional associated with moderate muscular hypoplasia. The patient demonstrates moderate hypoplasia of the mandible with occlusal canting or open bite, and the chin is deviated to the affected side.

\section{Type 2B}

There is moderate-to-severe involvement of the joint with condyle and the glenoid fossa grossly hypoplastic. The joint exhibits only rotation movement of the condyle and nearnormal function. Involvement of other facial bones and deficiency of masticatory muscles are clinically evident. The patient demonstrates severe asymmetry and occlusal canting with or without an open bite (Fig. 78.5a, b).

\section{Type 3}

There is gross facial asymmetry with severely hypoplastic or absent muscles of mastication. There is associated severe deformity of the skull and orbito-zygomatic complex as well. The mandible is severely affected with a "floating mandible" appearance due to absence of the condyle and ramus (Fig. 78.6a, b). These patients from birth may often present with signs of a compromised airway due to severe degrees of mandibular retrusion.

\subsubsection{Clinical Features}

The diagnosis of HFM is challenging owing to its wide phenotypic spectrum. There are no definite diagnostic crite- ria and classifications. The condition is diagnosed based on its clinical features of phenotype ranging from involving the orbit or ear alone to full-blown hemifacial microsomia under development with jaw malformations. For this reason, certain classification systems have been established to standardize the assessment in an organized manner and formulate treatment plan accordingly. The areas of examination include various components of the face, i.e. external ear, mandible, temporal bone, zygoma, orbit middle ear, facial musculature, facial nerve supply, and other adjacent bony and soft tissues [2, 5, 7, 14] (Fig. 78.7a-d and Table 78.3).

\subsubsection{Skeletal Defects}

\section{Cranio-orbital}

The cranial involvement is mainly limited to the squamous part of the temporal bone. Most individuals affected with HFM demonstrate hypoplasia of the zygomatico-maxillary complex. These patients clinically show malar depression with orbital dystopia. The zygomatic bone hypoplasia can lead to alterations in the glenoid fossa.

\section{Maxillomandibular}

The maxillomandibular region is primarily affected due to abnormal development of the first and second branchial arches. It presents as unilateral facial deformities with reduced dimensions of facial bones in all three dimensions (3D). This produces varying degrees of gross morphological asymmetry of the face and compensatory changes of the contralateral side. The affected side in HFM may vary in severity and also alters the morphology of the so-called normal contralateral side, resulting in gross deviation in 3D, making it a difficult term as unaffected normal side (Figs. 78.5, 78.7, $78.8 \mathrm{a}-\mathrm{c}$ and $78.9 \mathrm{a}-\mathrm{c})$.

Mandibular growth changes are the earliest manifestations of HFM and are accountable for its classical presentation of facial asymmetry. The ramus of the mandible is either absent or short, with a medial displacement. The contour of the entire mandibular corpus is altered with a shift of the Genium to the affected side. Dental compensations occur for the skeletal discrepancy, which may mask the actual severity of the clinical condition. 
a

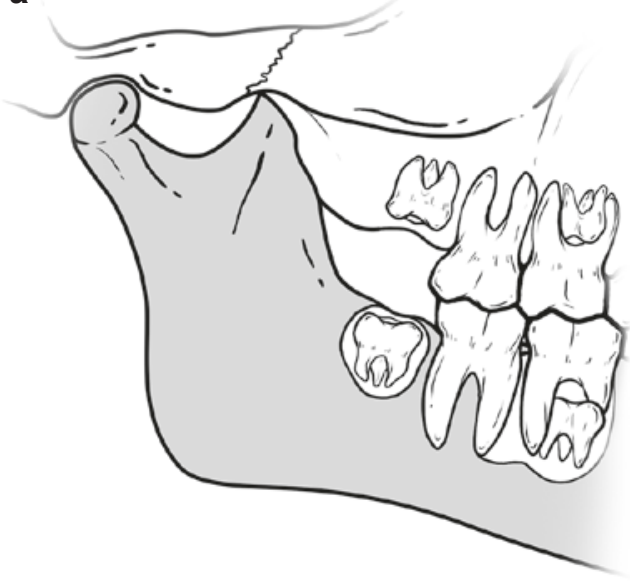

b

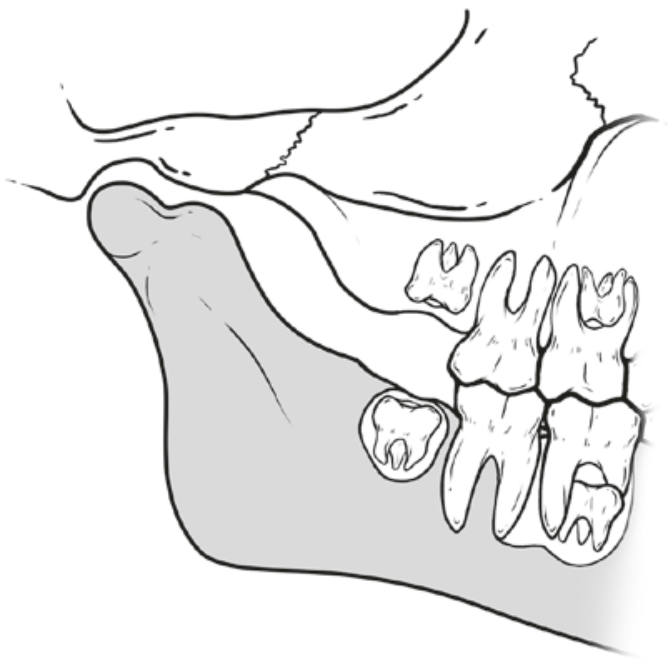

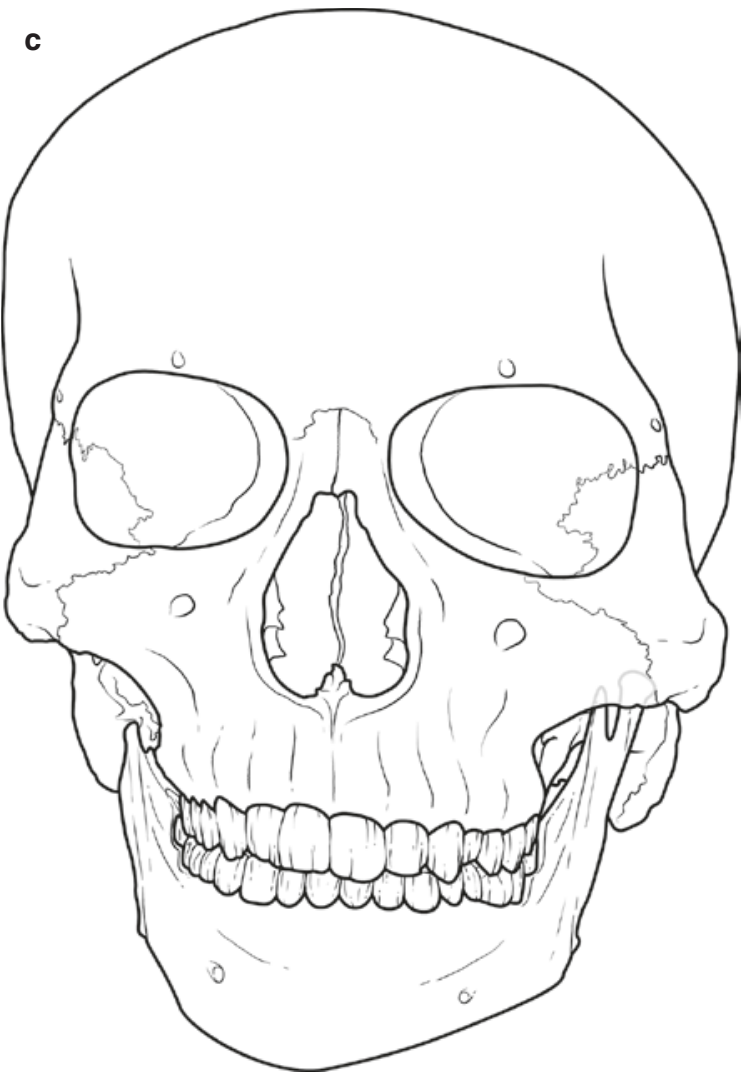

(CAssociation of Oral and Maxillofacial Surgeons of India

d

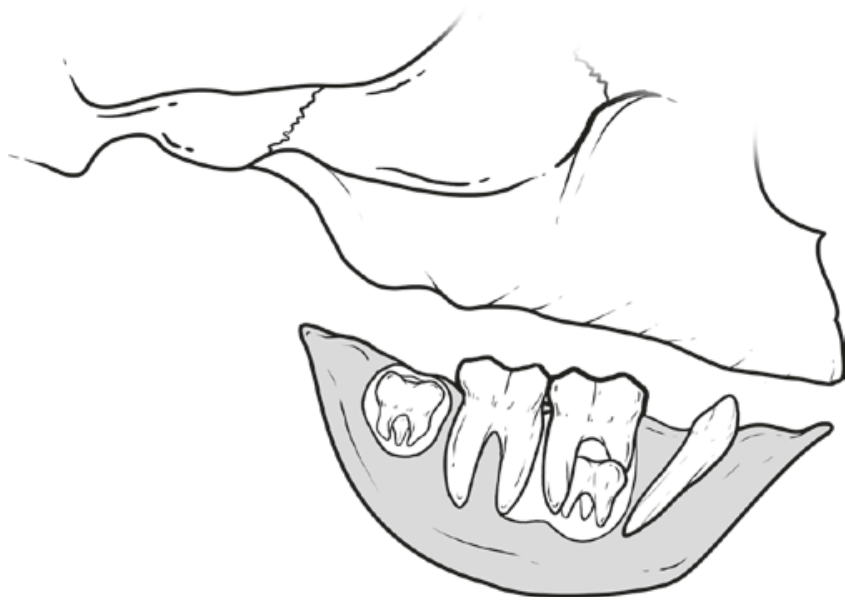

Fig. 78.3 (a-d) Kaban's modification of Pruzansky's classification for hemifacial microsomia (HFM). (a) Type 1, (b) Type 2A, (c) Type 2B (d) Type 3 Note that the temporomandibular joint (TMJ) in Type IIB is medially, inferiorly and anteriorly displaced so as to be operationally equivalent to Type III 

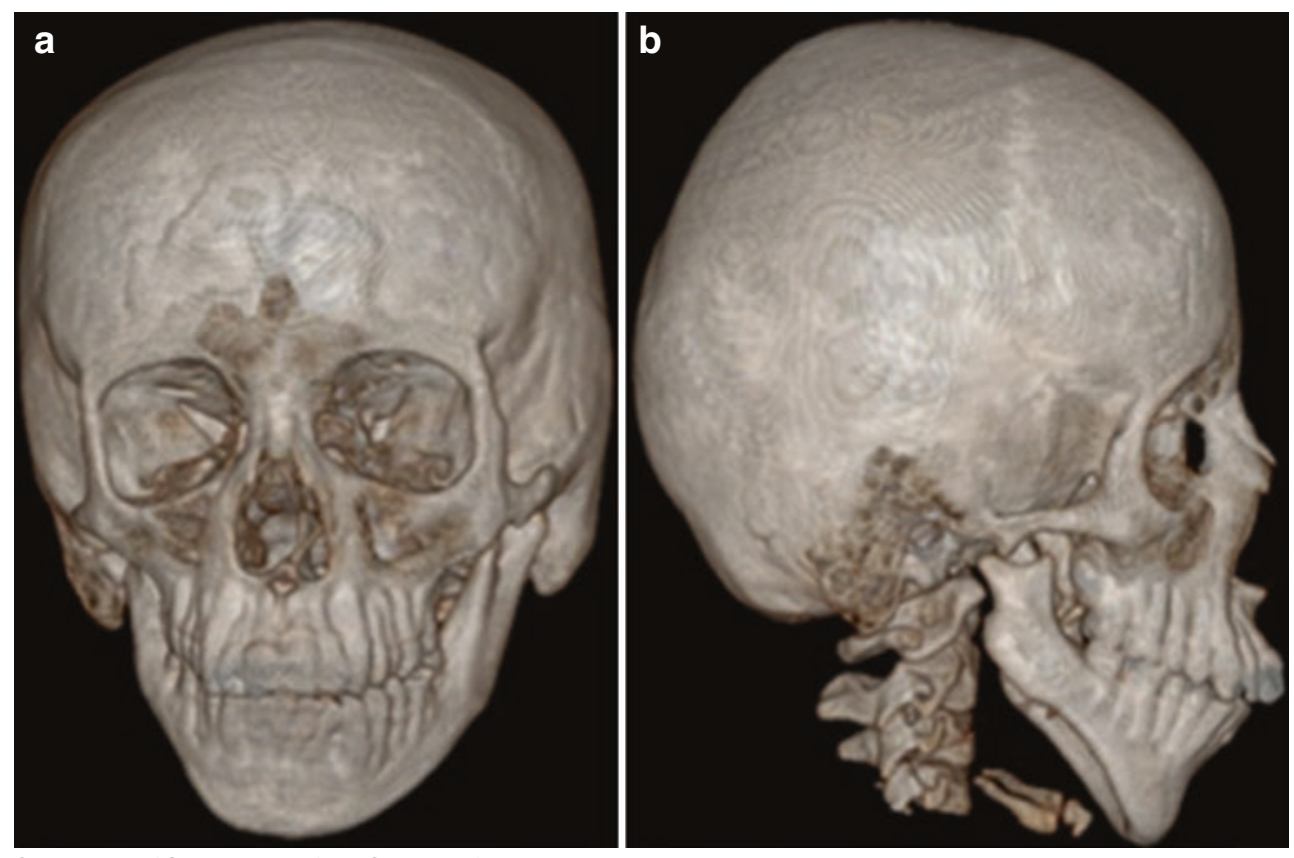

(CAssociation of Oral and Maxillofacial Surgeons of India

Fig. 78.4 (a, b) CT scan of patient with left-sided Type 1 Kaban-Pruzansky deformity
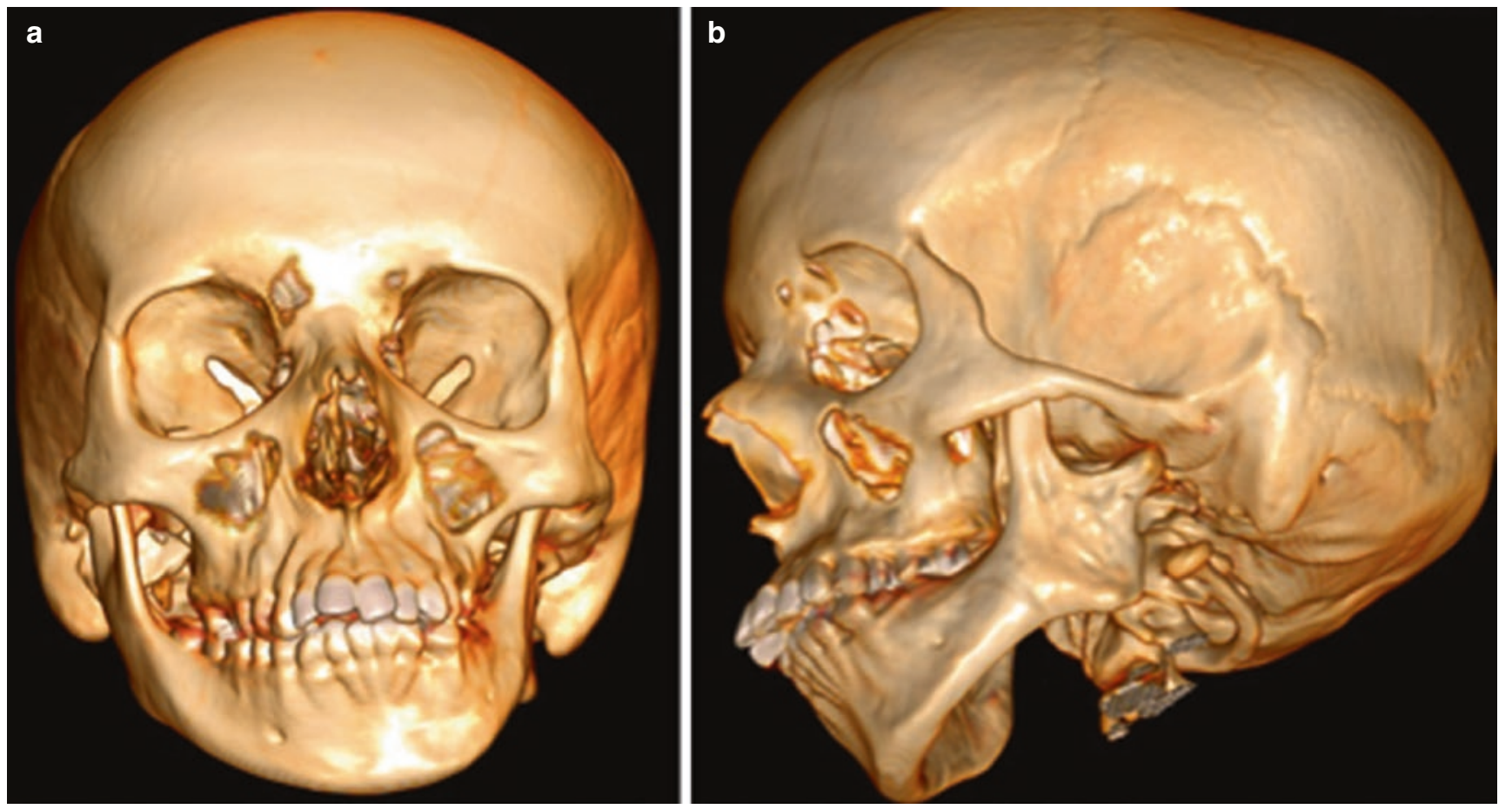

CAssociation of Oral and Maxillofacial Surgeons of India

Fig. 78.5 (a, b) CT scan of patient with right-sided Type 2B Kaban-Pruzansky deformity 

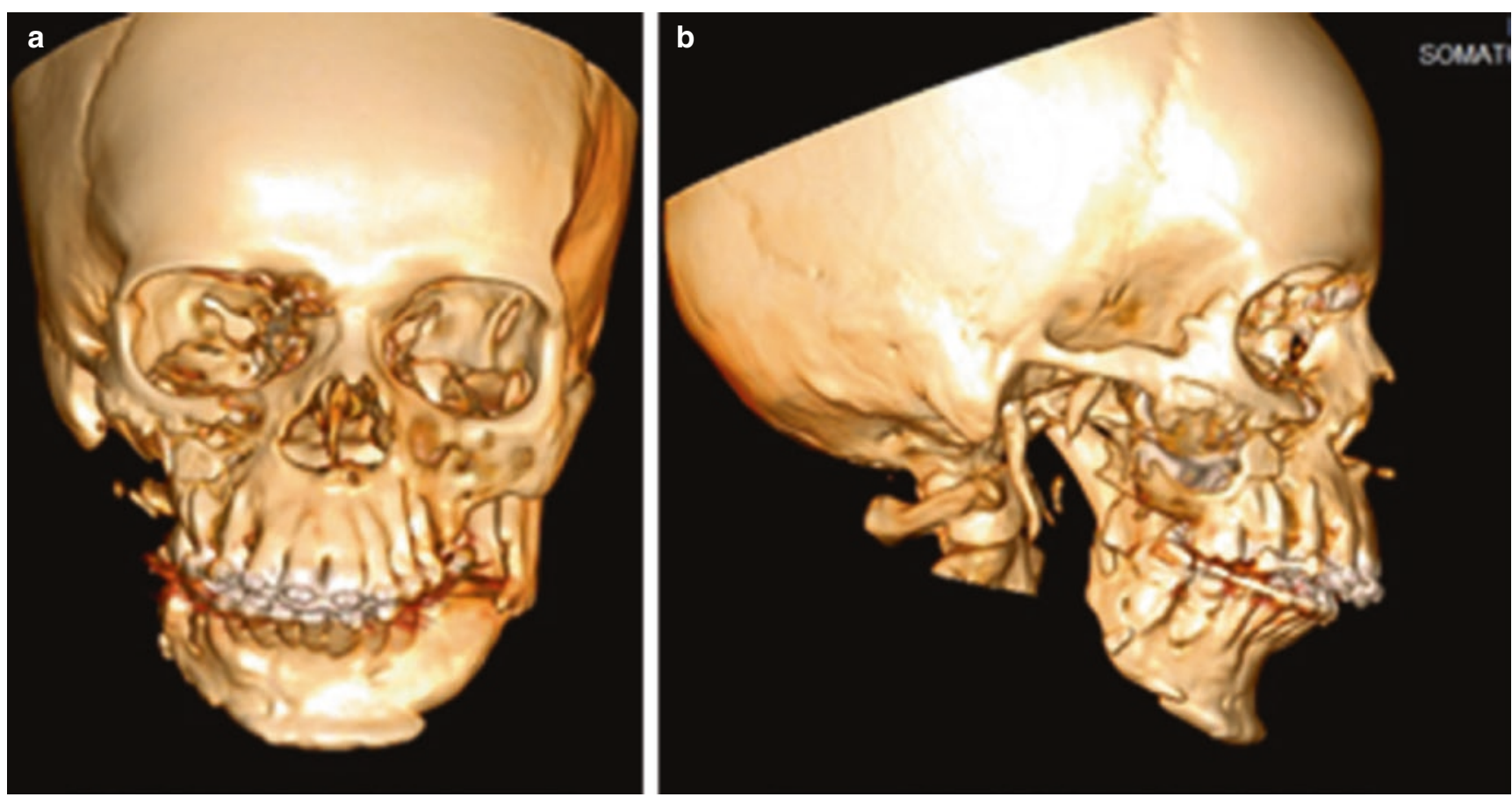

CAssociation of Oral and Maxillofacial Surgeons of India

Fig. 78.6 (a, b) CT scan of patient with right-sided Type 3 Kaban-Pruzansky deformity

\subsubsection{Soft Tissue Defect}

Soft tissue deformities may involve the ear, the seventh nerve and the muscles of facial expression and mastication. Subcutaneous tissues of the face may also be affected to varying degrees. Macrostomia is a common feature along with the presence of skin tags between the tragus and the commissure of the mouth. Lateral facial clefts (Tessiers 6, 7 and 8) may be present involving the soft tissue or hard tissue or both. Function of the cranial nerves, essentially the seventh and rarely the fifth, may be compromised $[15,16]$. General soft tissue bulk of the subcutaneous fat and muscles may exhibit deficiency (Fig. 78.7). There may also be compromise in the function of the soft palate.

\section{Skin Tags}

Vestigial skin rests also called as auxiliary hillocks or skin tags are usually present along an imaginary line connecting the tragus of the ear to the commissure of the mouth. This is the embryonic line of fusion between the first and second pharyngeal arches. The tags are frequently present in varying numbers and are associated with cartilaginous remnants, blind sinus tracts that may form inclusion cysts if obstructed [4-6] (Fig. 78.7).

\section{Macrostomia}

Macrostomia occurs as a result of failure of fusion of the maxillary and mandibular processes, leading to a cleft at the oral commissure including the skin and the underlying orbicularis oris (Fig. 78.10a, b). Sixty-one per cent of patients with HFM exhibit macrostomia as reported by Vento and colleagues [12].

\section{External Ear Deformities}

Meurman described a classification for deformities of the external ear which was modified by Marx [17, 18] (Fig. 78.11a-c):

- Grade I: Mild hypoplasia, with all structures present and obvious malformation.

- Grade II: Atresia of the external auditory canal, with a vertically orientated cartilaginous remnant. 

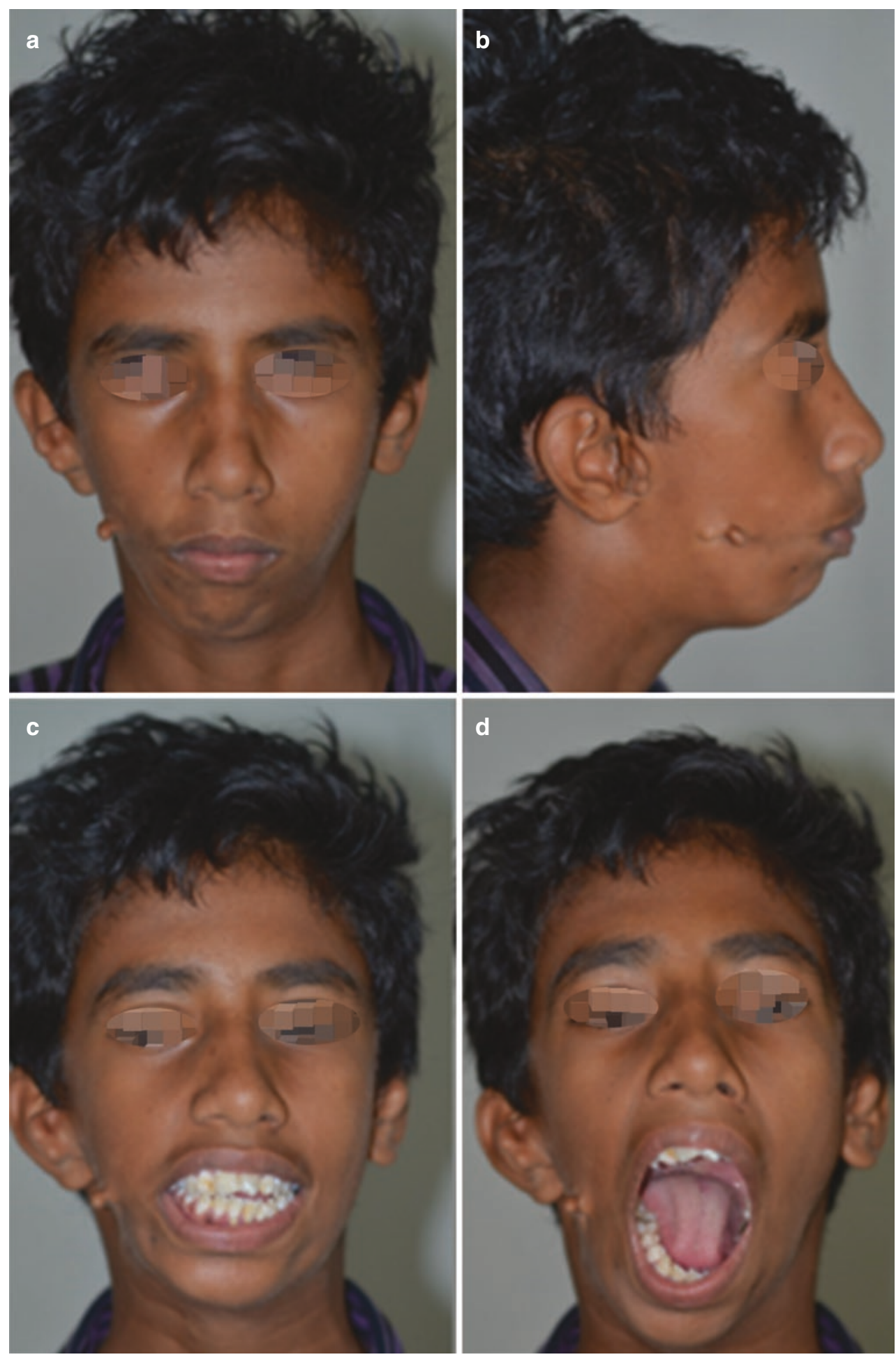

Fig. 78.7 (a-d) 15-year-old male, frontal and profile view (a, b) showing features of hemifacial microsomia such as lateral cleft and preauricular skin tags. (c) demonstrates macrostomia and maloccusion while

(d) shows exaggerated oral aperture with deviation of mandible to the right side on mouth opening (Also see Fig. 78.30b) 
Table 78.3 Clinical features of hemifacial microsomia and the spectrum of associated anomalies

\section{Head and neck}

Maxillary and mandibular asymmetry with hypoplasia on the affected side

Microphthalmia

Hypoplastic adnexal structures

Coloboma

Zygomatic hypoplasia

External ear abnormalities or atresia

Internal ear abnormalities

Temporomandibular joint hypoplasia or absence

Hypoplastic dentition or oligodontia

Parotid hypoplasia or agenesis

Plagiocephaly

Torticollis

\section{Associated congenital anomalies}

Cardiac defects (tetralogy of Fallot, ventricular septal defect, aortic coarctation, patent ductus arteriosus)

Lung hypoplasia

Renal agenesis, ectopic kidney, multicystic

Dysplastic kidney, vesicoureteral reflux, or ureteropelvic junction obstruction Vertebral anomalies

Mental retardation, Arnold-Chiari malformation, encephalocele
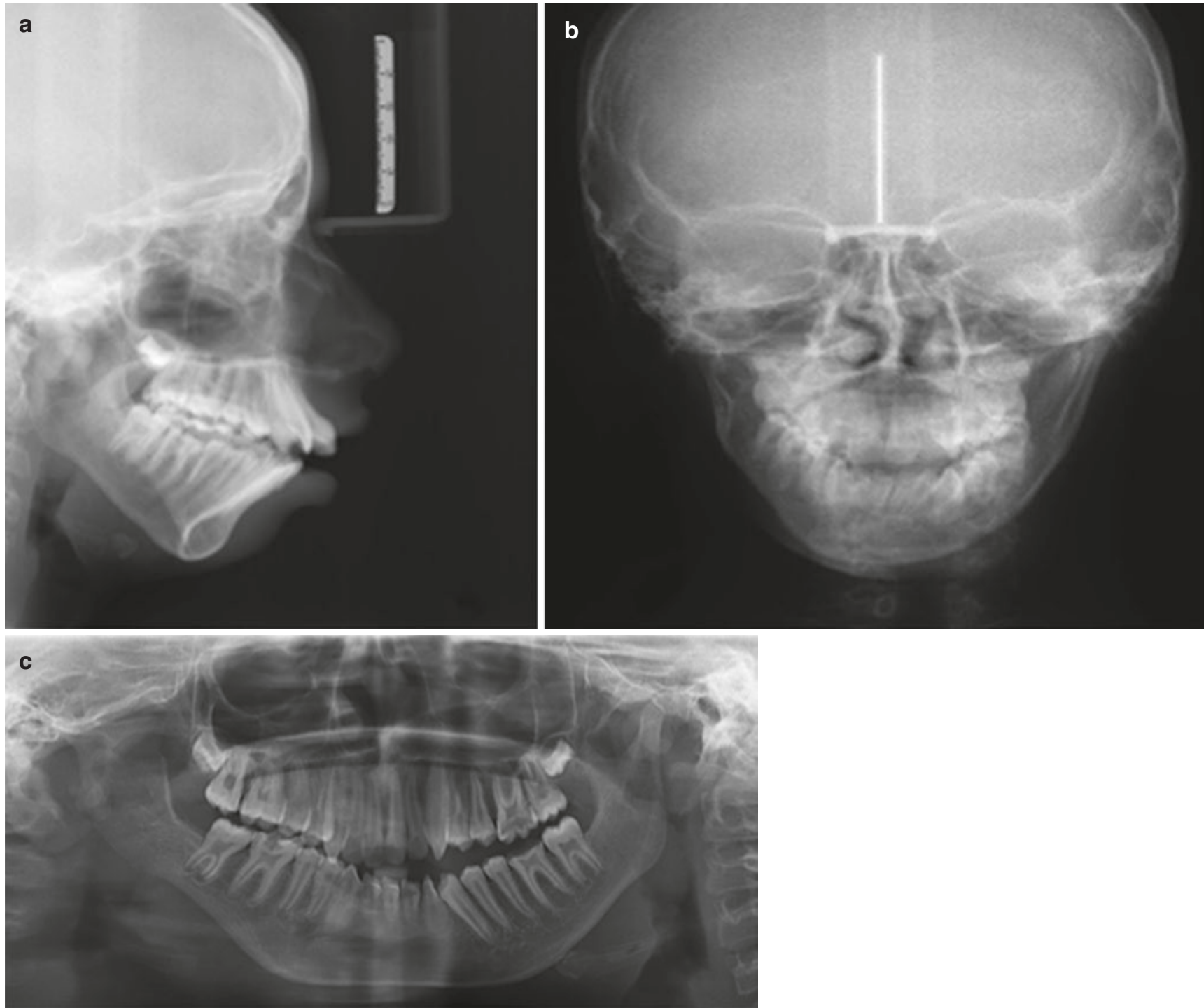

CAssociation of Oral and Maxillofacial Surgeons of India

Fig. 78.8 (a-c) Radiographs lateral cephalogram (a), posteroanterior cephalogram (b) and OPG (c) showing features of asymmetry. OPG showing deficient body and ramus region 

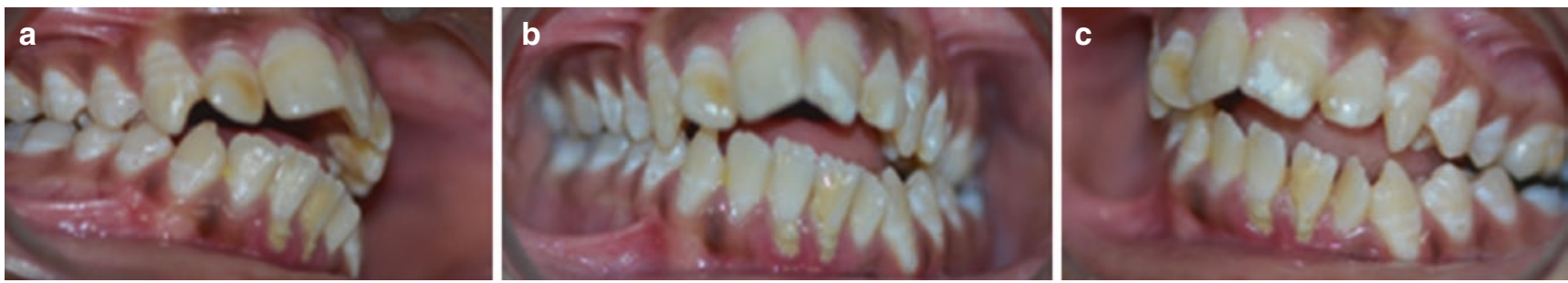

(C)Association of Oral and Maxillofacial Surgeons of India

Fig. 78.9 (a-c) Intraoral views showing malocclusion, asymmetric anterior open bite, canting and crowding
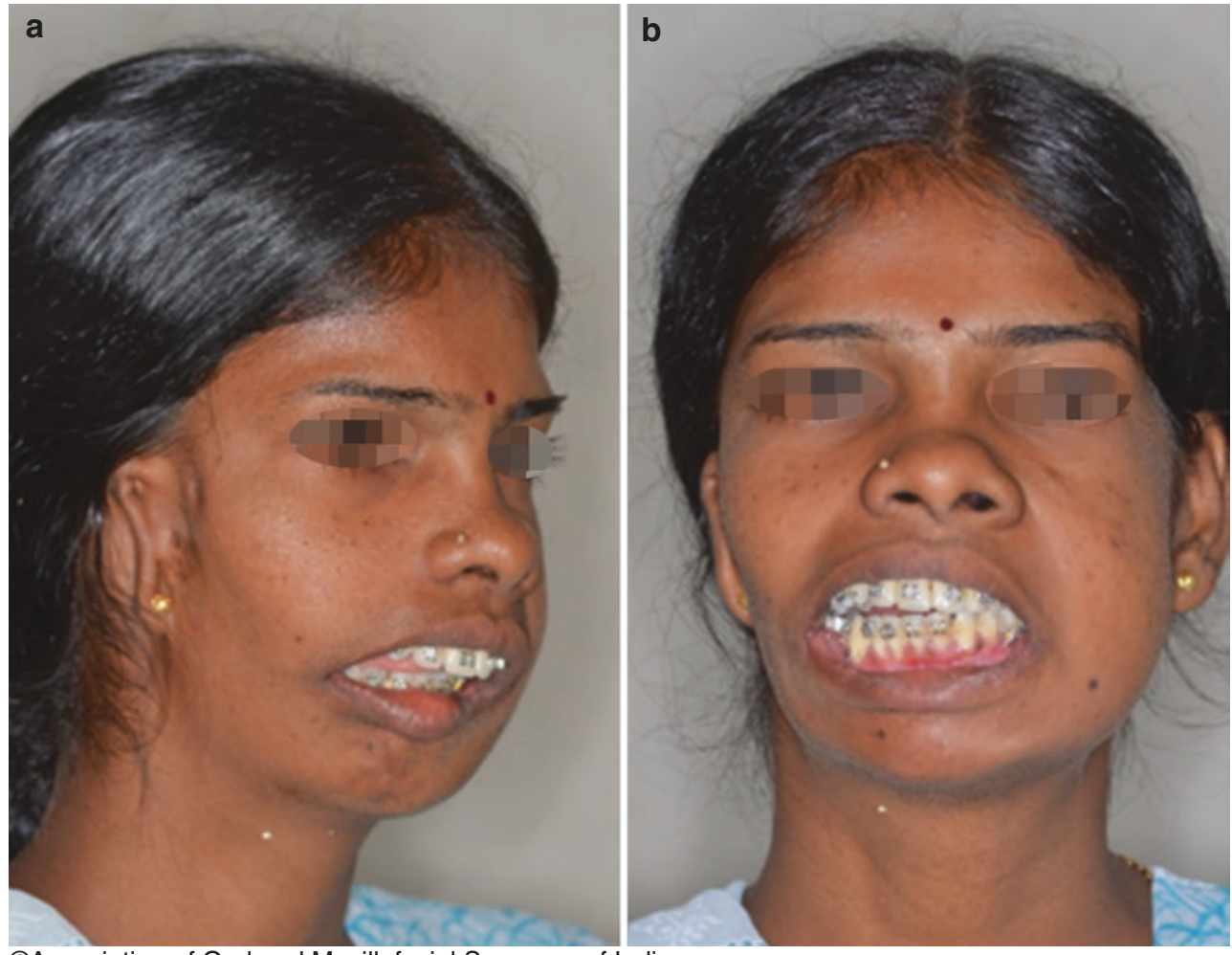

CAssociation of Oral and Maxillofacial Surgeons of India

Fig. 78.10 (a, b) (Left, profile view; right, frontal view): Adult with right-sided hemifacial macrostomia. Note the deviation on mouth opening to the deficient right side. Also note the preauricular skin tags and epibulbar lesions

- Grade III: Absent auricle, anteriorly and inferiorly displaced lobular remnant.

- Radiological assessment using temporal bone CT scans should be used to assess the middle ear structures.

\section{Muscle Deficit}

Deficits in the temporalis and the pterygo-masseteric group of muscles may be seen in HFM. This also contributes to the skeletal deficit seen. A hypoplastic temporalis may be associated with a hypoplastic or at times absent ramus-condyle unit (RCU) which includes the coronoid process also; a similar association is also evident with the presentation of the pterygo-masseteric muscles and the ramus of the mandible. With cases of increasing severity, the proximal aspect of the zygomatic arch may also be absent with the aponeurosis of the hypoplastic masticatory muscles filling that space. Lateral pterygoid muscle hypoplasia ranges from mild to complete absence and correlates with the extent of the skeletal defect. Hypoplasia of the muscles and deficiency of the RCU lead to abnormalities of the TMJ and also with absence or altered joint structures. This often leads to deviation of the mandible to the affected side at rest and on mouth opening (Fig. 78.12a). 


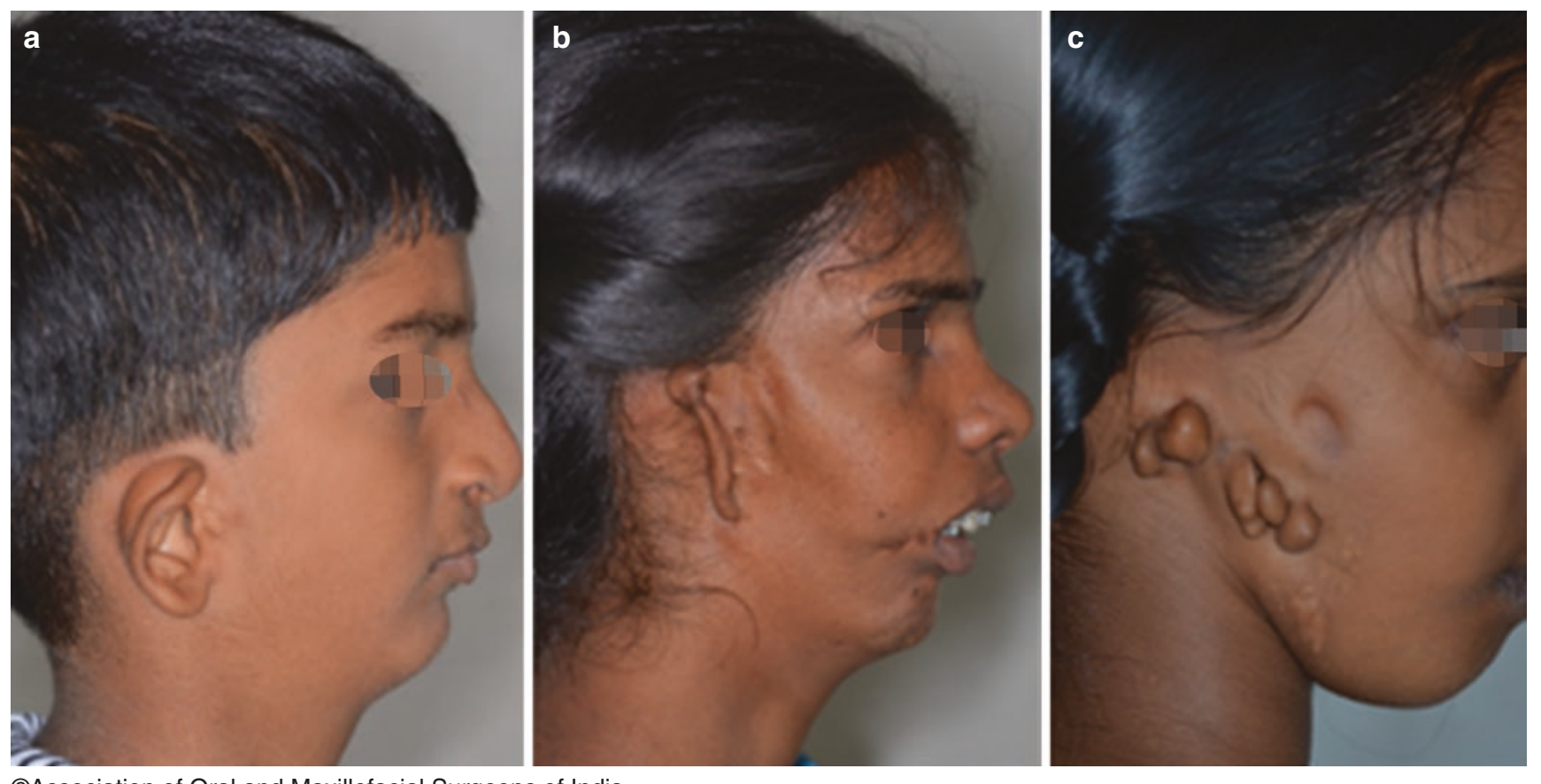

CAssociation of Oral and Maxillofacial Surgeons of India

Fig. 78.11 (a) Grade 1 mild ear deformity, (b) Grade 2 moderate ear deformity, (c) Grade 3 severe ear deformity

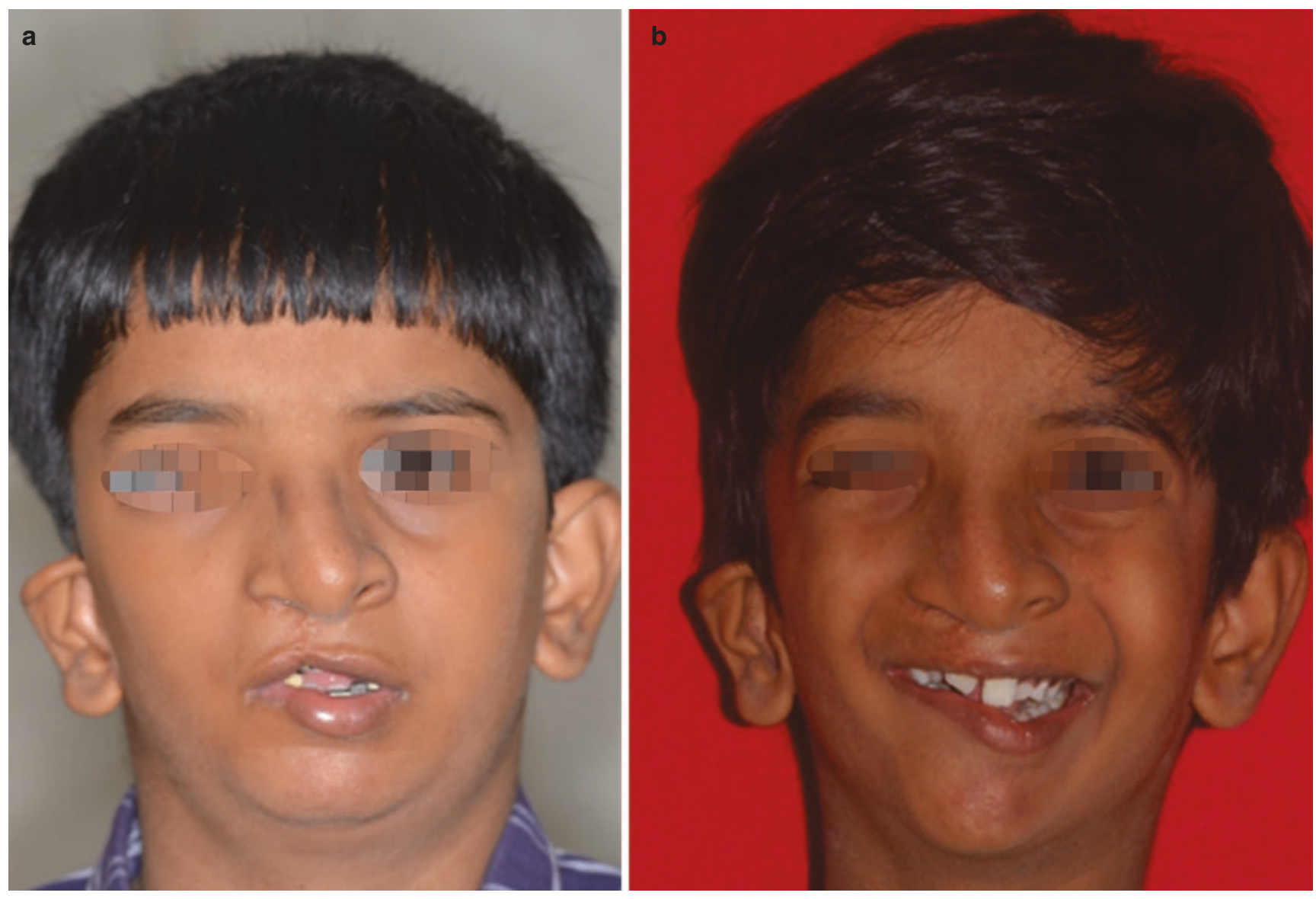

(C)Association of Oral and Maxillofacial Surgeons of India

Fig. 78.12 (a) Unilateral cleft lip and palate patient with right-sided hemifacial microsomia, Grade 1 ear deformity, right-sided muscle weakness of orbicularis oris, buccinator and orbicularis oculi. (b) Deviated smile due to facial nerve deformity 


\section{Cranial Nerve Abnormalities}

Approximately $25 \%$ of the patients with HFM are affected with cranial nerve deficits, resulting in features ranging from nerve weakness to complete paralysis. The marginal mandibular branch is the most commonly affected followed by the frontalis muscle dysfunction. Rarely, there may be a sensory deficit due to trigeminal nerve involvement along with total involvement of the facial nerve [19] (Fig. 78.12b).

\section{Soft Palate Function}

The cause for the soft palate deviation (to the normal side) in HFM has long been debated. It is proposed that the deviation may be due to a combination of skeletal asymmetry, neurological deficits, and hypoplastic musculature. Literature shows that patients with HFM are predisposed to velopharyngeal dysfunction, even in the absence of a palatal cleft [20].

\subsubsection{Radiological Assessment}

Considering the three-dimensional skeletal nature of the deformity, radiological assessment is of paramount importance. Conventional methods of 2D imaging are very helpful and still relevant in assessing the condyle anatomy and extent of asymmetry. Orthopantomogram, posteroanterior cephalogram, and lateral cephalogram should be taken for initial assessment (Fig. 78.9). With the advent of reconstructed 3D imaging, the surgeons can now evaluate the full extent of asymmetry including the cranial base and glenoid fossa (Figs. 78.5, 78.6 and 78.7). Scintigraphy or technetium scan can be done in these cases to rule out apparent hypoplasia due to hyperplasia of one side condyle (Fig. 78.13a, b).

\subsubsection{Differential Diagnosis of Hemifacial Microsomia}

Patient with HFM must be distinguished from those with Goldenhar syndrome, Treacher Collins syndrome, hemimandibular elongation, Parry-Romberg syndrome, juvenile rheumatoid arthritis, Nager syndrome, traumatic postnatal deformity, postaxial acrofacial dysostosis, muscle dysfunction, branchio-oto-renal syndrome (BOR), and maxillofacial dysostosis. The following is a table of distinguishing features of hemifacial microsomia and other entities (Table 78.4).
Hemifacial Microsomia with Cleft Lip and Palate

The incidence of HFM with concomitant orofacial clefting is a range between 18 and $61 \%$, including presentations of atypical clefts and macrostomia. Fan et al. reported cleft lip with/without cleft palate in $10 \%$ of HFM patients. Thus, cleft lip and palate may actually be considered as a part of the HFM spectrum $[20,21]$. The laterality and severity of presentation of cleft lip/palate correlate with the severity and side of presentation of HFM. This shows common embryological aetiopathogenesis of HFM and orofacial clefting. However, patients with HFM often present with velar deficiencies, leading to hypernasality and velopharyngeal insufficiency. Patients with HFM have a higher incidence of cleft maxillary hypoplasia than non-syndromic cleft patients. The already present abnormality in maxillary growth in HFM may further influence the midface deficiency seen in HFM patients with CL only.

\subsubsection{Principles of Management of Craniofacial/Hemifacial Microsomia}

The principles involved in the management of HFM are described below. We have categorized them as per age and the required intervention. Growth considerations are important in formulating treatment plan. Various challenges and treatment methods have been described in literature with focus on the mandible and TMJ reconstruction (Fig. 78.14 and Table 78.5).

\subsubsection{Neonates and Infants}

Due to the morphological severity of the skeletal deformities, severe functional compromise of the infant's airway can happen after birth. Later on, the presence of a compromised airway can also affect the child's ability to swallow. Hence, the primary management in a neonate should be focused on stabilization of the airway and assisted feeding [22].

\subsubsection{Airway}

A grossly compromised airway may necessitate procedures to maintain the patency of the child's airway and facilitate the child to thrive. These procedures are neonatal distraction (early distraction osteogenesis), tongue lip adhesion, or tracheostomy [22, 23]. The neonatal distraction has fallen into disfavour due to future unpredictable 

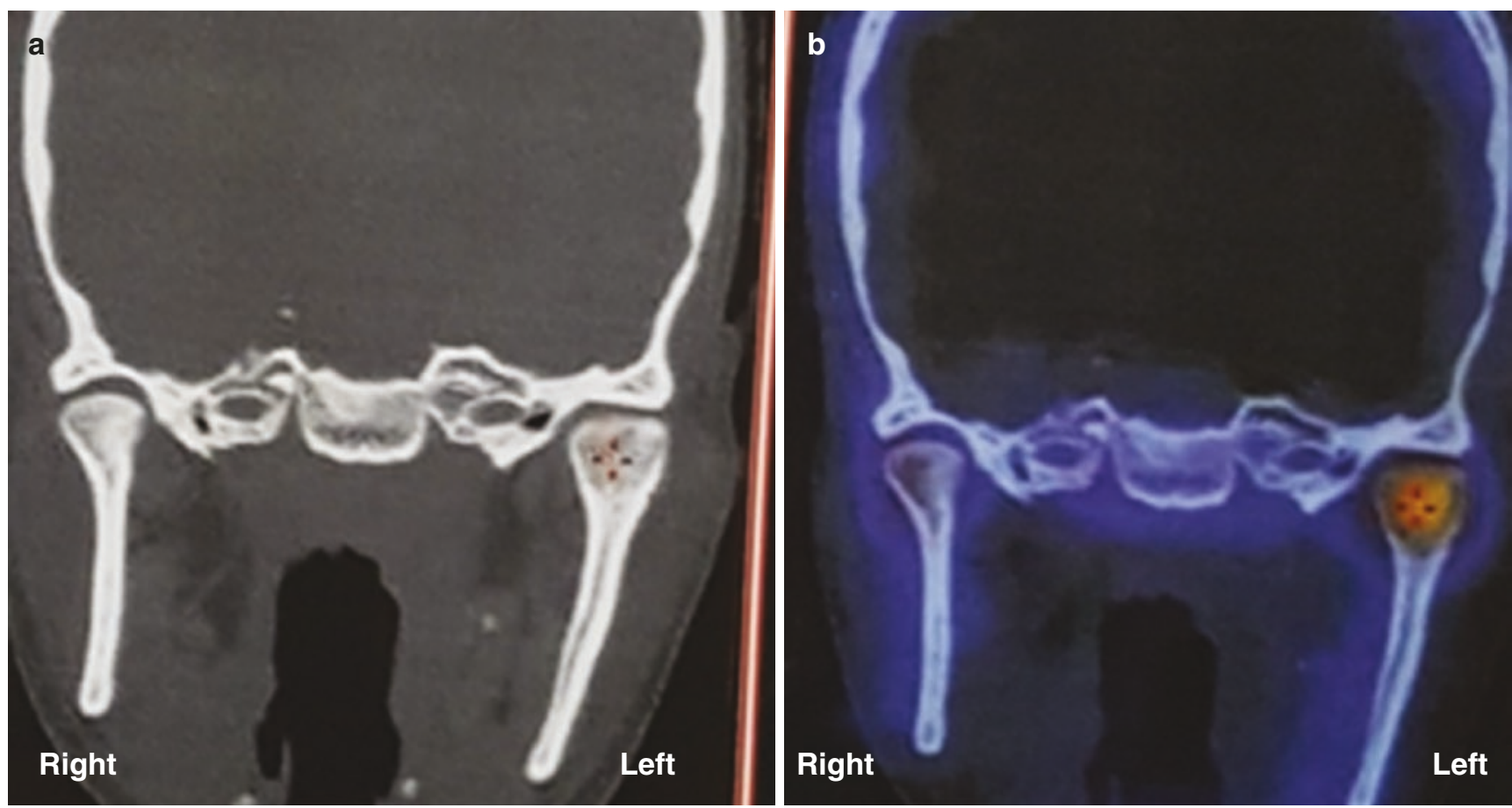

CAssociation of Oral and Maxillofacial Surgeons of India

Fig. 78.13 (a) SPECT scan in the case of facial asymmetry. (b) Note the active uptake on the left side. Technetium scan can be done to rule out asymmetry due to contralateral condylar hyperplasia

Table 78.4 Differential diagnosis of Hemifacial Microsomia

\begin{tabular}{|c|c|}
\hline Other entities & Distinguishing features \\
\hline Treacher Collins & Always bilateral \\
\hline $\begin{array}{l}\text { Old undiagnosed } \\
\text { condylar trauma }\end{array}$ & $\begin{array}{l}\text { Condyle and ramus are short, absence of any } \\
\text { other soft tissue features and normal ears. } \\
\text { History of trauma at birth }\end{array}$ \\
\hline Goldenhar syndrome & $\begin{array}{l}\text { Vertebral anomalies and epibulbar dermoids } \\
\text { and/or eyelid colobomas }\end{array}$ \\
\hline $\begin{array}{l}\text { Hemimandibular } \\
\text { elongation }\end{array}$ & $\begin{array}{l}\text { Mandible deviates to unaffected side. Normal } \\
\text { form and size of condyle, slender neck and } \\
\text { long ramus } \\
\text { Not present since birth, unlike HFM }\end{array}$ \\
\hline $\begin{array}{l}\text { Juvenile rheumatoid } \\
\text { arthritis }\end{array}$ & $\begin{array}{l}\text { Pain and morning stiffness in the affected } \\
\text { joint. Multi-articular nature of disease }\end{array}$ \\
\hline $\begin{array}{l}\text { Parry-Romberg } \\
\text { syndrome }\end{array}$ & $\begin{array}{l}\text { Facial atrophy of subcutaneous fat, } \\
\text { associated skin, cartilage, and bone which is } \\
\text { often unilateral and slow progressing } \\
\text { Multisystem involvement in some cases. } \\
\text { Presence of coup de sabre } \\
\text { Acquired unlike HFM }\end{array}$ \\
\hline $\begin{array}{l}\text { Nager acrofacial } \\
\text { dysostosis }\end{array}$ & $\begin{array}{l}\text { Disorder of facial, limb, and skeletal } \\
\text { morphogenesis }\end{array}$ \\
\hline
\end{tabular}

growth and possibility of tooth bud damages. Most children presenting with HFM may require assisted feeding using nasogastric tubes or gastrotomy for a few weeks to months.

\subsubsection{Management of Associated Orofacial Clefting}

The incidence of orofacial clefting occurring with HFM is approximately $10 \%$. The most common form of clefting apart from cleft lip is Tessier 7 facial cleft or macrostomia (Fig. $78.15 a, b)$. The cleft is repaired at 3-6 months of age as per the standard protocol [20]. Cleft lip and palate is more severe in HFM and is associated with worse outcomes. There is tissue hypoplasia and neuromuscular deficiency of pharyngeal muscles in patients with HFM. This may be responsible for the development of palatal fistulas and exacerbation of VPI, making management of cleft palate more challenging in such cases.

\subsubsection{Intermediate Surgical and Orthodontic Management}

Management during the growth phase in HFM differs from that of an adult. Intermediate surgical management includes reconstruction of the external ear which may be planned at 6-7 years as the contralateral ear achieves its full growth during this time. Reconstruction of the cranio-orbital region is usually accomplished between 7 and 9 years as calvarial growth is almost complete during this time. A split calvarial graft to reconstruct the lateral orbital rim and zygoma is the 


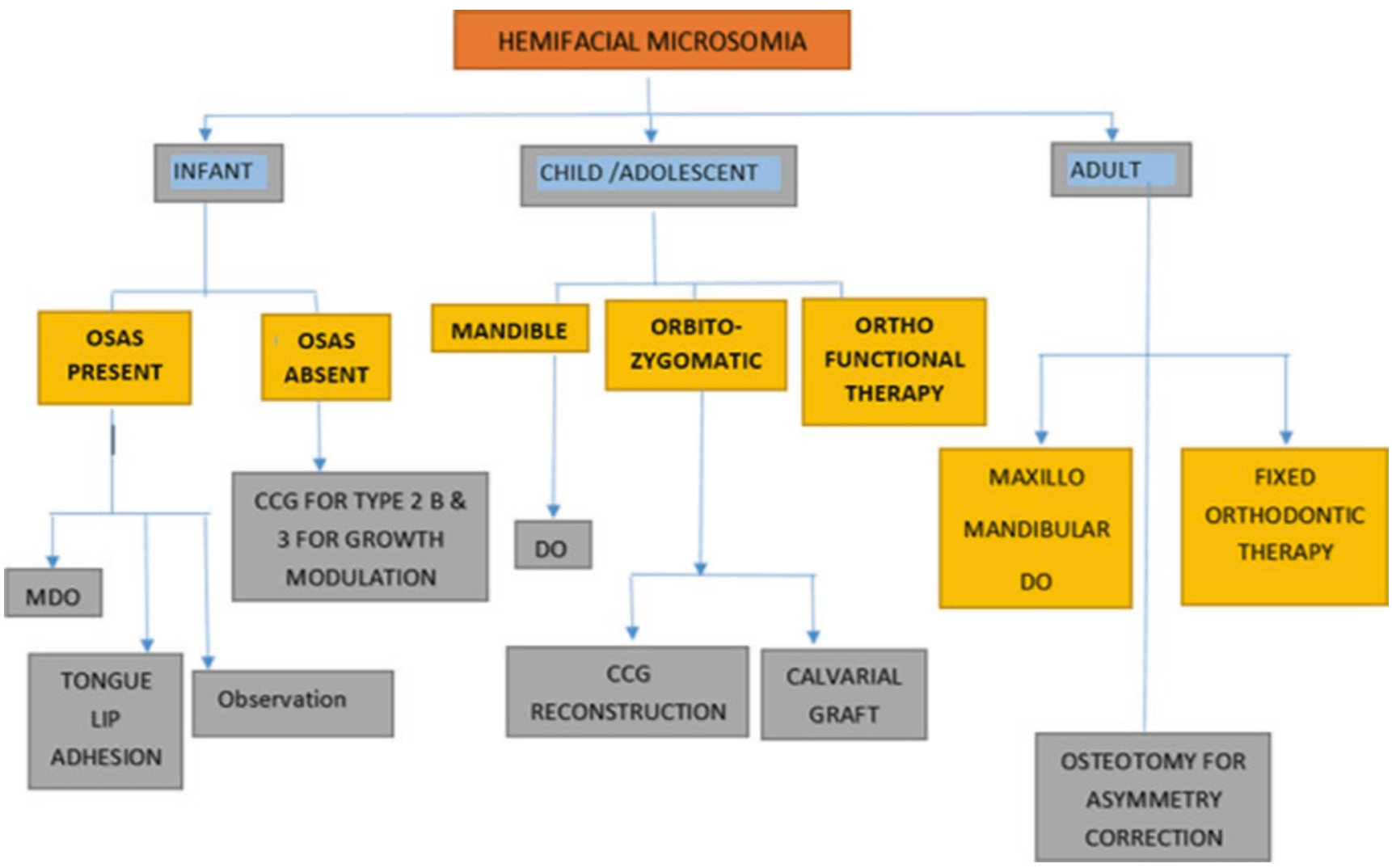

Fig. 78.14 Flowchart depicting algorithm of treatment at various levels according to growth

Table 78.5 Challenges and corrections needed necessary at different ages

\begin{tabular}{|c|c|c|}
\hline Early & $\begin{array}{l}\text { Intermediate (during } \\
\text { growth) }\end{array}$ & $\begin{array}{l}\text { Delayed (after completion } \\
\text { of growth) }\end{array}$ \\
\hline $\begin{array}{l}\text { - Airway } \\
\text { - Swallowing } \\
\text { - Vision } \\
\text { - Hearing } \\
\text { - Cleft lip and } \\
\text { palate }\end{array}$ & $\begin{array}{l}\text { - Skeletal correction } \\
\text { (DO) } \\
\text { - Soft tissue correction } \\
\text { (free fat transfer) } \\
\text { - Nerve deficit }\end{array}$ & $\begin{array}{l}\text { - Definitive skeletal } \\
\text { correction (DO + OGS) } \\
\text { - Soft tissue correction (fat/ } \\
\text { microvascular free flaps) }\end{array}$ \\
\hline
\end{tabular}

graft of choice for reconstruction of deficient zygomaticoorbital region. Surgeons have also used temporo-parietal myoosseous flaps for better bulk, contour and retention of graft in place.

Orthopaedic growth modification can help these patients to correct occlusion in early stage [23-25]. If the patient has growth potential, with the stimulus provided by a hybrid functional appliance and stretching the soft tissue, growth can be increased on the affected side. The child must have at least $20 \mathrm{~mm}$ mouth opening to ensure that proper translation of condyles allows mandible growth. An asymmetric func- tional appliance (hybrid) that guides the mandible to a new postural position, controls the eruption of teeth and inhibits the soft tissue pressure is used [26]. It directs the developmental growth of mandible three dimensionally.

An orthodontist should constantly monitor the eruption of primary and permanent teeth to improve mandibular deficiency and maxillary canting. After the adolescent growth spurt, occlusion can be achieved by means of fixed orthodontic appliances.

\subsubsection{Correction of Maxillomandibular Complex}

Variations in the maxillomandibular complex management range from early intervention (Figs. 78.16a, b, $78.17 \mathrm{a}, \mathrm{b}$ and $78.18 \mathrm{a}, \mathrm{b})$ to late reconstruction after growth completion. Wait-and-watch policy with only dental and orthodontic interventions may be adopted to reduce the impact of the deformity on the dental occlusion and masticatory function. Definitive surgical reconstruction of the maxilla, mandible and TMJ can be taken up after cessation of growth [27-31]. 

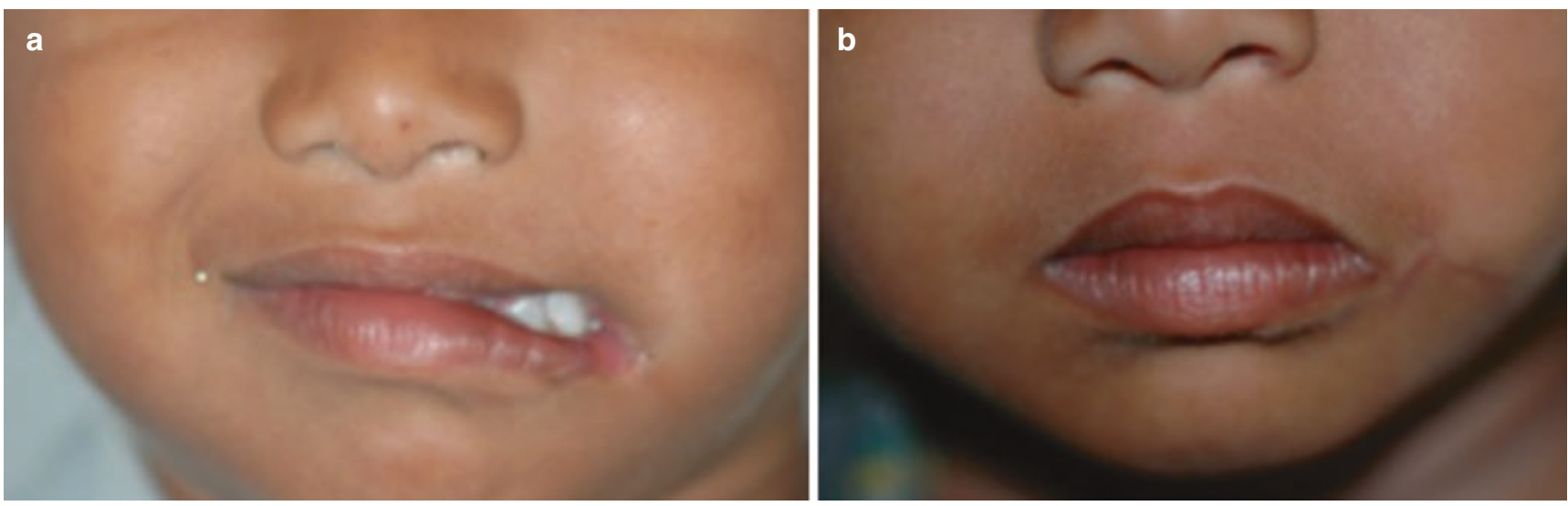

CAssociation of Oral and Maxillofacial Surgeons of India

Fig. 78.15 (a, b) Surgical correction of lateral facial cleft through commissuroplasty. (a) pre-operative photo showing macrostomia. (b) post-operative photo demonstrating correction with commissure reconstruction
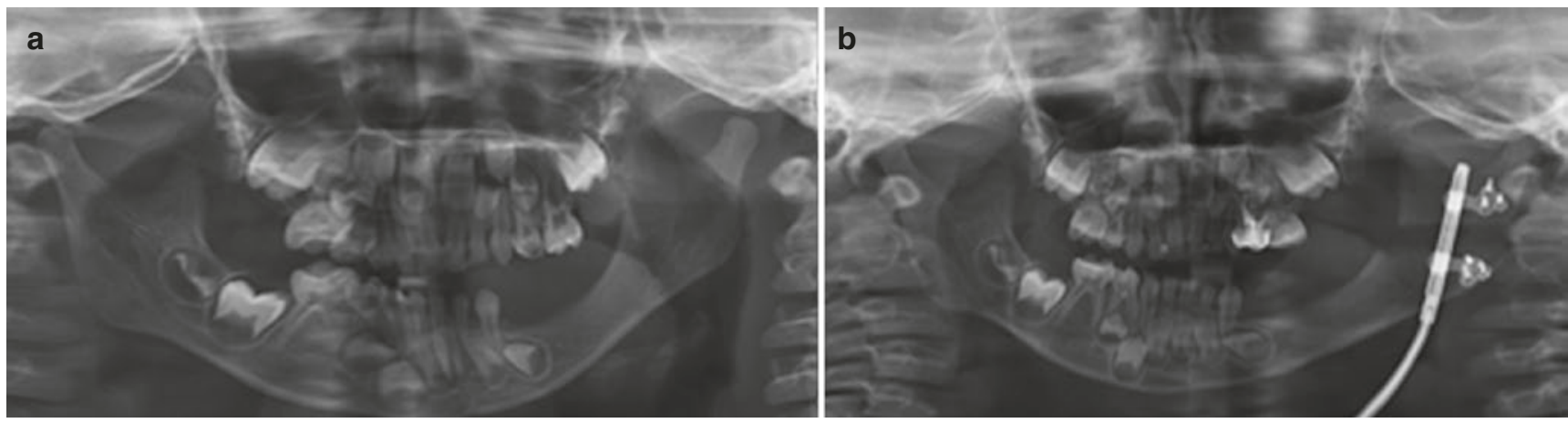

CAssociation of Oral and Maxillofacial Surgeons of India

Fig. 78.16 (a) Preoperative radiograph-deficient left ramus and body. Note the absence of teeth and tooth buds on the left side. (b) Vertical ramus distraction done to achieve symmetry of the mandible and chin
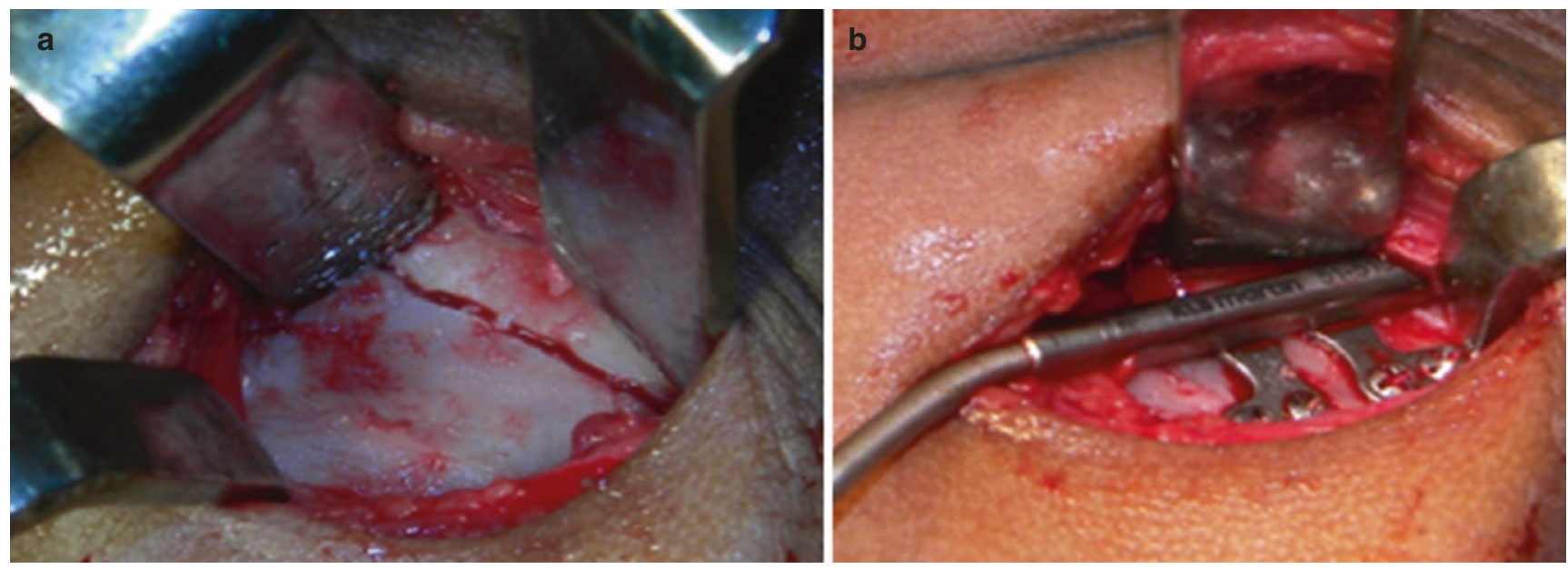

CAssociation of Oral and Maxillofacial Surgeons of India

Fig. 78.17 (a) Intraoperative photograph of the same patient as in Fig. 78.16, showing the horizontal cut. (b) Distractor removal after 3 months showing consolidated anatomic bone formation 

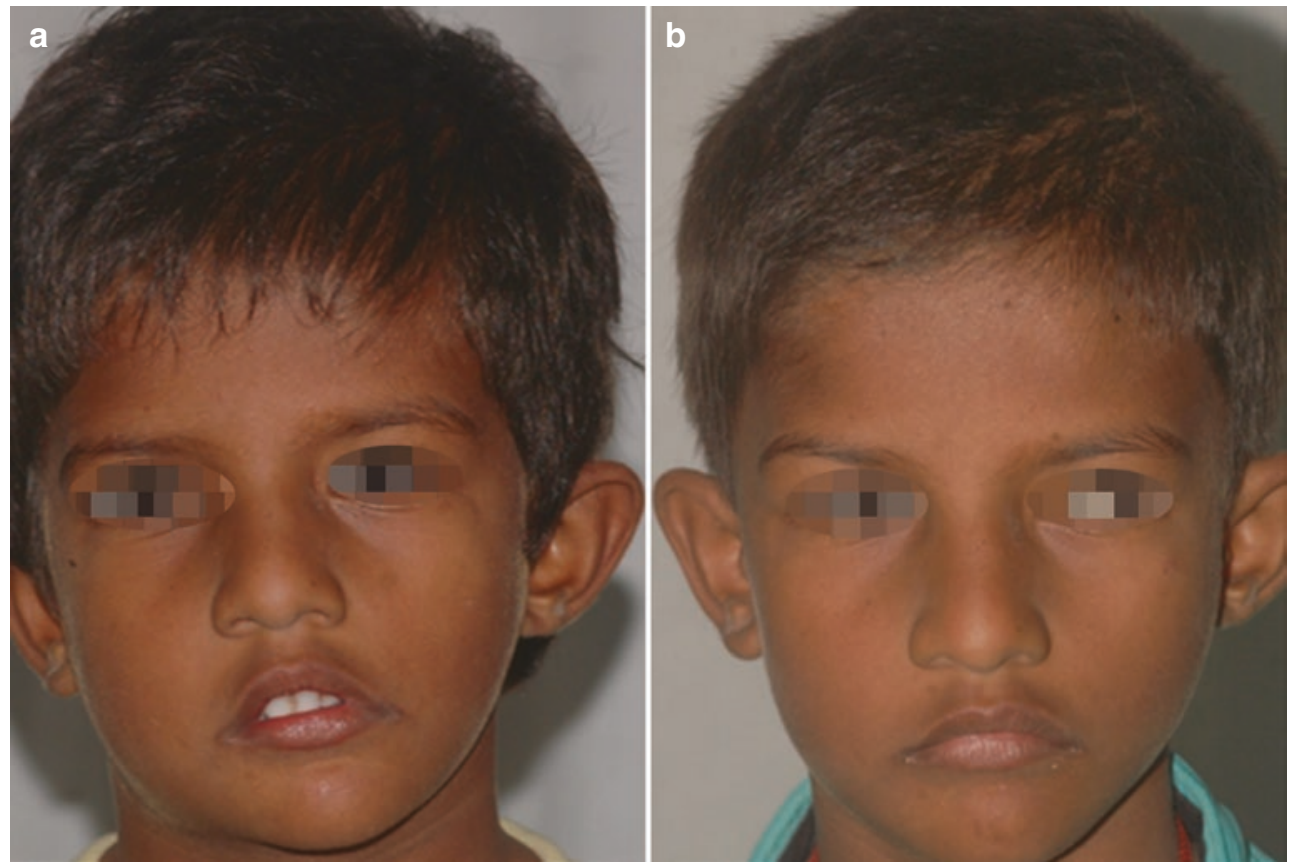

CAssociation of Oral and Maxillofacial Surgeons of India

Fig. 78.18 (a) Preoperative frontal photo of the same patient in Fig. 78.16 showing left-sided HFM with ipsilateral chin deviation and facial asymmetry. (b) Postoperative view showing considerable symmetry of the face

\section{Functional Appliance Therapy}

In cases where the ramus-condyle unit (RCU) shows reasonable function to translate into skeletal growth, growth modification with the use of functional appliances does play a role by achieving the following outcomes:

1. To facilitate eruption of the dentition in a favourable pattern.

2. To prevent dentoalveolar compensatory mechanisms from worsening the deformity.

3. To passively guide the growth of the ramus-condyle unit.

The focus of functional therapy is repositioning the affected condyle to a more inferior and anterior position to enable the mandible to grow and catch up for the intrinsic skeletal deficit [29-31].

\section{Ear Reconstruction}

Construction of the external ear is a priority in the aesthetic management of HFM patients. Two important factors that affect the ability to construct the ear are the decreased anteroposterior dimension of the upper face and the absence of an adequate platform (i.e. temporal bone cavity). The position and quality of the soft tissue remnants should also be kept in mind while planning surgery. An ear reconstructive surgeon and the maxillofacial surgeon should work collaboratively to determine the most ideal location of the ear relative to the future constructed ramus-condyle unit. Reconstruction options include (1) autogenous rib cartilage, (2) alloplastic options such as Medpore, and (3) tissue-engineered auricular framework. The technique of ear reconstruction is dealt with in detail in Chap. 35 on "Ear Reconstruction".

Though autologous chondral cartilage for reconstruction still remains the best option, it requires a multistage approach to (1) harvest the costal cartilage grafts and create a framework by carving (time-consuming and fixation and retaining of shape challenges), (2) place the graft (positioning as per existing altered morphology), (3) transpose the lobule (soft tissue deficiency - tissue expander may have to be used) and (4) create a post-auricular sulcus (with skin graft and split temporalis graft) (Fig. 78.19a, b).

Various materials have been used for alloplastic ear reconstruction with varied results. Porous polyethylene's inert nature and pore size provide and allow for some tissue ingrowth and are safe to use. The alloplastic materials always carry a risk of rejection and infection and may not have accurate sizes and shapes as they are stock implants with limited sizes. 

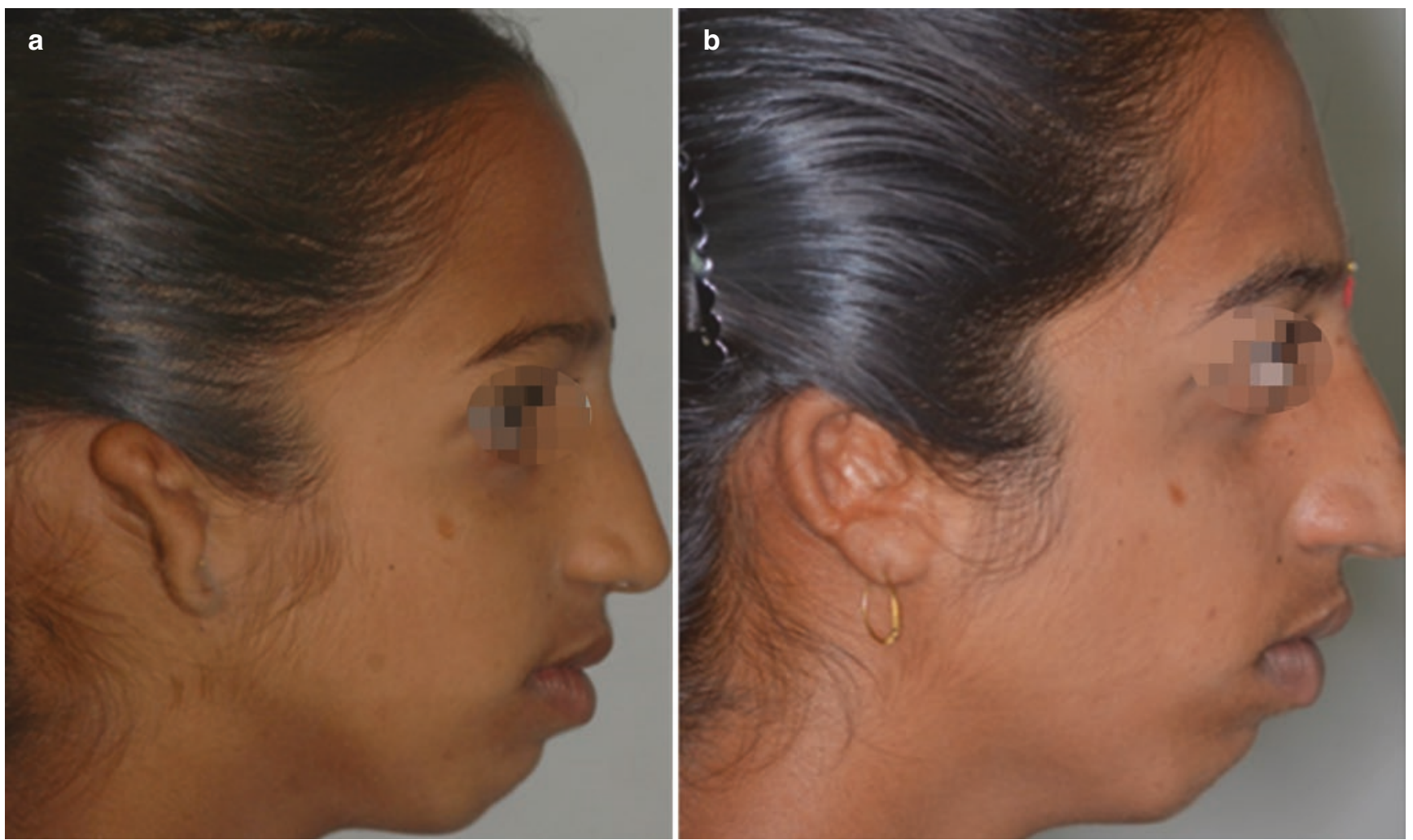

CAssociation of Oral and Maxillofacial Surgeons of India

Fig. 78.19 (a) Pre- and (b) post operative photograph of ear reconstruction using rib graft (Also refer Chap. 35 on Ear reconstruction)

Tissue-engineered 3D cartilage reconstruction and its use in regular clinical practice are under trial in many parts of the world though long-term clinical studies still lack regarding its application and optimal results.

\section{Delayed Management in Adults}

Management in adults includes definitive reconstruction for skeletal and residual soft tissue deficits. With the advent of 3D imaging and computer-assisted surgical planning and printing, precise spatial relationship of the cranial structures with maxillomandibular complex can be studied. This printed models give the surgeon extra weapon outside theatre to simulate surgery and make appropriate decisions before going to theatre. Appropriate treatment plan can be virtually executed, and a CAD-CAM splint can be fabricated to facilitate the accurate surgical outcome [32, 33] (Table 78.6).

\section{Orthodontics for Definitive Skeletal Surgery}

Orthodontic preparation before definitive surgical correction of the face is similar to the conventional pre-surgical orthodontic protocols. These include arch levelling and alignments, de-crowding and transverse widening if neces-
Table 78.6 Principles of management of the deformed temporomandibular joint

\begin{tabular}{|l|l|}
$\begin{array}{l}\text { Type of TMJ } \\
\text { involvement }\end{array}$ & Management \\
\hline Type I & $\begin{array}{l}\text { Correction of vertical dimension } \\
\text { Adjusting maxillomandibular relationship and } \\
\text { facial asymmetry }\end{array}$ \\
\hline Type IIa & $\begin{array}{l}\text { Augmentation of RCU, preservation of condyle/ } \\
\text { glenoid fossa }\end{array}$ \\
\hline Type IIb & $\begin{array}{l}\text { Neocondyle reconstruction/preservation of } \\
\text { glenoid fossa, augmentation of RCU + type I } \\
\text { management }\end{array}$ \\
\hline Type III & $\begin{array}{l}\text { Neocondyle and glenoid reconstruction, } \\
\text { augmentation of RCU + type I management } \\
\text { Autogenous or alloplastic reconstruction (refer } \\
\text { Chap. 89) }\end{array}$ \\
\hline
\end{tabular}

sary. Compromise may be necessary in many cases due to the extreme lingual tilt on the affected premolar-molar areas, leaving few options for the orthodontist due to limited bone availability for straightening the teeth $[29,30]$.

Conventional orthodontic treatment may take longer period and may necessitate the use of anchorage screws for aligning some teeth. 


\section{Type 1 and $2 \mathrm{~A}$}

In types 1 and $2 \mathrm{~A}$, the glenoid and condylar components of TMJ are morphologically intact with minimal hypoplasia. There is no specific indication for the reconstruction of the TMJ since the joint exhibits normal movement characteristics, and the patient is able to demonstrate adequate mouth opening and masticatory function. Deviation while mouth opening can be seen towards the affected side.

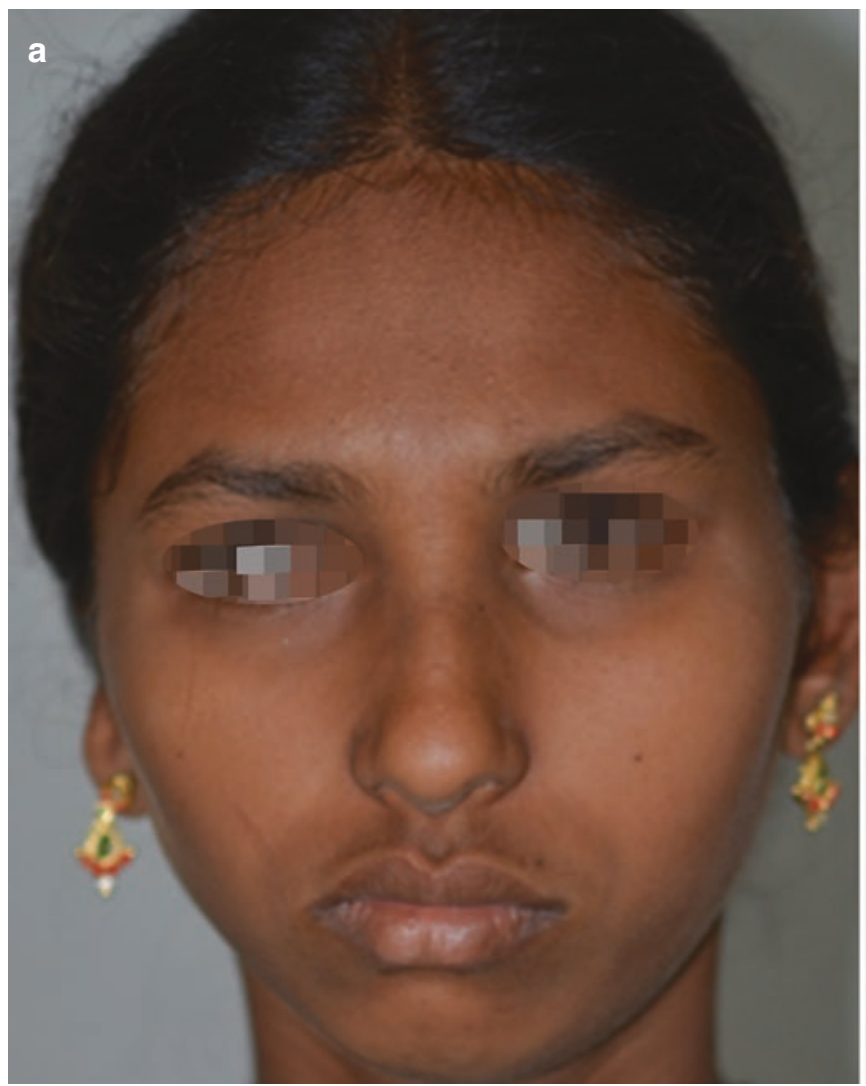

CAssociation of Oral and Maxillofacial Surgeons of India
Teeth eruption and angle of its placement will be hampered even in these two types of situations which will require further definitive treatment. Simultaneous maxillomandibular distraction introduced by Monasterio and Molina is an alternate method for achieving maxillary and mandibular corrections without disturbing the dental intercuspation and occlusal cant [34] (Figs. 78.20a, b and 78.21a, b).

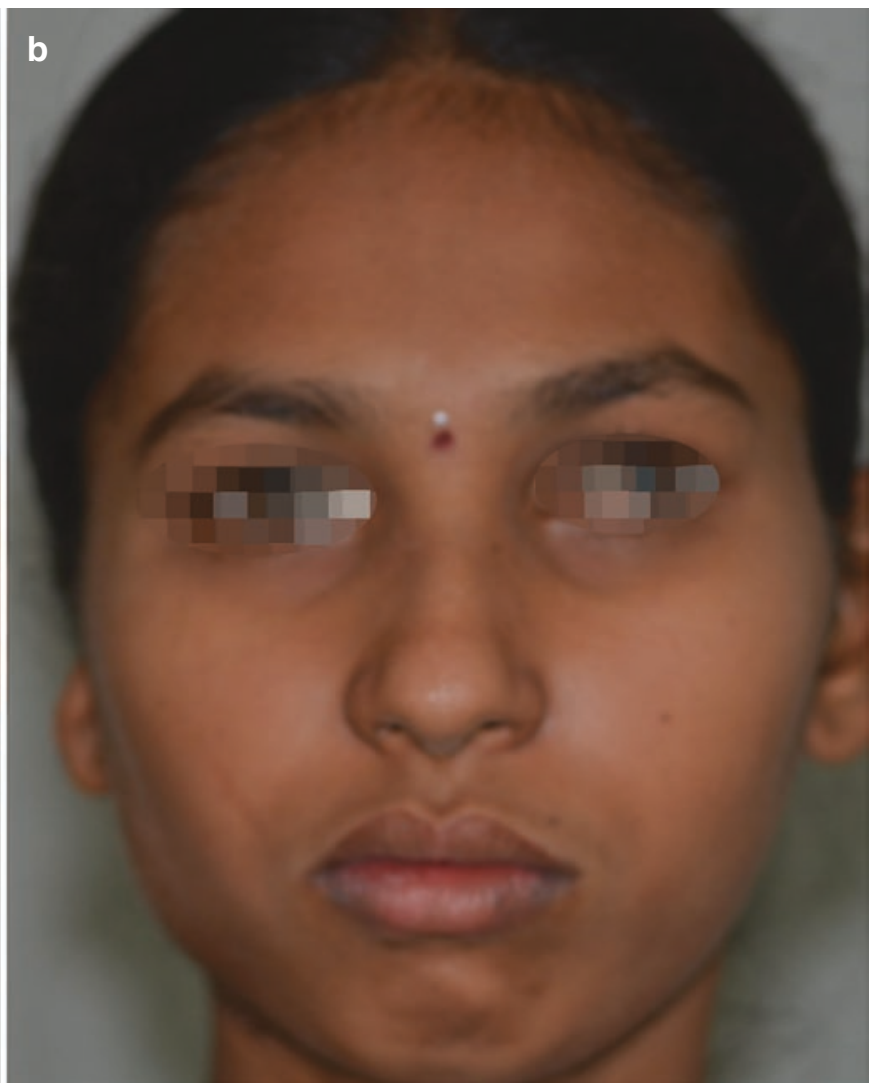

Fig. 78.20 (a) Preoperative view showing right-sided maxillomandibular deficiency. (b) Postoperative view showing correction of asymmetry following simultaneous maxillomandibular distraction

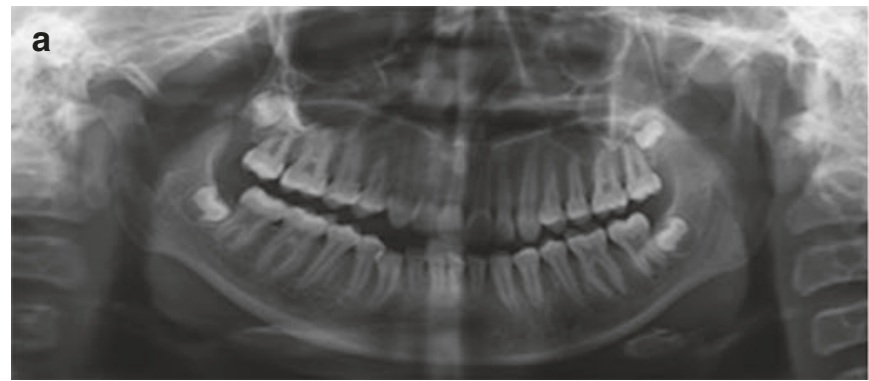

CAssociation of Oral and Maxillofacial Surgeons of India

Fig. 78.21 (a, b) Radiographs of the same patient as in Fig. 78.20 treated with maxillomandibular distraction (Molina's technique). (a) Pre-distraction orthopantomogram demonstrating vertically deficient

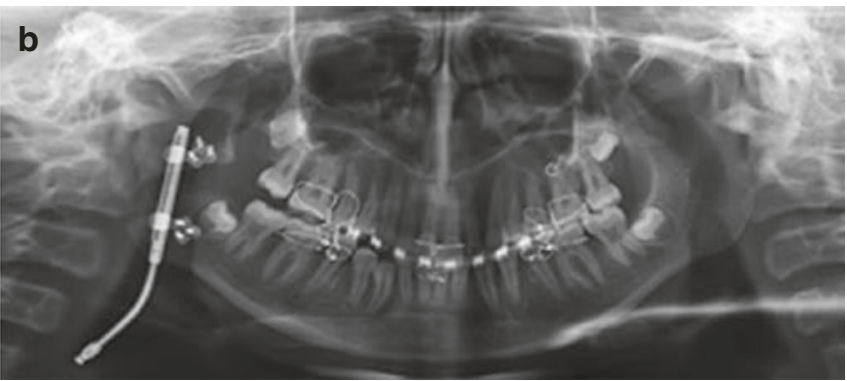

ramus-condyle unit on the right side. (b) Post-distraction xray showing lengthening of the right ramus-condyle unit with the distractor in-situ 


\section{Type 2B}

Type 2B patients exhibit severe hypoplasia of both the condylar and the glenoid elements of the joint, thus causing altered functioning of the joint. This greatly reduces or there is a complete absence of the translatory movement of the joint sparing the rotatory movement. The mandible may completely deviates towards the affected side. The arc of rotation completely shifted, leading to malocclusion and scissor bites sometimes.

Distraction osteogenesis can be used to correct the deficiency of the mandibular body along with reshaping the glenoid and condylar process. The use of osteotomies to correct the dentofacial deformity is also performed either in the same setting or in a staged manner.

Options for reconstruction of the ramal-condylar unit are another concern which can be approached with costochondral grafting and alloplastic joint reconstruction [35]. The costochondral graft for stimulated growth should be used by the age of 7 years, which can be used as an onlay graft on top of the existing ramal segment in the correct position of glenoid fossa. However, large series of cases with success in this technique lacks the scientific evidence of growth similar to the unaffected joint, and reports of under- and overcorrection are plenty in literature.

\section{Type 3}

Patients with Type 3 deformities require total reconstruction of the TMJ, i.e. the glenoid-zygomatic complex region and the ramal-condylar unit. For the growing adolescent due to growth completion, glenoid reshaping and costochondral graft reconstruction of the RCU may be undertaken. Total alloplastic joint reconstruction with concomitant orthognathic surgery should be done in adults.

Posterior distraction of existing mandibular segment to create ramal-condylar unit has ended up with limited success due to lack of posterior support of distraction advancing segment and unpredicted movement in 3D dimensions. It was found in authors' experience that the correct direction control of upwardly directing condylar segment is difficult to achieve towards a missing or defective glenoid fossa, and many times the position can alter more medial and anterior than expected rather than posterior towards external auditory meatus.

\section{Management of the Maxillomandibular Complex}

Type 1

The minimal asymmetry and deformity associated with a Type 1 HFM may be amenable to minor surgical corrections such as genioplasty (Fig. 78.22a, b). Since the occlusion may
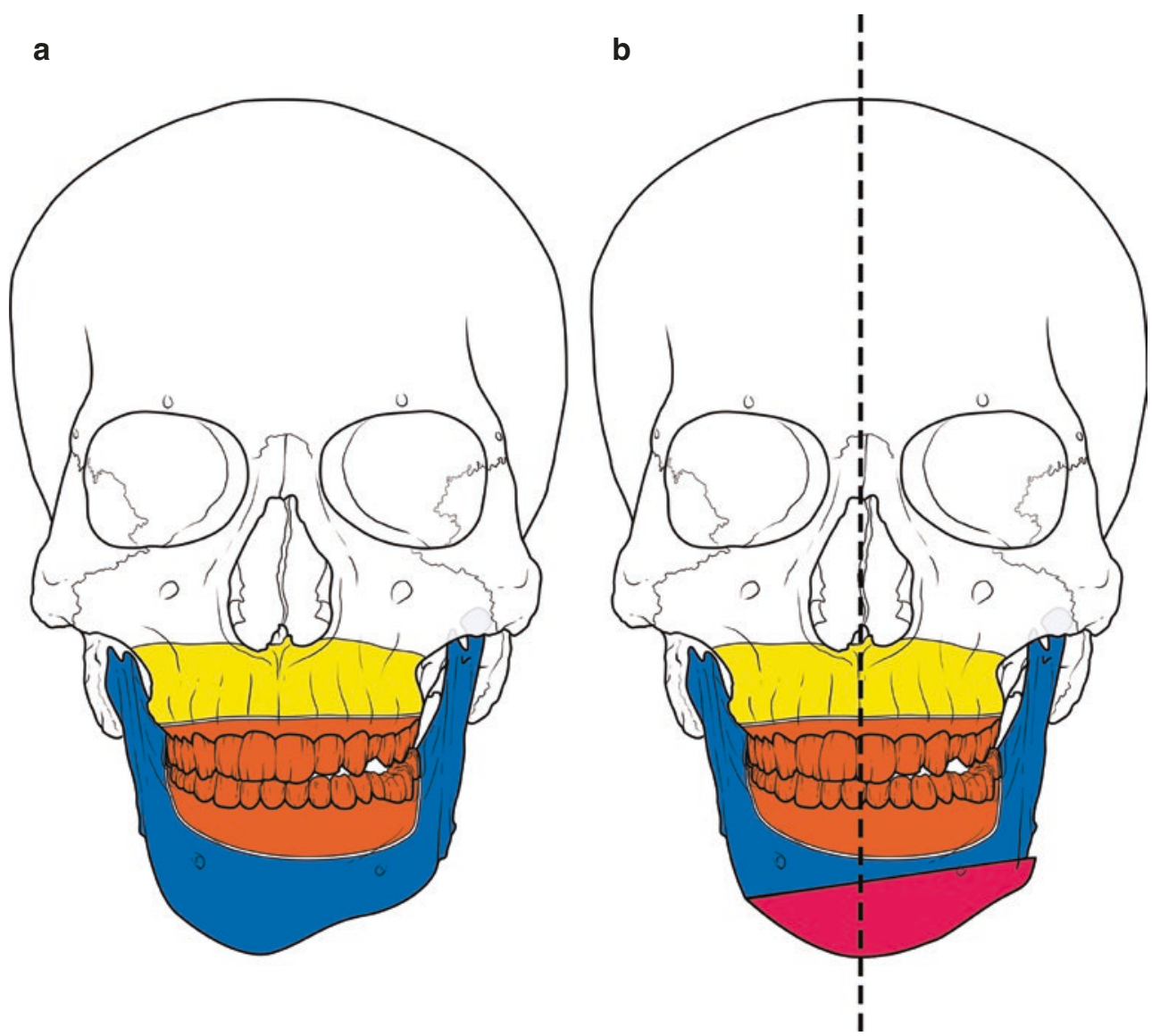

CAssociation of Oral and Maxillofacial Surgeons of India

Fig. 78.22 (a, b) Diagrammatic representation of surgical management of Type 1 Kaban-Pruzansky (a) deformity with isolated genioplasty for asymmetry correction $(\mathbf{b})$ 
be normal or demonstrate minimal occlusal canting, orthognathic surgical correction may not be warranted.

In cases with minimal asymmetry where the patient is not willing to undergo a surgery of the entire maxilla-mandibular complex, it is possible to achieve facial midline symmetry by means of altering the midline chin and mandibular body orientation through an extended operation involving the basal bone of the chin and body of the mandible. It was published by Paul C Salins in 2008 [36]. The author of this chapter was happy to have learned this technique from Salins himself and greatly understood the concept of this 3D movement of genial bone along with body and ramus of the mandible to the unaffected side without altering the occlusal relationship of the maxilla or mandible.

But this technique had obvious disadvantage in the form of significant relapse due to large movements and requirement for multiple points of fixation.
At this juncture, the author of this chapter has designed a distractor which can be placed below the lower border of the mandible to move the genial-body-ramus unit in desired direction by incremental distraction similar to other distraction protocols. This completely eliminated the need for any plate usage, better stability without relapse and more or less excellent unlimited movement in all three directions. This is completely a basal bone distraction which can be either performed in isolation or in combination with other distractions and osteotomies of the maxilla-mandibular skeleton (Figs. 78.23a, b, 78.24a, b, and 78.25a, b).

One of the key advantages of MDO is that the bone movement produces good contour of the chin area along with flat unaffected part of the mandible, and it obviously stretches and accommodates the redundant excess submentalsubmandibular skin available to a more symmetrical position as shown in Fig. 78.26a, b.

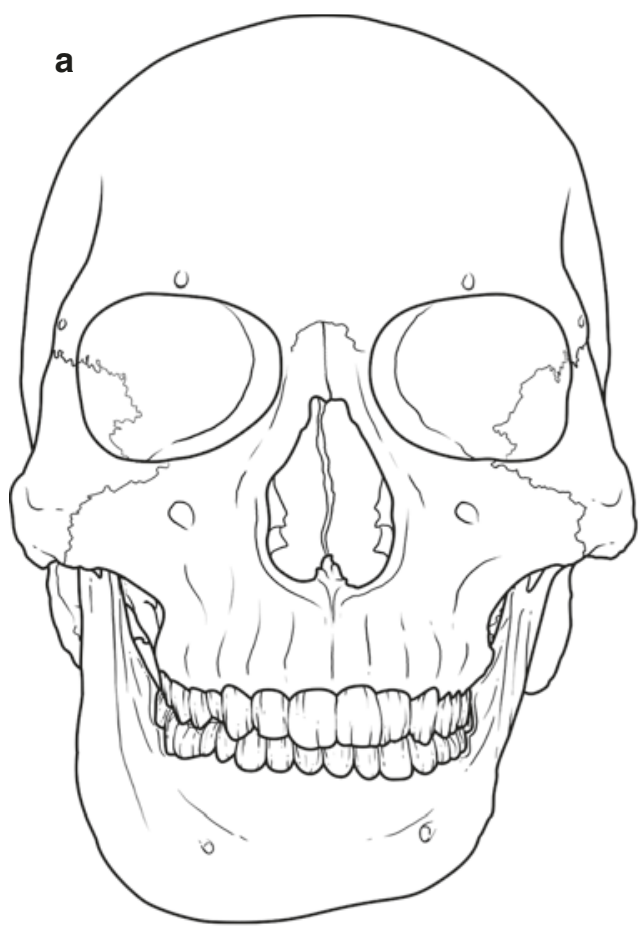

Association of Oral and Maxillofacial Surgeons of India

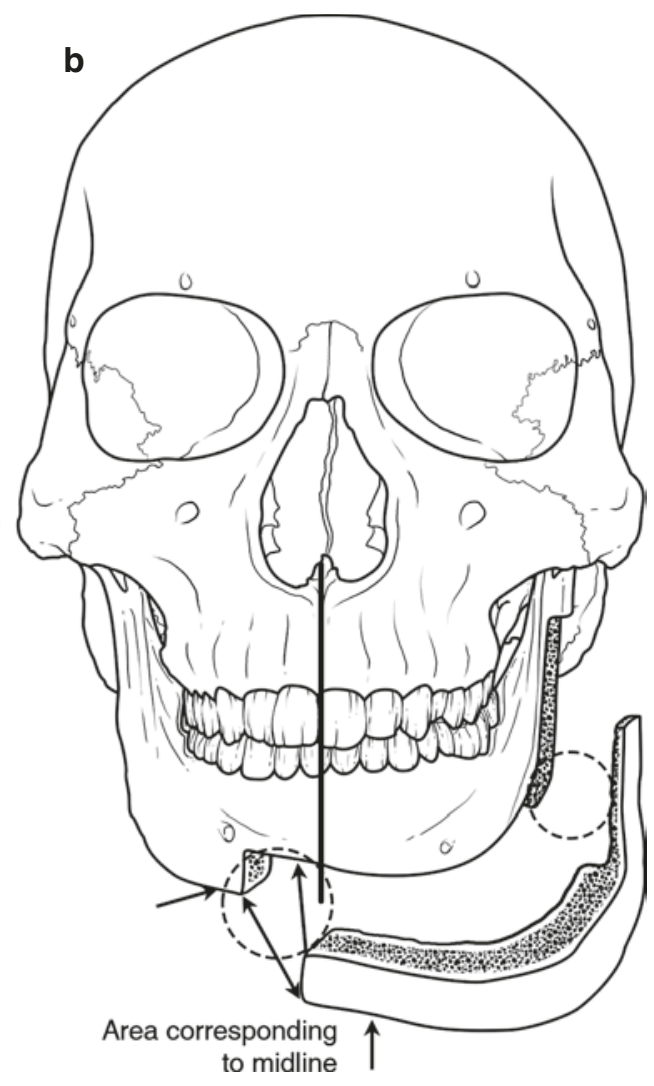

Fig. 78.23 (a, b) Orthomorphic correction of deficient mandible. (a) Diagrammatic representation of a left sided HFM, (b) osteotomy design for correction of the left sided deficiency 
Type 2A

Patients with Type 2A deformities require planned presurgical orthodontic interventions for definitive orthognathic correction (Fig. 78.27a-d).

Bimaxillary surgery is planned to achieve the following goals:

Maxilla and midface

1. Segmental maxillary procedures for correction of cross-bites.

2. Derotation of the maxilla to achieve midline corrections.

3. Augmentation of the zygomatic complex where necessary.

4. Cant correction.

\section{Mandible}

1. Bilateral sagittal split osteotomy procedure to correct the occlusal canting and yaw correction.

2. An inverted "L" or a subsigmoid osteotomy is indicated to achieve elongation of the RCU.

\section{Types 2B and 3}

As explained earlier, types $2 \mathrm{~B}$ and 3 patients require reconstruction of the TMJ as the primary goal. This may be executed either as a Stage 1 correction with only maxillomandibular correction or as Stage 2 with joint reconstruction (Fig. 78.27).

Thus, although skeletal correction improves the dental occlusion and skeletal symmetry, it may accentuate the existing soft tissue discrepancy. Soft tissue augmentation should be taken up after hard tissue correction. Various methods are available such as fat transfer, microvascular free flap for adipose tissue transfer and alloplasts such as Medpore and nanogels to give shape to deficient soft tissue (Fig. 78.28a, b).

\subsubsection{Controversies in Surgical Management of HFM}

\section{Growth Considerations and Role of Early Mandibular} Reconstruction in HFM.

HFM has been reported as a nonprogressive disorder, i.e. proportional deficiency of the face is maintained throughout the growth of the child. Indications for early reconstruction of the RCU during early childhood, especially in types $2 \mathrm{~B}$ and 3
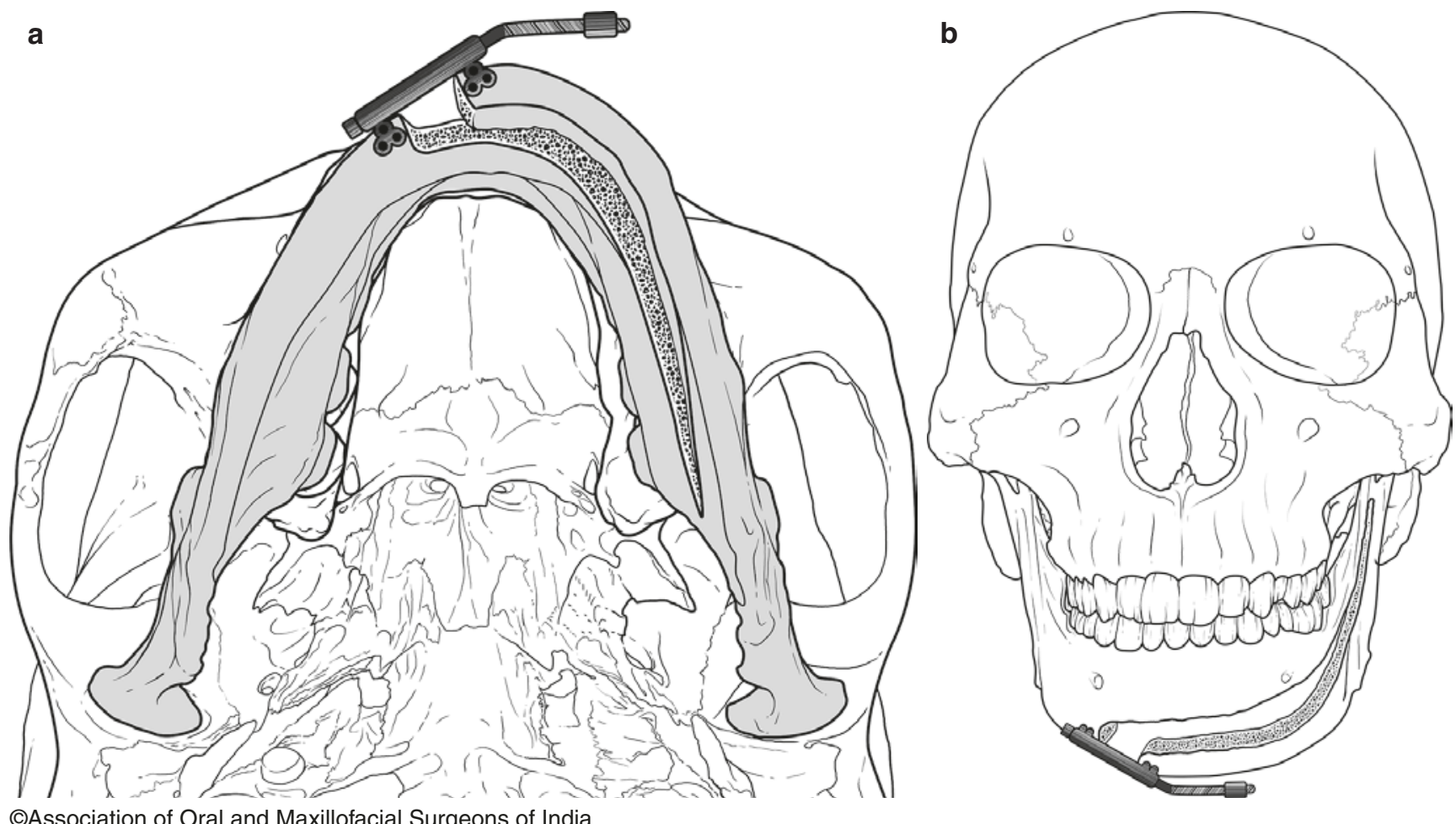

(C)Association of Oral and Maxillofacial Surgeons of India

Fig. 78.24 (a, b) Pictorial view of basal bone osteotomy and orthomorphic distractor placement. (a) Basal view showing distractor position for orthomorphic distraction method, (b) frontal view of the distractor postion 

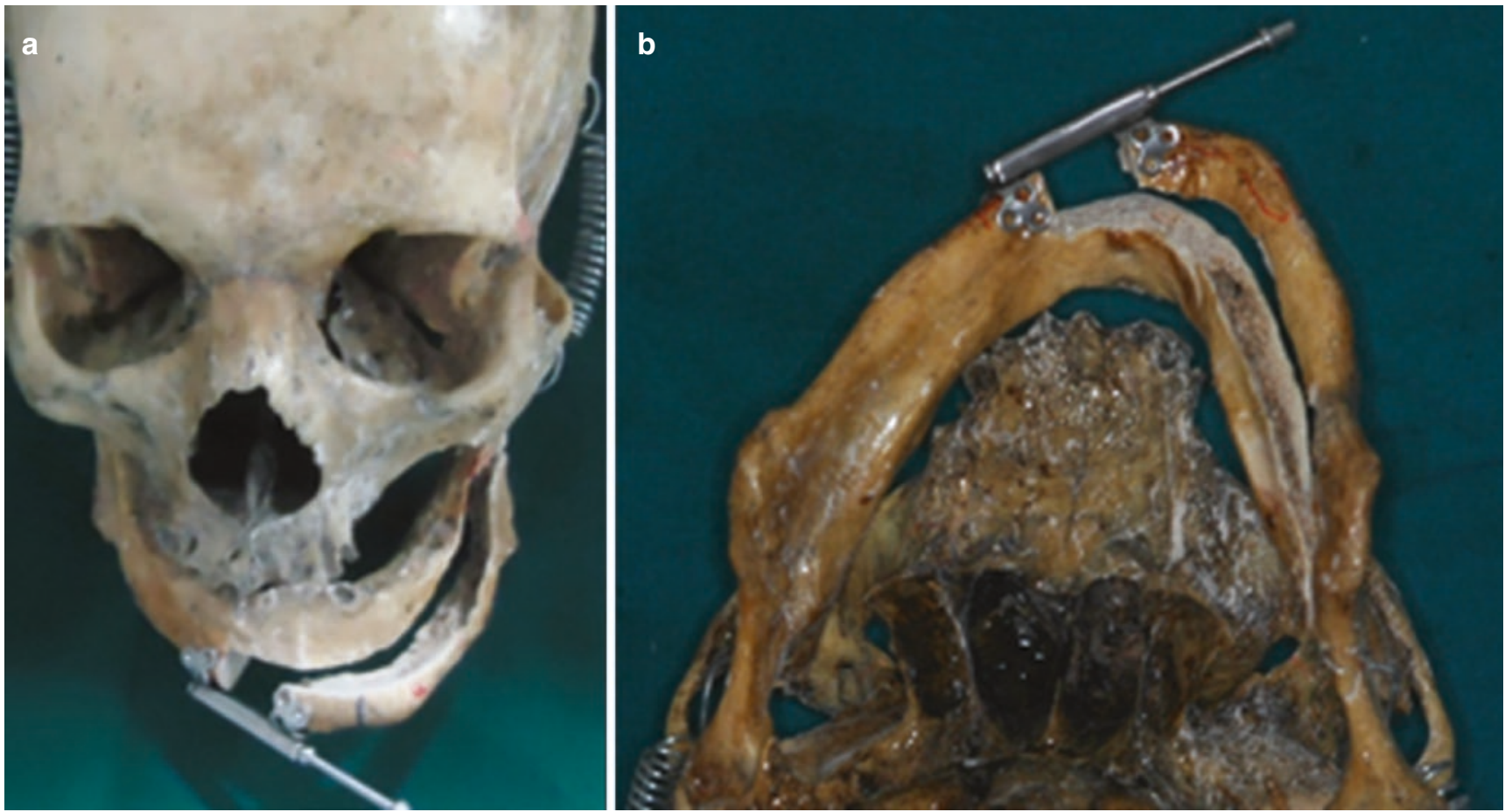

CAssociation of Oral and Maxillofacial Surgeons of India

Fig. 78.25 (a, b) Indigenous distractor made and modified, placement showed in a dry skull mandible. Note the placement of distractor on the basal bone. (a) frontal view of distractor placement, (b) basal view
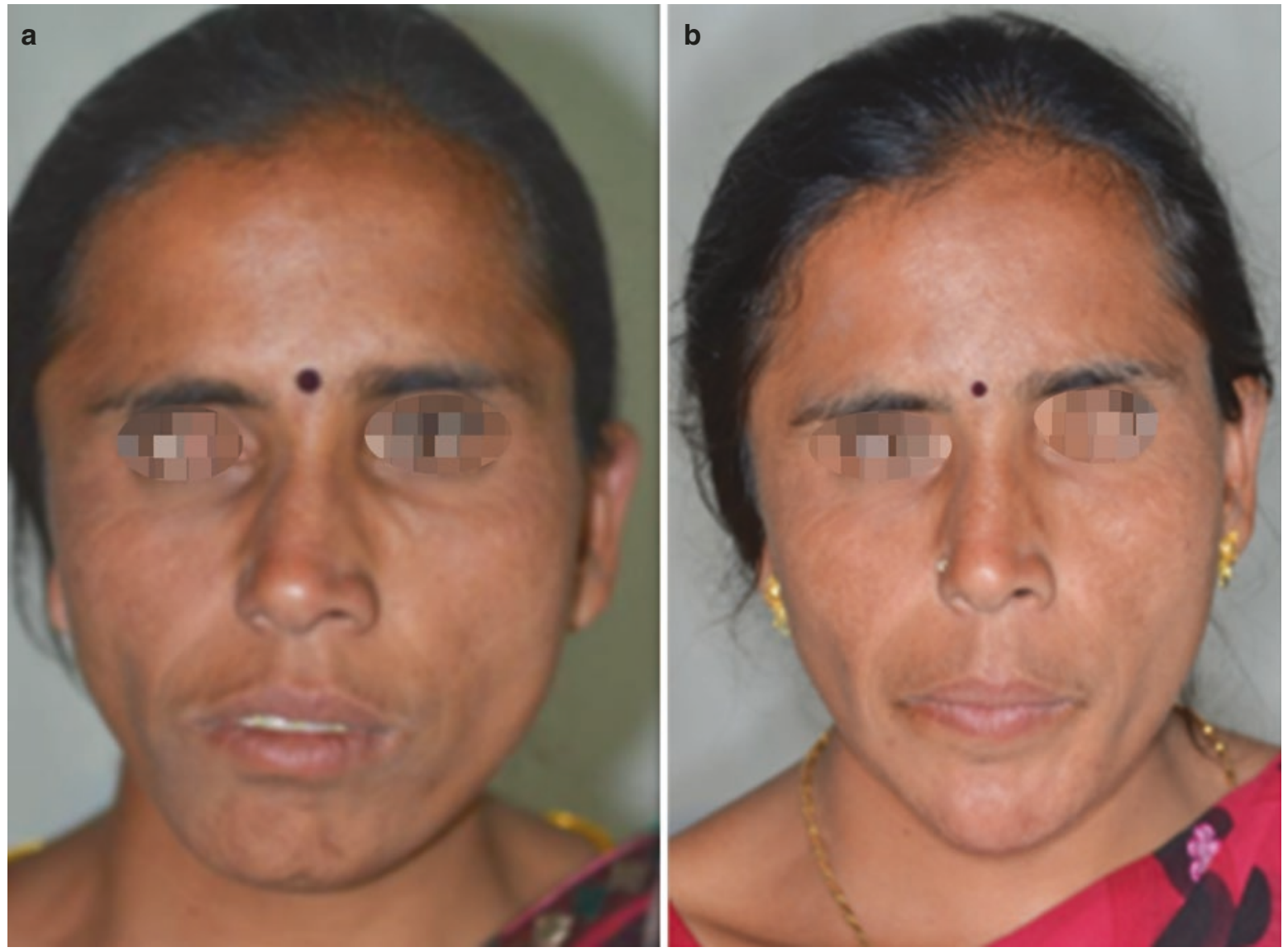

CAssociation of Oral and Maxillofacial Surgeons of India

Fig. 78.26 (a, b) Orthomorphic distraction done in a patient having hemifacial microsomia. (a) Pre- and (b) postoperative photograph showing achievement of anatomic chin and contour and mandibular asymmetry 

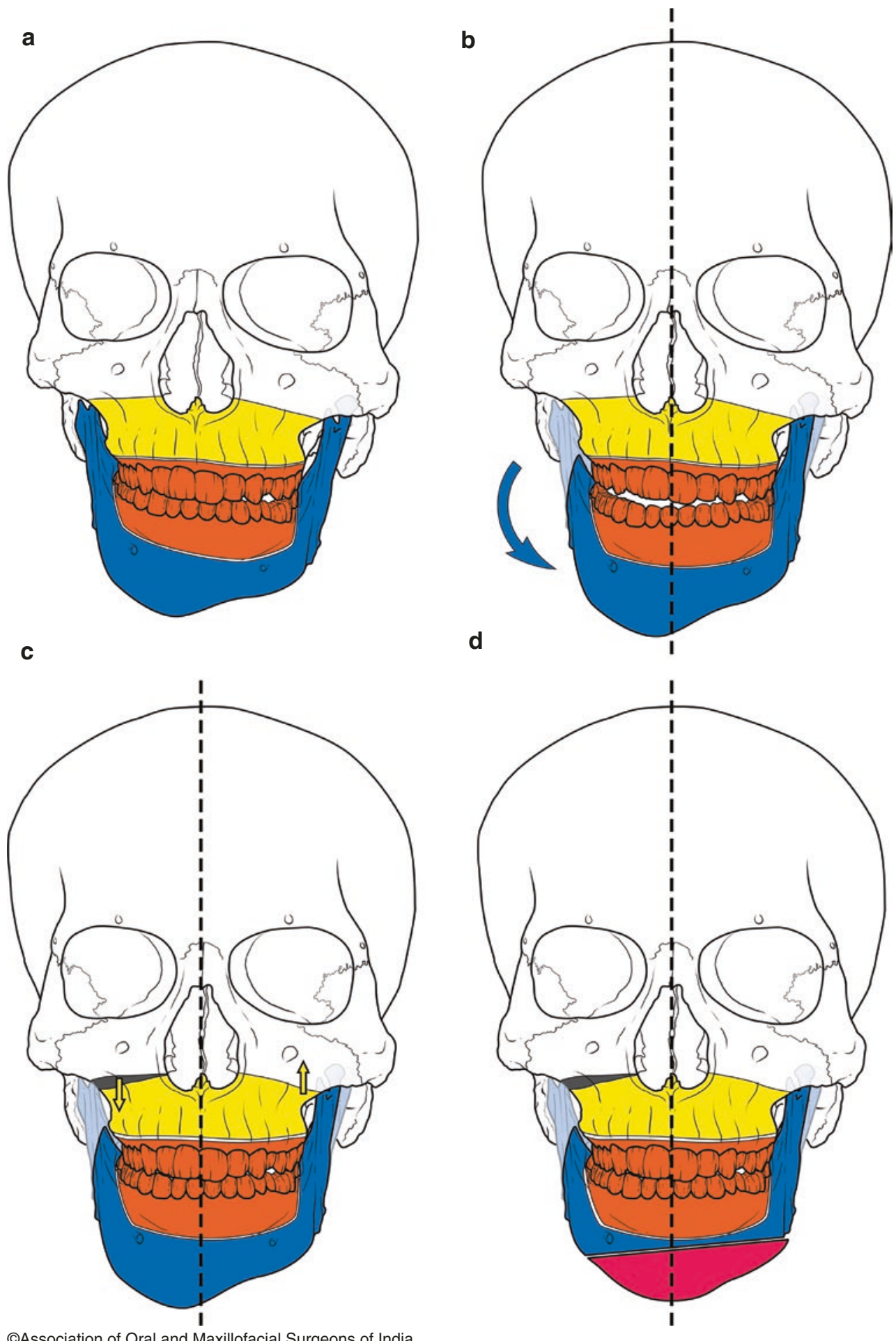

Fig. 78.27 (a-d) Diagrammatic representation of surgical management of Type 2 Kaban-Pruzansky deformity (a). Derotation of the maxillamandibular complex by orthognathic surgery (b and $\mathbf{c})$. Midline skeletal correction with a centring genioplasty (d)

classes, has mixed reports of success. Longitudinal studies provide evidence for stable results with early osteodistraction in mild-to-moderate skeletal deformities [20, 33, 34] (Type 1 and Type 2A). However, the role of mandibular distraction may be more relevant in severe deformities. It is also suggested that early intervention makes definitive final correction easier to achieve, since the extent of deformity is reduced.

\subsubsection{Long-Term Results}

Long-term evaluation of growing HFM patients treated by surgical correction and distraction osteogenesis depends on two main factors: the time of intervention and the severity of the skeletal deformity. According to Hollier et al., by achieving normal mandibular dimensions at a young age, it is 

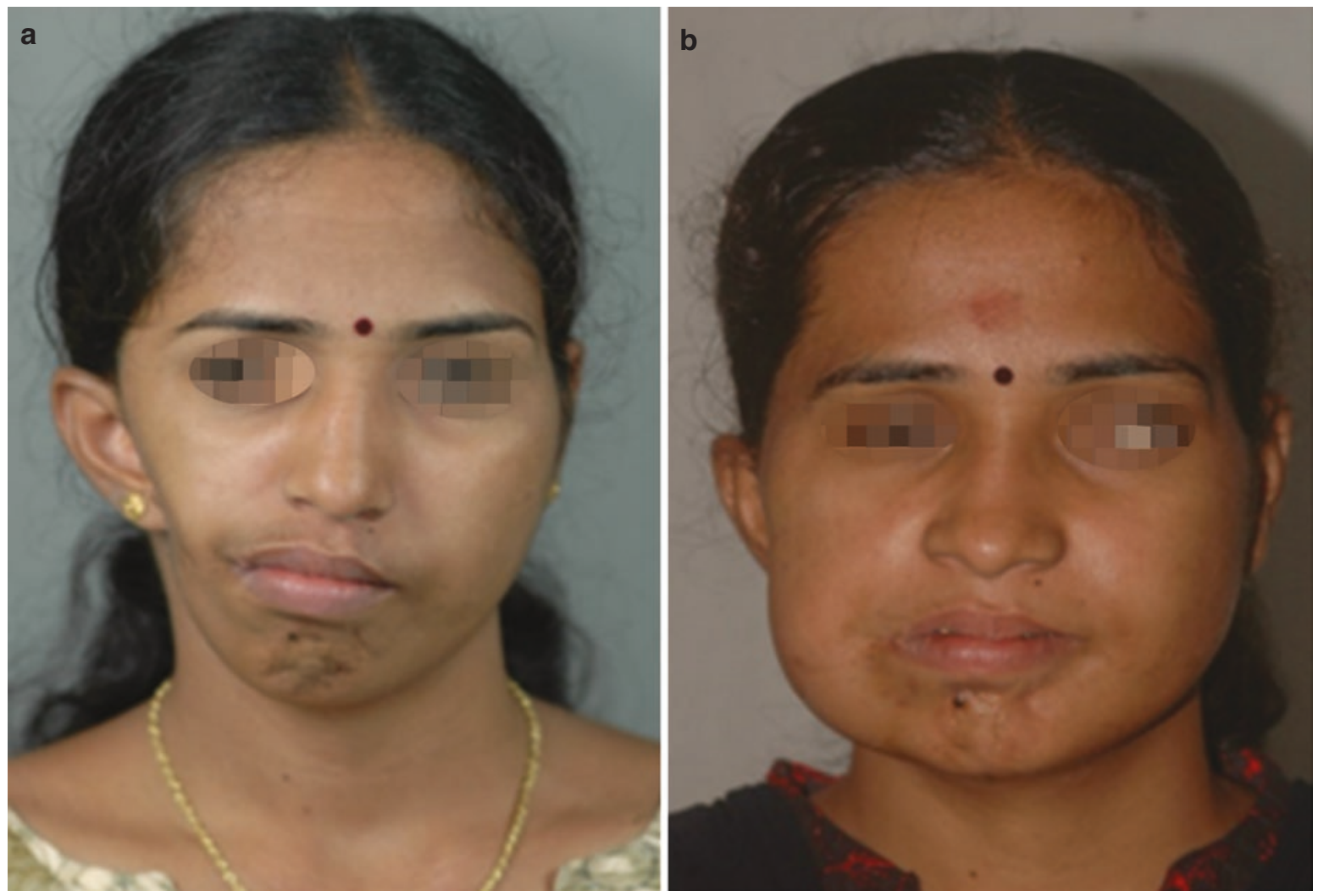

CAssociation of Oral and Maxillofacial Surgeons of India

Fig. 78.28 (a, b) Soft tissue augmentation using abdominal autologous fat transplant. (a) pre-surgical frontal view demonstrating severe right sided deficiency in a patient with HFM, (b) frontal view showing soft tissue augmentation

hypothesized that the maxilla, overlying muscle and soft tissue envelope may develop along with a balanced functional matrix [19]. Proponents of mandibular distraction believe that an early intervention would prevent the secondary compensations from taking place or would unravel the compensations at the onset. This means the contralateral and ipsilateral distortions can be reduced in comparison with patients not undergoing distraction in the younger age (Figs. 78.29a, b and 78.30). Clinicians have found that early distraction can also prevent the long orthodontic decompensation phase followed by orthognathic surgery. Considering severity of deformity, the more severe deformities demonstrate less stable and favourable results when attempted early.

The indications for early skeletal correction maybe (1) compromise of airway necessitating immediate mandibular lengthening irrespective of age and (2) negative psychological impact on the child in school-going age.

In authors' experience irrespective of area and direction of distraction in the mandible or in maxilla in younger age, the following findings were concluded in 20 years of clinical follow-up:

1. It is difficult to predict the future growth of already distracted area of bone though claims of growth potential on distracted bone have been debated by many.
2. In majority of the cases, the intensity of the severity of the disease has reduced due to distraction than simply curing the disease as the age advances.

3. The 3D volume achievement in the ipsilateral side is difficult to achieve irrespective of technique of distraction and conventional osteotomies in later ages.

4. Orthodontic compensations, alignment and other associated corrections of teeth on a weak hypoplastic bone are difficult at least in some cases.

5. Many cases after pubertal age needed conventional orthognathic surgeries to achieve symmetry.

6. Soft tissue augmentation was necessary in many patients to balance the soft tissue profile equal on both sides.

7. Compromised occlusions and dental rehabilitation were necessary in some cases especially Type 2B and Type 3 cases and accepted as standard norms to finish orthodontic alignments.

8. The airway disease is not cured to $100 \%$ in all cases due to extreme variability treatment outcomes and procedures followed by different surgeons.

9. Expectations of the patient may not be achieved completely, so caution should be given to patient the compromised results outcomes in extreme cases of asymmetry. 

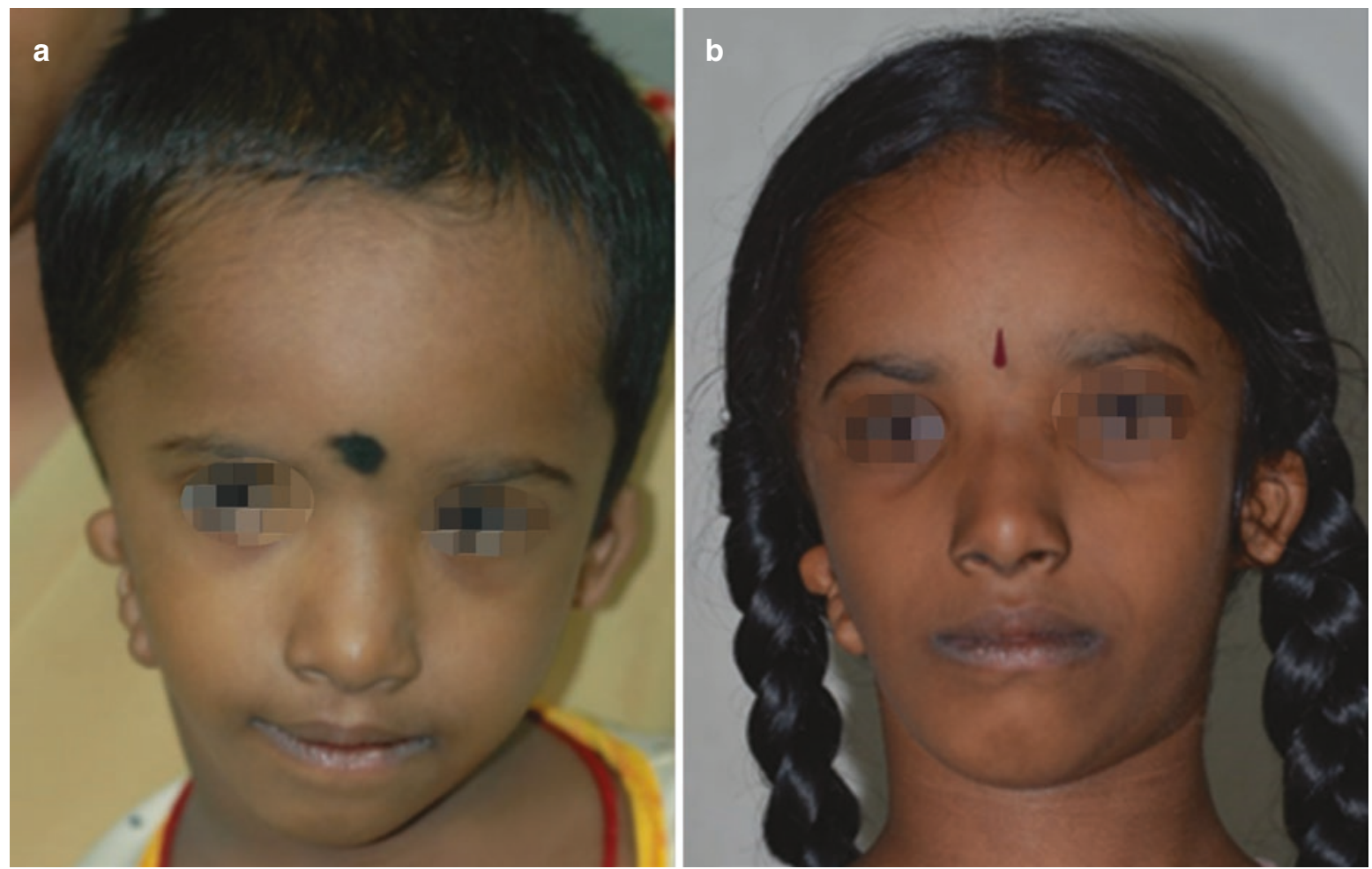

CAssociation of Oral and Maxillofacial Surgeons of India

Fig. 78.29 (a, b) Long-term results of patient treated with mandibular distraction in childhood. (a) frontal photo of patient with right sided HFM at, (b) frontal photo of patient after 8 years follow up

10. Alloplastic prosthetic condyles should be reserved as a last resort if all other techniques fail to achieve a functionally stable total agenesis of condyles [21].

\subsubsection{Recent Advances}

The assessment of facial topography using non-invasive methods, such as laser surface scanners, stereophotogrammetry or ultrasonographic measurements, has been recently reported in several studies. Particularly, 3D stereophotogrammetry for the evaluation of soft tissue surface facial asymmetry has been extensively studied [36]. In distraction osteogenesis, recent advancements like automated distraction using battery-operated and hydraulic distractors have been tried. Since hemifacial microsomia involves bone augmentation in a multiplanar fashion, the advent of curvilinear and multiplanar distractors has greatly helped overcome this challenge [37, 38].

Tissue-engineered osteogenic material comprising of culture-expanded mesenchymal stem cells (MSCs) and platelet-rich plasma (PRP) can now be injected at the distraction site to ensure more predictable bone formation. Not only animal studies but also clinical trials have demonstrated that this material can effectively regenerate osseous tissue $[39,40]$.

\subsection{Treacher Collins Syndrome}

\subsubsection{Introduction}

Treacher Collins syndrome (TCS), also called mandibulofacial dysostosis (MFD), is an autosomal dominant disorder of craniofacial development with variable penetrance. It has a worldwide incidence of 1 in 50,000 live births (Gorlin et al. 1990) [41]. Early descriptions were given by Berry (1889), Treacher Collins (1900) and Franceschetti and Klein in 1949. Therefore, this entity is also named as Berry's syndrome and FranceschettiZwahlen-Klein syndrome [42, 43]. While $40 \%$ of TCS cases have a previous family history, $60 \%$ of cases could possibly arise as a result of de novo mutations (Jones et al. 1975) [44].

The TCOF1 gene plays an important role during early embryonic development for tissues derived from the first and second branchial arches, ectodermal clefts and endodermal pouches. TCOF1 gene encodes a nuclear phosphoprotein "Treacle" that may serve as a link between rRNA gene transcription and pre-rRNA processing. TCOF1 mutation leads to abnormal neural crest cell migration or anomalies in the extracellular matrix [45]. Sulik et al. also documented excessive cell death in the maxillary and mandibular processes of the first branchial arch and the apical ectodermal ridge of the limb bud [46]. These deductions have been made on the basis of experimental studies wherein animals were exposed to 

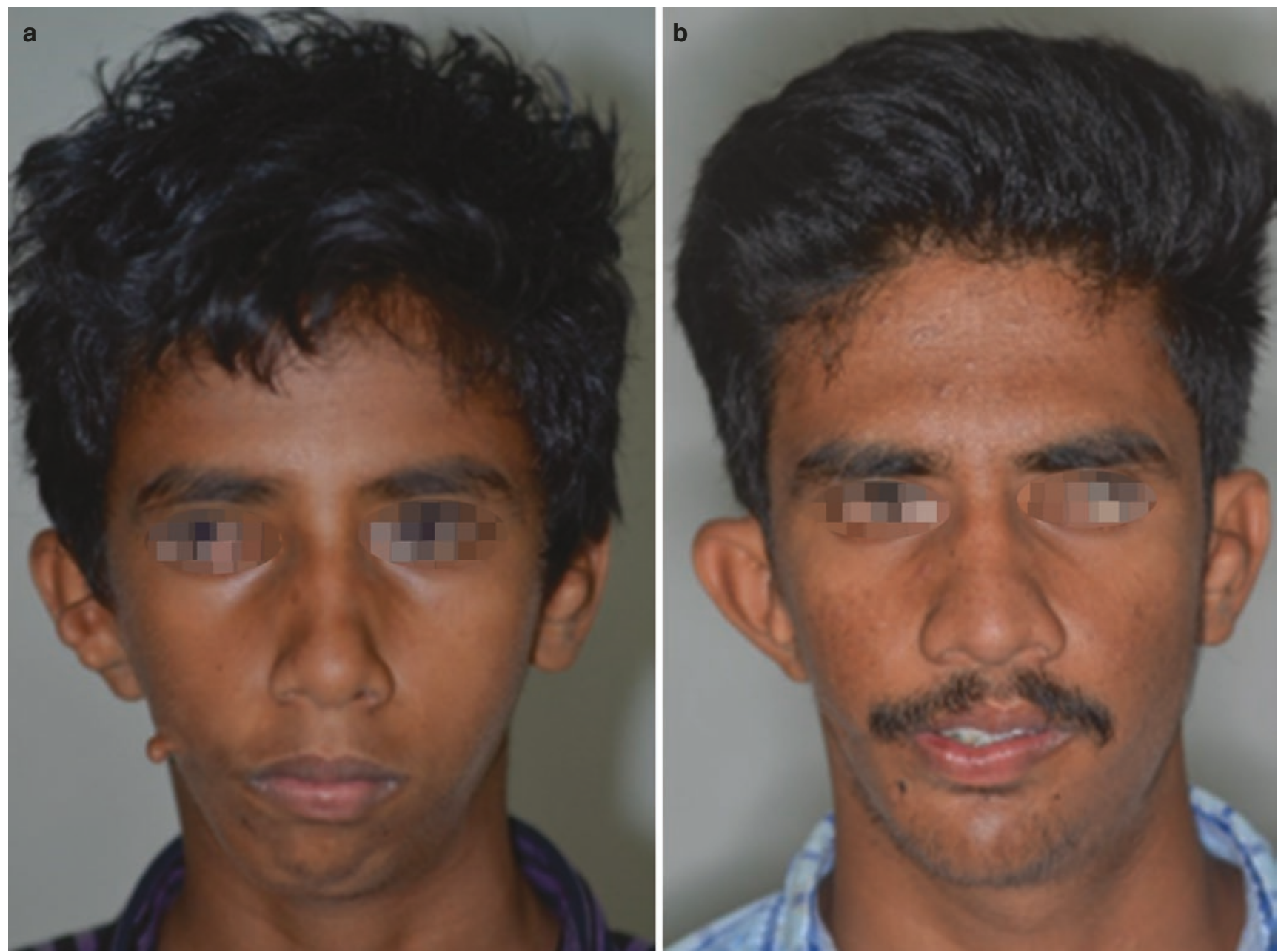

CAssociation of Oral and Maxillofacial Surgeons of India

Fig. 78.30 (a, b) Definitive skeletal management of patient with HFM. (a) Preoperative Frontal photo of patient with right sided HFM at 15 years of age. He underwent mandibular distraction for correction of

teratogenic cis- or trans-retinoic acid during embryonic development. Recently, Dauwerse et al. [47] detected mutations in genes encoding subunits of RNA polymerases I and III in Treacher Collins patients.

Normally, prenatal diagnosis is recommended for families with a history of TCS using fetoscopy or ultrasound imaging [USG]. Prenatal diagnosis using either of these methods can only be performed in the second trimester of pregnancy (approximately 18 weeks). Due to the late nature of the diagnosis, termination of pregnancy can be a particularly traumatic procedure. Imaging with USG has improved immensely in recent years [e.g. 3D sonography], allowing non-invasive prenatal diagnosis to be made. However, mild cases of TCS are still difficult to diagnose. Genetic counselling is highly recommended for affected individuals and their families for prevention of further affected child birth. asymmetry followed by second stage Bi maxillary orthognathic surgery at 18 years of age (Fig. 78.7a). (b) Stable skeletal results after a 7 year followup when patient is 25 years of age

\subsubsection{Clinical Features and Presentation}

The complete spectrum of features which can be present are explained in the table below [48] (Table 78.7).

A case of Treacher Collins syndrome in a 13-year-old female with the following features (Fig. 78.31a, b):

- Eyes: Antimongoloid palpebral fissures are short and slope laterally downwards with either a notch or coloboma of the outer third of the lower eyelid. Lashes are absent medial to coloboma.

- Face: Bilateral and usually symmetric hypoplasia of facial bones is present, e.g. malar and mandibular bones. Depressed cheekbones, receding chin, tongue-shaped process of the hair that extends towards the cheek and large down-turned mouth can be identified. 
- Ears: Malformation of the external, middle and inner ear, with low implantation of the auricle which is common. The pinnae are often crumpled and misplaced towards the angle of the mandible. Bat-fan ears, deafness, microtia, extra ear tags and blind fistulas [which may occur anywhere between the tragus and the angle of the mouth] are the other common findings.

Table 78.7 Clinical features of TCS

\begin{tabular}{|c|c|}
\hline Region & Characteristic feature \\
\hline \multirow[t]{4}{*}{ Eyes } & Antimongoloid slant of palpebral fissures \\
\hline & $\begin{array}{l}\text { Colobomata and hypoplasia of the lower lids and } \\
\text { lateral canthi }\end{array}$ \\
\hline & Hypertelorism \\
\hline & Partial absence of eyelid cilia \\
\hline \multirow[t]{3}{*}{ Ears } & Microtia \\
\hline & Conductive hearing loss \\
\hline & Hypoplasia of middle ear ossicles \\
\hline \multirow[t]{4}{*}{ Nose/mouth } & Nasal deformity \\
\hline & Cleft palate with or without cleft lip \\
\hline & High-arched palate \\
\hline & Class II or III malocclusion open bite \\
\hline \multirow{6}{*}{$\begin{array}{l}\text { Facial bone } \\
\text { formation }\end{array}$} & Hypoplasia of the malar bones \\
\hline & Hypoplastic lateral aspects of orbits \\
\hline & Hypoplastic maxilla and mandible \\
\hline & Variable effects on the temporomandibular joints \\
\hline & Anterior open bite \\
\hline & A steep occlusal plane \\
\hline
\end{tabular}

- Oral findings: Cleft palate, congenital palatopharyngeal incompetence, high-arched palate and a narrow maxillary and mandibular arch with dental crowding are common (Fig. 78.32a-e).

- Nose: The nose appears larger due to the hypoplastic midface skeletal structures. Hypoplastic alar cartilages, narrow nares and obliteration of the nasofrontal angle are also common.

\subsubsection{Imaging for TCS}

The conventional OPG and the lateral and frontal cephalometric image are pivotal in diagnosing TCS along with clinical correlation. The OPG helps identify the following: hypoplastic condyle with a short condylar neck, absent articular eminence, shortened ramus-condyle unit and severely hypoplastic coronoid process (Figs. 78.33 and 78.34). The lateral cephalogram shows a severely retrognathic mandible with microgenia, clockwise-rotated maxillomandibular complex and a reduced posterior airway space. However, threedimensional computed tomography [3DCT] is the gold standard in diagnosis as well as treatment planning (Fig. 78.35a-c). The features that are remarkably seen on the 3DCT are hypoplasia of the orbito-zygomatic complex, poorly developed lateral orbital and supraorbital ridges, mandibular hypoplasia and reduced overall facial width. The orbits are hyper-teloric and the infraorbital foramen is usu-
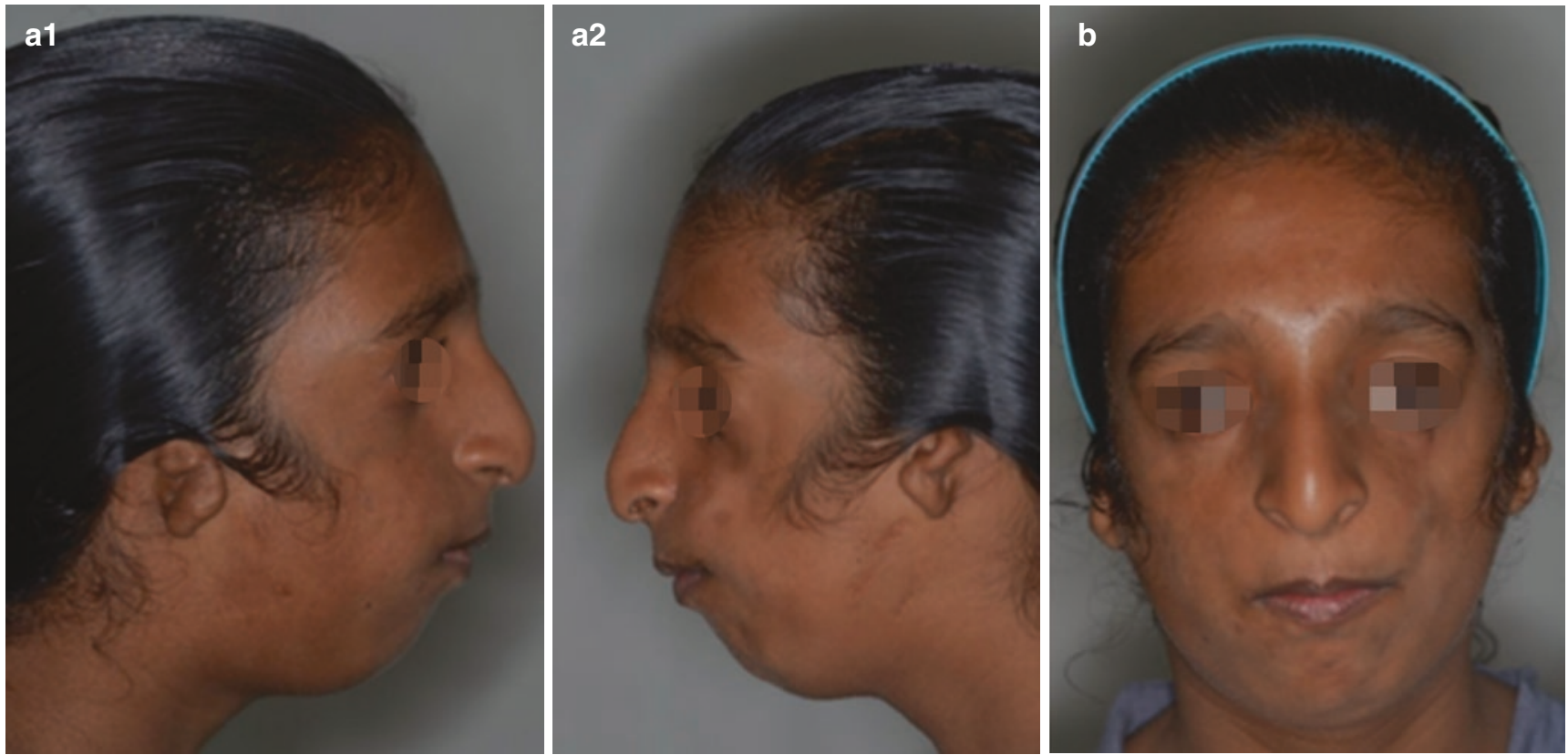

CAssociation of Oral and Maxillofacial Surgeons of India

Fig. 78.31 (a, b) Case of a 13-year-old female with Treacher Collins syndrome, (a) profile and (b) frontal photos (Also see Fig. 78.41b) 

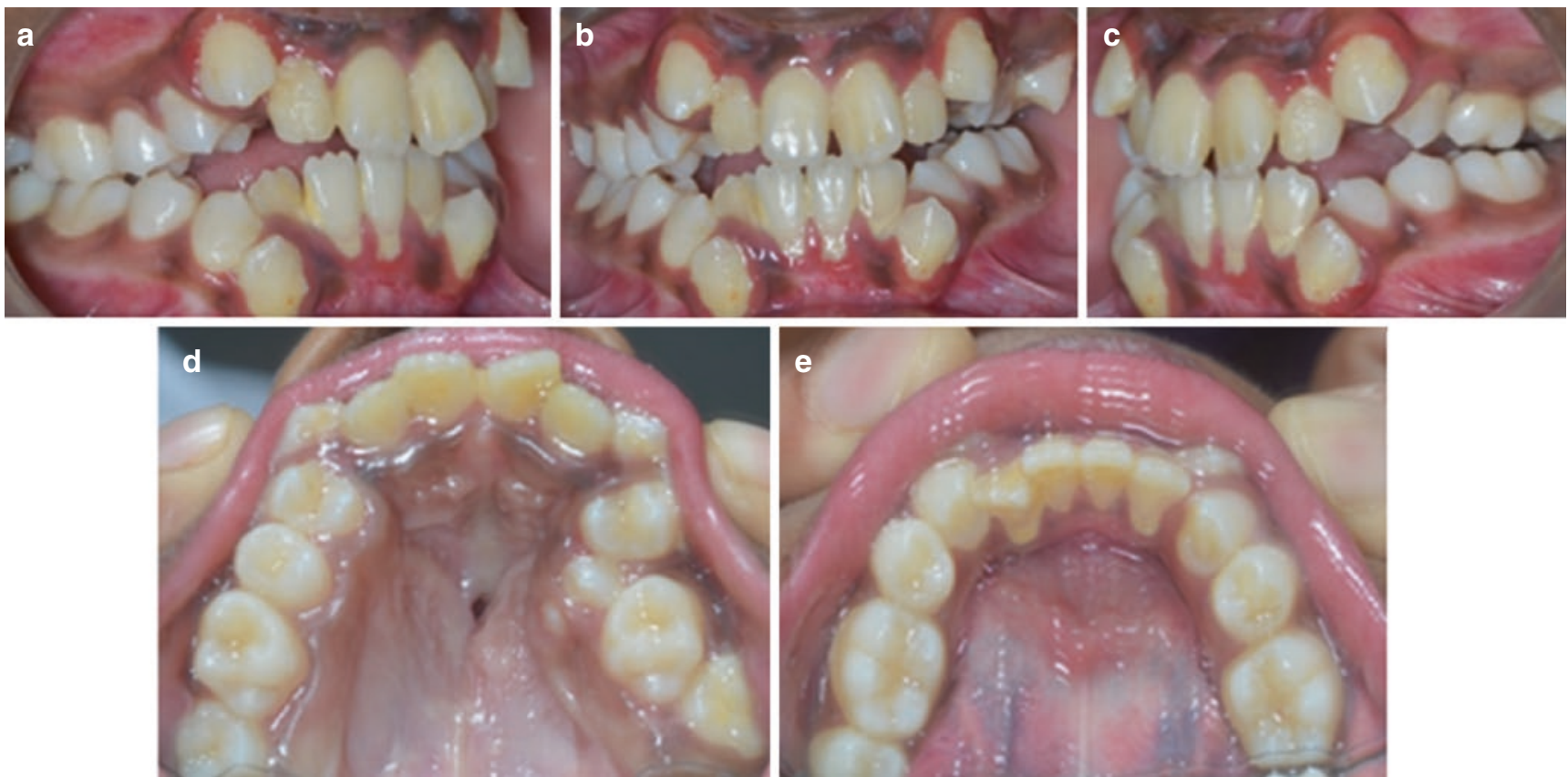

CAssociation of Oral and Maxillofacial Surgeons of India

Fig. 78.32 (a-e)Intraoral pictures of the same patient in Fig. 78.30 showing operated cleft palate, mixed dentition stage with severe crowding. (a-c) frontal and lateral intra-oral dental views, (d) maxillary occlusal and (e) mandibular occlusal views

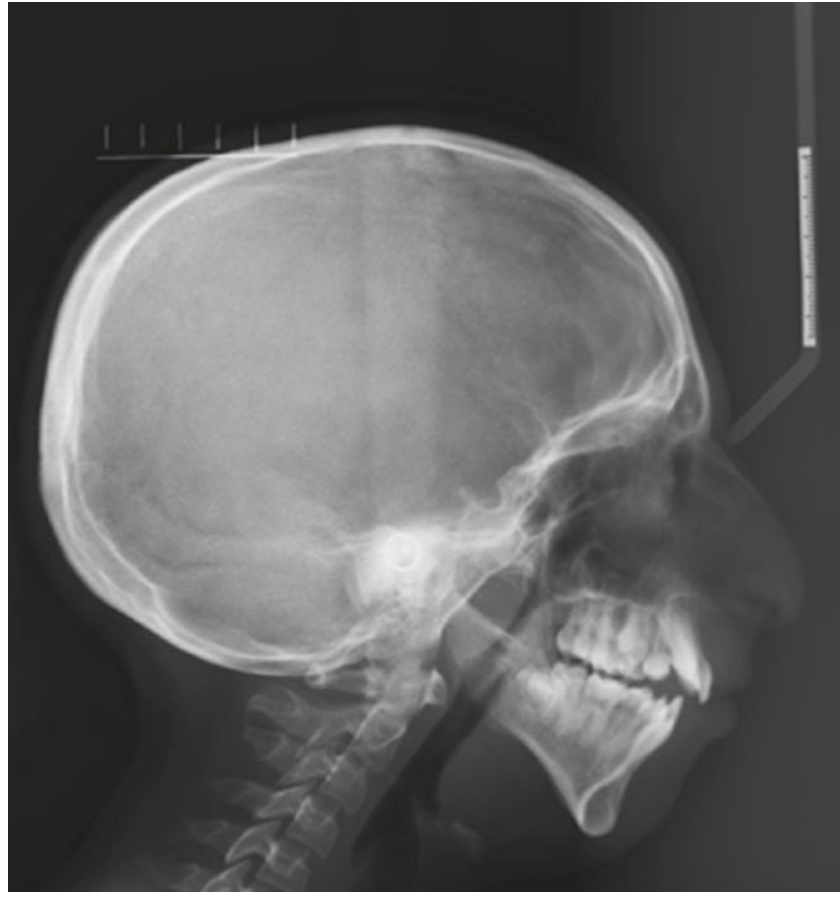

CAssociation of Oral and Maxillofacial Surgeons of India

Fig. 78.33 Lateral cephalogram of the same patient in Fig. 78.31 showing reduced posterior airway space, micrognathia and microgenia

ally absent. The paranasal sinuses are often small and may be completely absent. Furthermore, the mastoids are not pneumatized and are frequently sclerotic. The cranial base is also progressively kyphotic [48]. Lastly, these patients require

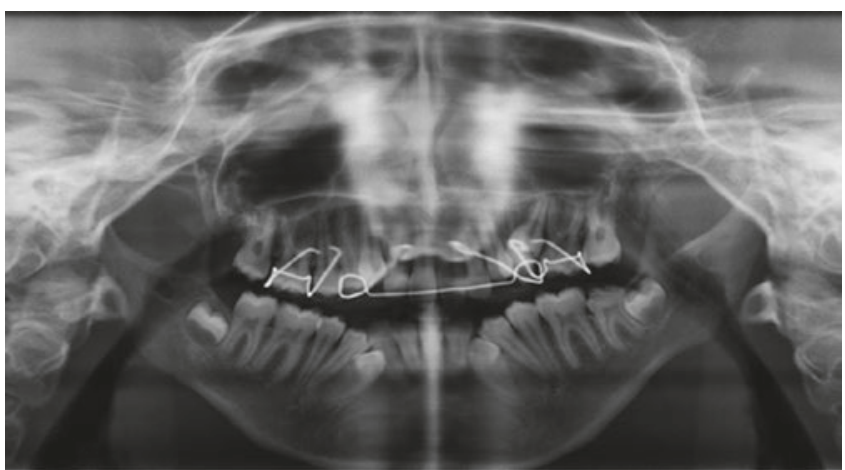

CAssociation of Oral and Maxillofacial Surgeons of India

Fig. 78.34 Orthopantomogram of the same patient in Fig. 78.31 showing hypoplastic ramus-condyle unit

long-term follow-up in order to evaluate the effects of mandibular growth, airway dimensions, degree of surgical relapse and the need for additional surgical intervention.

\subsubsection{Proposed Classification}

A classification system of the orbito-zygomatic skeletal deformities seen in TCS has been proposed by Nikkah D et al. The classification is designed to characterize the degree of deformity and as a guide to the reconstructive planning [49]. Treatment planning becomes complex as TCS can have a variable presentation with respect to the severity of the hypoplasia/dysplasia of the skeletal and soft 

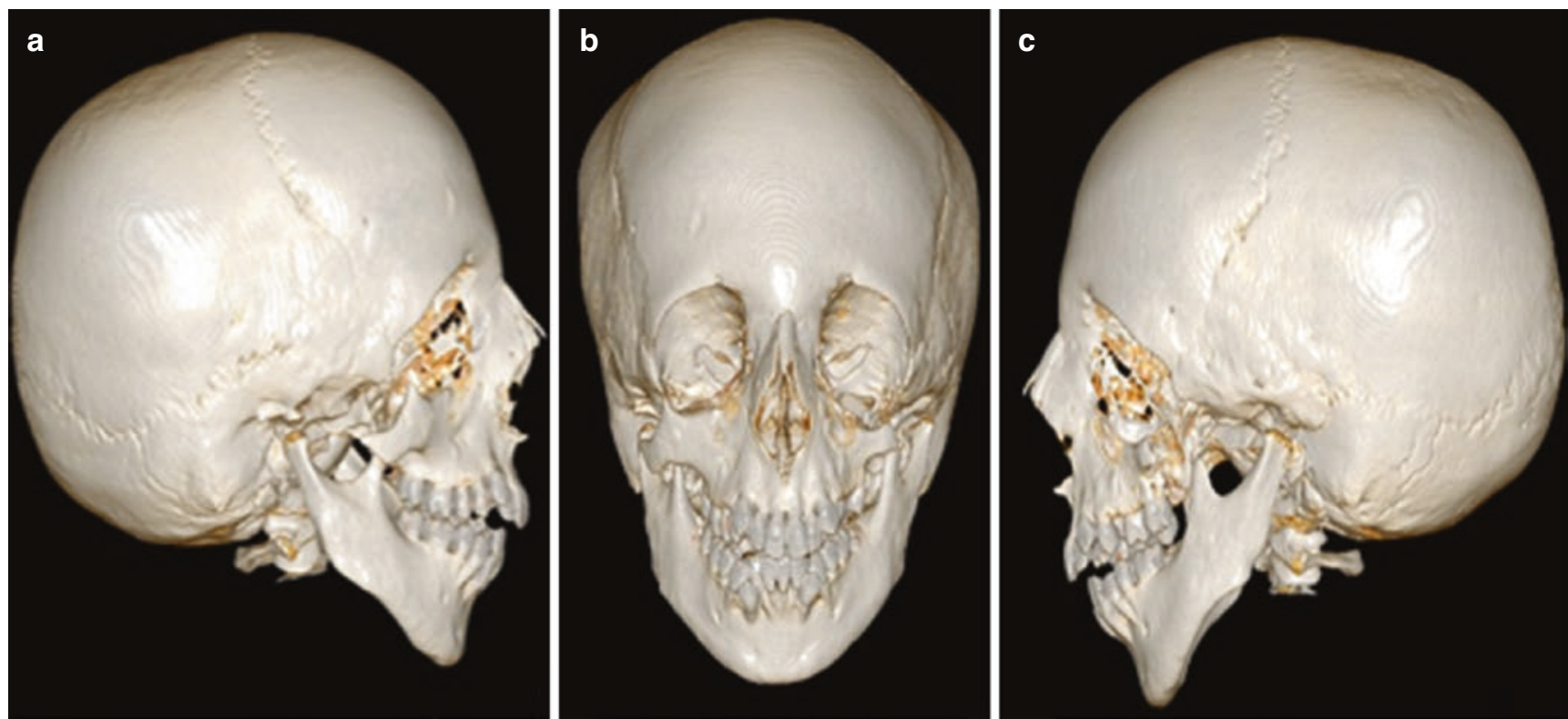

CAssociation of Oral and Maxillofacial Surgeons of India

Fig. 78.35 (a-c) 3DCT view of TCS patient showing hypoplasia of orbito-zygomatic complex. (a) Right lateral view demosntrating type $2 b$ deformity, (b) frontal view showing type 2 b deformity on the right and type 3 deformity on the left, (c) left lateral view showing type 3 deformity
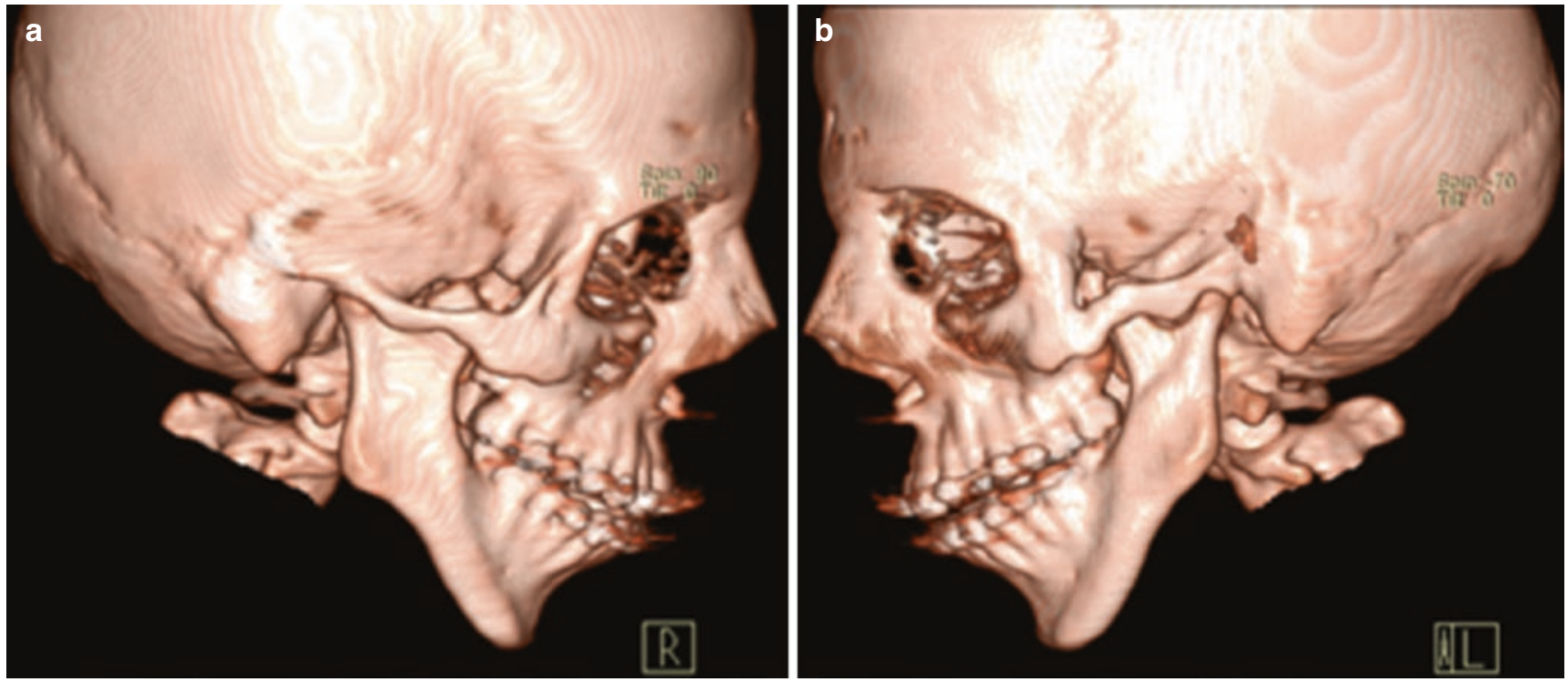

CAssociation of Oral and Maxillofacial Surgeons of India

Fig. 78.36 (a, b) Type 1: Patients have the entire orbito-zygomatic complex present but the region is dysplastic and hypoplastic

tissue elements, shape and position of the affected structures and resulting functional deformity. Thus, the challenges faced in treating TCS are similar to those faced in treating HFM.

\subsubsection{Methods}

- Type 1: orbito-zygomatic complex present but, dysplastic and hypoplastic (Fig. 78.36a, b).
- Type 2: a hypoplastic zygomatic body with a vestigial zygomatic temporal process and a lateral orbital wall that is either dysplastic (2a) or absent (2b) (Fig. 78.35a, b).

- Type 3: a hypoplastic zygomatic body and dysplastic orbital wall but with complete absence of the zygomatic temporal process (Fig. 78.35b, c).

- Type 4: complete absence of the entire orbito-zygomatic complex (Fig. 78.37a, b). 

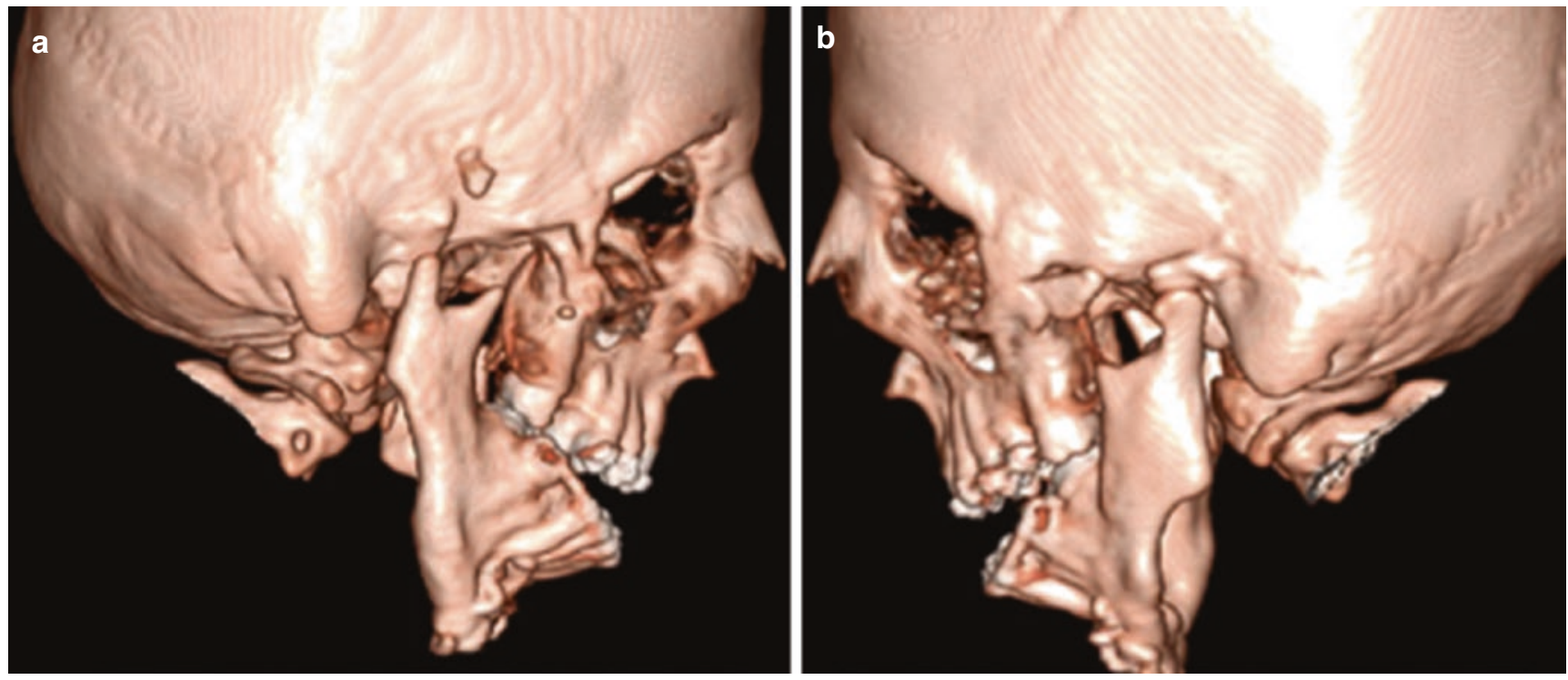

CAssociation of Oral and Maxillofacial Surgeons of India

Fig. 78.37 (a, b) Type 4: Is the most severe with complete absence of the entire orbito-zygomatic complex

There is not always a symmetrical classification as $25 \%$ of the TCS demonstrated asymmetry.

\subsubsection{Classification of Temporomandibular Joint and Mandibular Malformation}

The Kaban and Pruzansky classification system for the degree of TMJ-mandibular malformation in HFM is applicable to TCS patients as well $[13,26]$. This classification is useful in defining the anomalies and directing reconstruction similar to HFM patients.

\subsubsection{Differential Diagnosis}

Differential diagnosis of TCS includes acrofacial dysostosis (Nager and Miller syndromes) and oculo-auriculo-vertebral spectrum (hemifacial microsomia and Goldenhar syndrome).

Nager syndrome has facial features similar to that of TCS. In addition, the thumb[s] may be hypoplastic, aplastic or duplicated, and there may be fusion of the radius and ulna. Miller syndrome also has features similar to TCS. Ectropion or outturning of the lower lids is an additional diagnostic feature. Clefting of the lip and palate is more common in this syndrome than in TCS [50]. HFM primarily affects development of the ear, mouth and mandible. Goldenhar syndrome has a spectrum of deformities that include those of HFM in addition to vertebral abnormalities and epibulbar dermoids [51].

\subsubsection{Treatment}

Though there have been immense medical advances in terms of in utero surgery, stem cell therapy and genetic manipulation, there is currently no treatment for TCS in utero. Treatment is performed postnatally according to the nature of the deformity and severity of functional disturbance [52].

The following issues are present in case of TCS:

1. Airway, i.e. obstructive sleep apnoea.

2. Feeding problems.

3. Brain development.

4. Orbito-zygomatic growth.

5. Mandibular retrognathism with open bite.

6. Dentoalveolar issues including orthodontic alignment.

7. Cleft palate.

8. Hearing issues.

9. Psychosocial development.

10. Deficient soft tissue.

These issues can challenge clinicians from birth to adulthood as concerns vary from aesthetic to functional in nature. Thus, a multidisciplinary approach is indispensable for achieving optimal outcomes. 


\subsubsection{Multidisciplinary Management: Team Members Necessary from Birth to Adult Stage}

1. Geneticist.

2. Paediatrician.

3. Anaesthetists.

4. Oral and maxillofacial surgeon.

5. Orthodontist.

6. Paedodontist.

7. General dentist.

8. Paediatric neurosurgeon.

9. Psychiatrist.

10. ENT surgeon.

11. Audiologist.

12. Pulmonologist.

13. Paediatric neuro-physician.

14. Speech therapist.

15. Oculoplastic surgeon.

\subsubsection{Airway Management}

Syndromic patients [e.g. TCS] with micrognathia suffer from OSA frequently due to narrowing of the upper airway
[53]. Despite respiratory effort, partial or complete obstruction of the upper takes place, leading to frequent episodes of oxygen desaturation and sleep disruption. In the long term, OSA can harm an individual's physical and mental health, as has been documented recently in the literature [54].

Respiratory compromise is due to two reasons:

(i) Maxillary hypoplasia, constricting the nasal passages and resulting in a degree of choanal stenosis or atresia.

(ii) Mandibular micrognathia and a retro-positioned tongue obstructing the oropharyngeal and hypopharyngeal airway.

Earlier, long-term tracheostomy was the only solution available for severe cases of infantile OSA. However, longterm tracheostomies are commonly associated with morbidities like tracheomalacia, chronic bronchitis, throat tightness and dislocation of the tracheostomy tube [55] (Fig. 78.38a, b). Today, distraction osteogenesis [DO] has become the favoured treatment method for TCS patients with OSA. Mandibular advancement by means of DO helps in increasing the posterior airway space, thus relieving the symptoms of OSA and preventing severe respiratory distress [56]. Due to the unique mandibular and oropharyngeal anat-
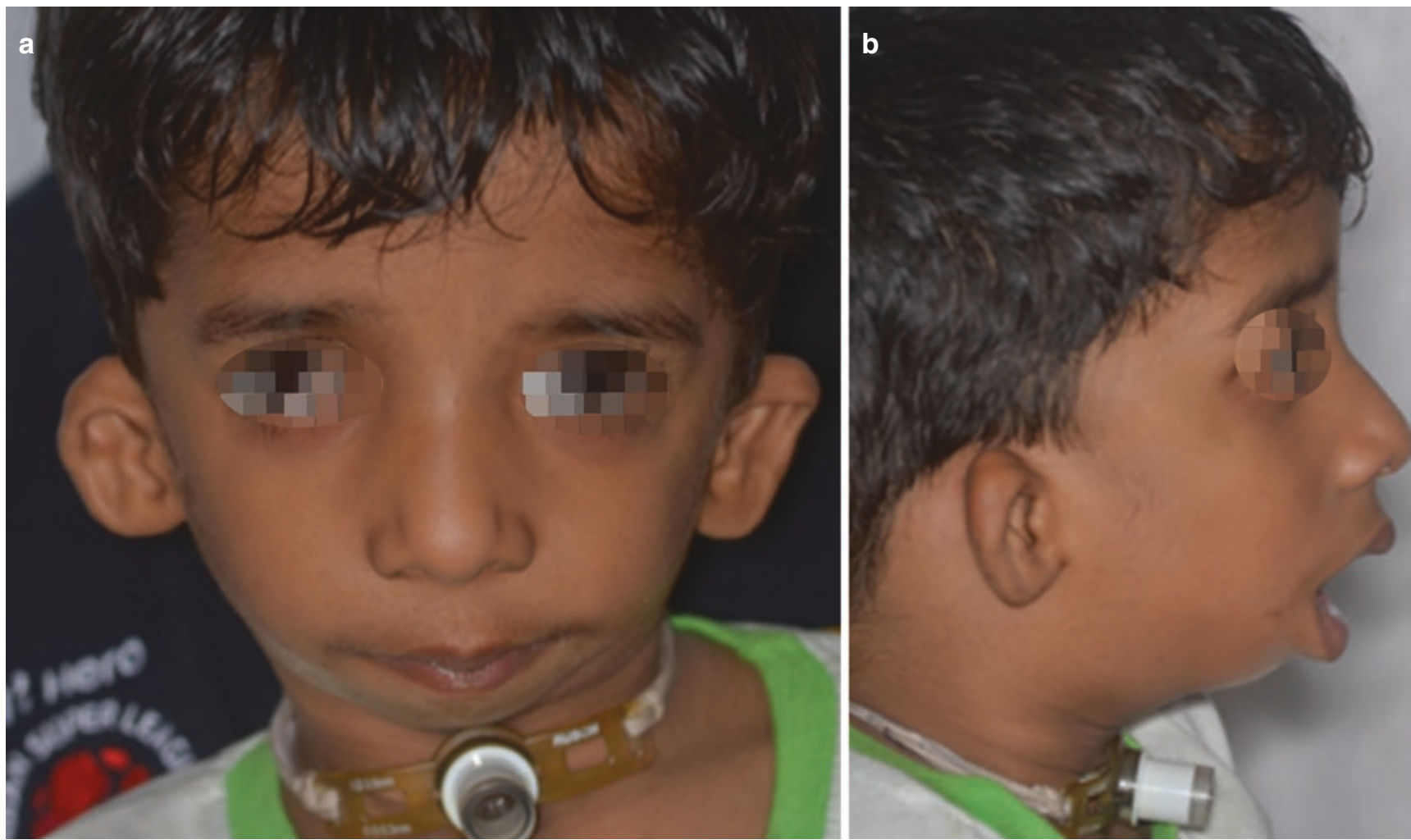

CAssociation of Oral and Maxillofacial Surgeons of India

Fig. 78.38 (a, b) Photograph of a 4-year-old male with TCS. Patient had history of hospitalization due to respiratory distress. Tracheostomy tube in situ since 7 months of age 


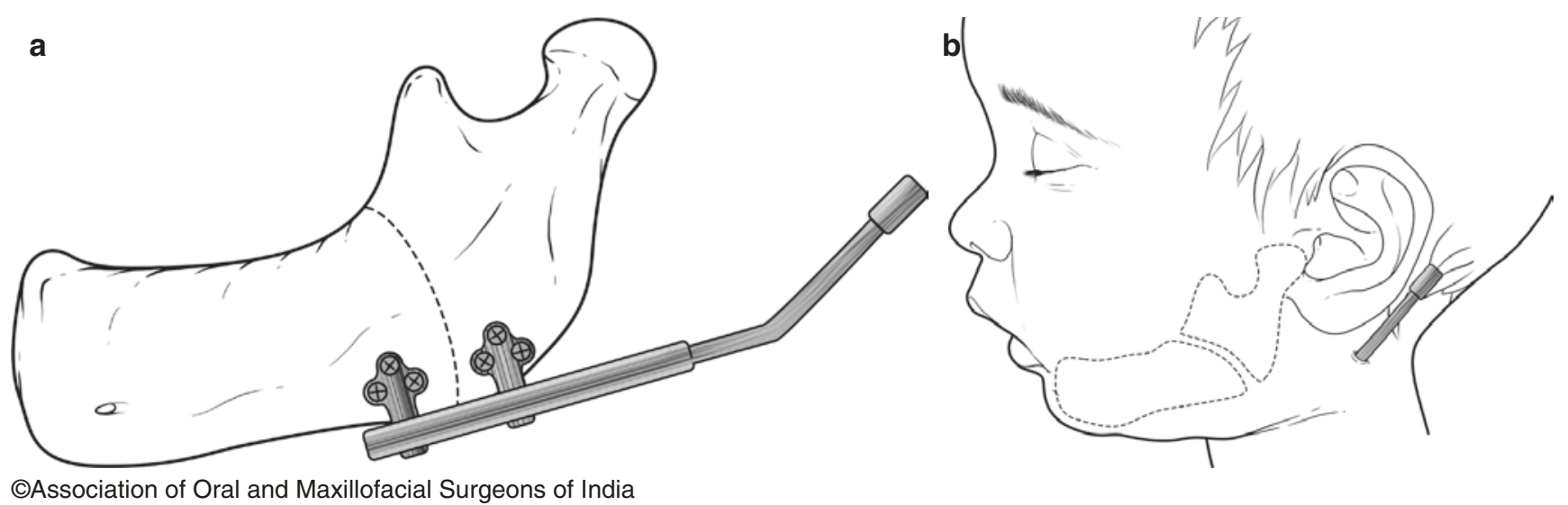

Fig. 78.39 (a, b) Mandibular advancement using distraction in neonates to increase posterior airway space as a treatment of obstructive sleep apnoea. (a) Position of the distractor on the mandible, (b) Emergence of activation port in the retromandibular region

omy of TCS patients, a fibre-optic-assisted intubation method similar to that described by Ellis et al. can be successfully used [57].

Paediatric mandibular advancement was initially performed using bilateral external distractors which are advantageous because of their ease of use, manipulation and versatility [ 58]. However, external devices also create aesthetic [e.g. scarring] and social problems. Another important point to be noted is that retention period of such devices is reduced and an increased relapse rate is seen compared to internal distractor devices [59]. If the child is extremely uncooperative and parents are unable to maintain and monitor the external distractors, an internal distractor should be used (Fig. 78.39a, b).

Recently, paediatric mandibular distraction for OSA has been discouraged in many centres around the world due to concern of permanently damaging the teeth buds. Instead, tongue lip adhesion (TLA) has been popularized by many centres instead of DO as it has significantly lower morbidity. After the airway improves, better feeding and weight gain are expected and cleft palate closure is done. Subsequently, TLA release can be attempted [60]. In comparison to DO, the TLA needs stricter postoperative care in intensive setup as feeding and breathing need to be assessed regularly for a week at the minimum.

\subsubsection{Feeding Problem}

The abnormal or hypoplastic craniofacial issues in TCS can sometimes produce severe feeding problem for infants, leading to weight loss and failure to thrive. Most feeding problems relate to cleft lip and palate, retrognathic jaws and airway problems. Ideally, a craniofacial feeding management team should guide the parents regarding position of feeding, type of nutrition and dietary plan for such children.

Position (holding the baby upright or supporting the cheek and jaw while feeding) is important to avoid aspiration.
It is also preferable to do a video-fluoroscopic swallow study (VFSS) to understand the swallowing pattern of the patient and its coordination with breathing [61].

Primary palatoplasty for closure of the cleft palate should be done once the patient gains weight, to assist in normalizing the swallowing pattern without nasal regurgitation.

\subsubsection{Brain and Psychological Development in TCS}

Individuals with TCS have a tendency towards a shorter stature, at least early in life. Intelligence is usually unaffected, but brain and behavioural anomalies such as microcephaly and psychomotor delay have been occasionally reported as part of the condition. Additionally, the facial deformity of this syndrome may affect psychosocial development, school adjustment and other milestones. A psychologist or social worker should be made available for evaluation and counselling if needed.

In the Indian scenario, poor parental awareness, lack of medical advice, social taboos and feeding difficulties lead to failure to thrive among TCS infants and children belonging to lower socio-economic classes. Psychological stress during schooling [e.g. marked out as different by peers] is one of the more challenging issues to be addressed throughout the life of the patient.

\subsubsection{Management of Cleft Palate}

Isolated cleft of the soft palate is the most common form of cleft in TCS. Complete cleft palate up to the alveolus may also be seen. Closure of the soft palate is routinely done at the end of 1 year. Meticulous dissection and suturing of soft palate muscles can produce excellent results, nearing to that of a normal palate. Postoperative maintenance of oral hygiene is necessary and can become challenging in these children for fear of aspiration. Velopharyngeal insufficiency [VPI] is a common issue in these children. VPI can be cor- 
rected secondarily with intra-velar palatoplasties or buccal advancement flaps for velar lengthening.

\subsubsection{Ophthalmological, Auricular and Hearing Issues}

\section{Ophthalmological Issues}

Eye anomalies include aberrations in the extraocular muscle function, corneal exposure difficulties and visual acuity. Ophthalmologic issues may include vision loss (37\%), amblyopia $(33 \%)$, refractive errors $(58 \%)$, anisometropia (17\%) and strabismus (37\%). A thorough paediatric ophthalmological assessment should be done to establish proper management.

\section{Hearing Issues}

A 3D CT of the petrous temporal bones should be done to accurately assess the external auditory canal and middle and inner ear anatomy. TCS patients with microtia can have congenital aural atresia and extremely narrow canals, leading to significant conductive hearing loss as the bone blocks passage of sounds to tympanic area and middle ear. Furthermore, exfoliated skin cells and ear wax cannot drain out, leading to otitis media and occasionally form cholesteatoma. Despite hearing loss, these children tend to grow normally. However, the chances of developmental cognitive deficits are not uncommon.

\section{Microtia Correction}

Microtia ear correction can be done when the patient is around 6 to 7 years old, an age at which external ear development is complete. The most preferred way of auricle reconstruction is the use of autogenous rib cartilage, in a staged manner. The rib cartilage is harvested from the sixth to the ninth rib. The sixth and seventh rib cartilage are utilized to form the base of the framework. The triangular fossa and scapha are carved in the superior portion of the previously created cartilaginous base. The eighth rib cartilage is then carved to replicate the helical rim. The carved cartilage is then inserted under the skin in the region of the missing ear, with or without skin expansion (Fig. 78.19).

Bone-conduction hearing aids such as the bone-anchored hearing appliance (BAHA) or a middle ear implantable prosthetic device can significantly improve hearing in these patients.

\subsubsection{Nasal Issues}

Nasal deformities can be classified as external or internal in nature. Commonly seen external nasal deformities are the dorsal hump $(73 \%)$, external deviation $(\leq 55 \%)$, bifid or bulbous nasal tip (55\%) and columellar septal luxation $(55 \%)$. Commonly seen internal nasal deformities are nasal obstructions due to septal deviation and presence of spurs. Due to presence of the above structural deformities, functional problems, e.g. snoring and impaired phonation, are commonly present in these patients.

A detailed physical examination along with nasal endoscopy and 3D CT of the nasal and paranasal regions can help identify all the deformities present. The commonly performed procedures that should be paid attention to are dorsal hump reduction, correction of the deviated external osseous deformity, septoplasty and tip plasty.

\subsubsection{Dentoalveolar Issues and Orthodontic Alignment}

- Due to the presence of an anterior open bite and compulsive mouth breathing, there is an increased risk for poor oral hygiene. This is evidenced by the face that up to $60 \%$ of TCS patients need dental care [e.g. restorative treatment]. However, the difficulty of performing even simple dental procedures is far higher due to reduced mouth opening, presence of concurrent medical co-morbidities [e.g. congenital heart defects], decreased posterior airway space and hearing loss $[61,62]$.

- During the late mixed dentition phase, orthodontic treatment aims to increase the transverse dimensions of the constricted maxilla [e.g. quad helix]. In the permanent dentition phase, the fixed therapy is used in order to achieve intercuspation and arch levelling.

- For moderately severe cases, the final goal is to prepare the patient for orthognathic surgical correction of the anterior open bite and skeletal class 2 relationship [63]. Studies have established that bimaxillary orthognathic surgery gives stable long-term results in TCS patients [64]. Sometimes, additional procedures to improve the shape of the chin are required. Figures $78.40 \mathrm{a}, \mathrm{b}, 78.41$ and $78.42 \mathrm{a}$, b show double sliding genioplasty done in a patient in early age due to psychological impact owing to the facial appearance.

- For severe cases, DO with external distractors is the ideal surgical intervention wherein gonial angle control is necessary for increase in height of the ramus and lengthening the body of the mandible. In this aspect, multi-vector devices have an advantage with respect to the ability to control the transverse width during distraction (Fig. 78.43a-f).

\subsubsection{Management of the Adult TCS Patient}

\section{Clinical and Cephalometric Features}

The adult patient with TCS has a convex facial profile due to severe mandibular retrognathia. However, the horizontal projection of the maxilla to the cranial base remains normal. Over the growth period, the facial convexity angle remains relatively constant, thus confirming that the facial profile morphology of the infant with TCS remains similar to that of the adult. 

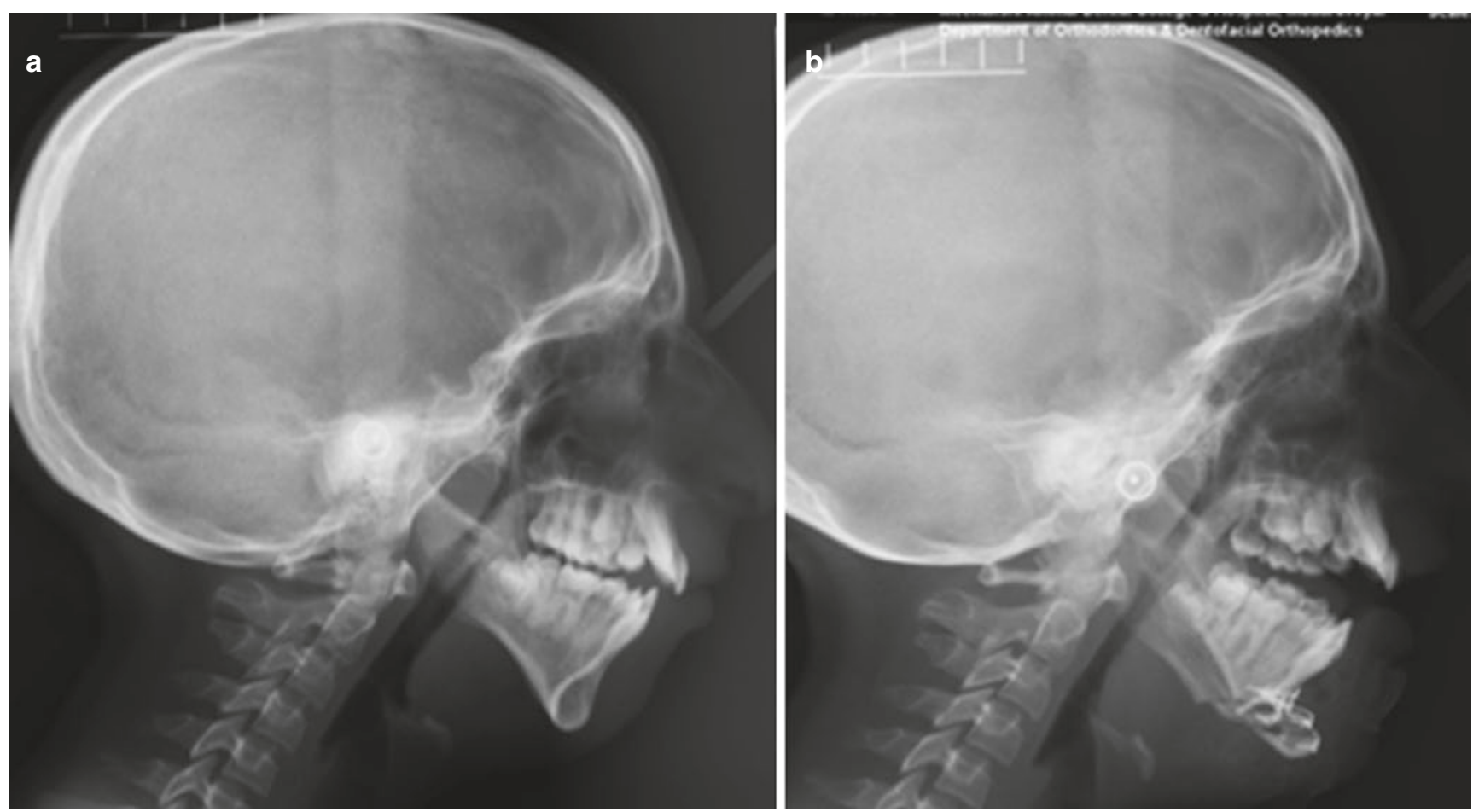

(CAssociation of Oral and Maxillofacial Surgeons of India

Fig. 78.40 (a) Preoperative and (b) postoperative lateral cephalogram radiographic view of a patient with Treacher Collins syndrome who underwent double sliding genioplasty

The total facial height is often excessive, with a normal upper facial height. This is due to combination of anterior open-bite malocclusion, mandibular retrognathism and chin dysplasia. Hypoplasia of the orbito-zygomatic complex is a characteristic feature. These hypoplastic facial skeletal features have variable effects on the TMJ, masticatory function and facial soft tissues and expressions.

Both the maxilla and mandible are rotated in a counterclockwise rotation. Thus, the maxillary and mandibular plane angles are excessively steep. Clinically, this translates to a shorter posterior facial height in TCS patients.

The mandible size is evidently decreased in both the ramus height and the body length. The gonial angle is obtuse with anti-gonial notching. The steepness due to clockwise rotation of the maxillomandibular complex along with the anterior and posterior vertical height disproportions and severe horizontal deficiency is reflected in the A-point-to-Bpoint discrepancy. All of these cephalometric findings explain the clinical facial dysmorphology.

Incidence of cleft palate with or without cleft lip (and choanal atresia of the nasal cavity) is variable. Dental anomalies are present in $60 \%$ of individuals such as tooth agenesis enamel, opacities and ectopic eruption of the maxillary first molars.

\subsubsection{Surgical Management of the Orbito- zygomatic Region}

Treatment of the skeletal defect in the orbito-zygomatic region varies according to the severity of the defect. The following classification categorizes the deformities according to severity and their treatment. Since this region attains growth by age of 9 , most surgeons postpone definitive reconstruction up to this age.

Type 1 defects: The orbito-zygomatic complex is dysplastic and hypoplastic. Type 1 represents the mildest form of the defect and can be easily treated by autologous fat, either by liposuction and injection or dermis fat graft [65]. The merit of autologous fat grafting is that it is repeatable with minimal donor site morbidity and can be done before growth completion. It is ideal for growing children who are psychologically affected due to a poor facial appearance. The disadvantage of this technique is that it may have to be performed repeatedly to maintain the volume of correction.

Fat transfer can be used alone for correction of minor defects. It has more of an adjunctive role in severe defects after wherein hard tissue augmentation is the preferred intervention. 

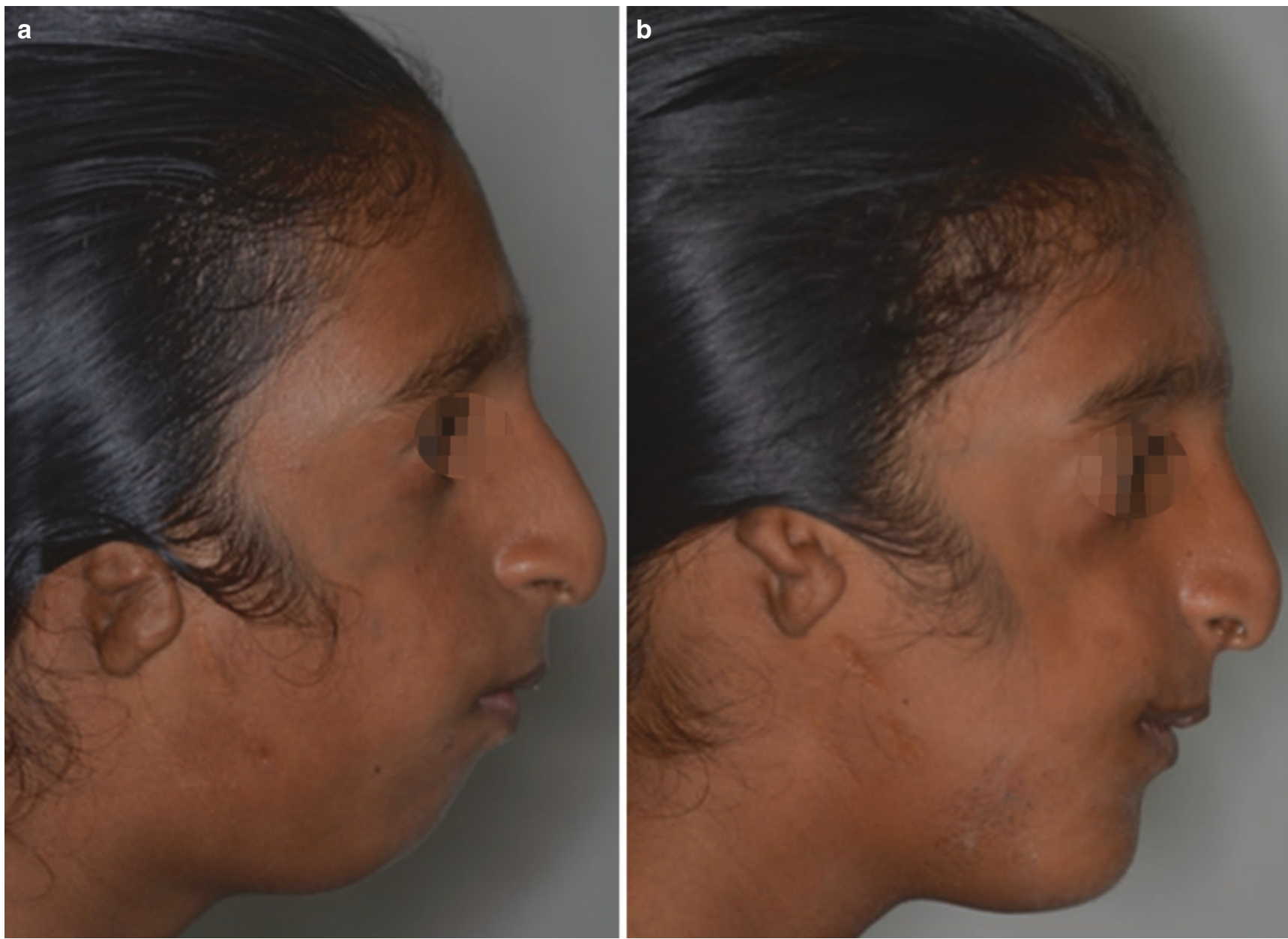

CAssociation of Oral and Maxillofacial Surgeons of India

Fig. 78.41 (a, b) Extraoral profile view showing marked improvement in the lower third of the face. (a) Pre-surgical profile photo showing retrogenia (Fig. 78.31a1), (b) post-surgical profile photo after a double sliding genioplasty, showing good chin prominence
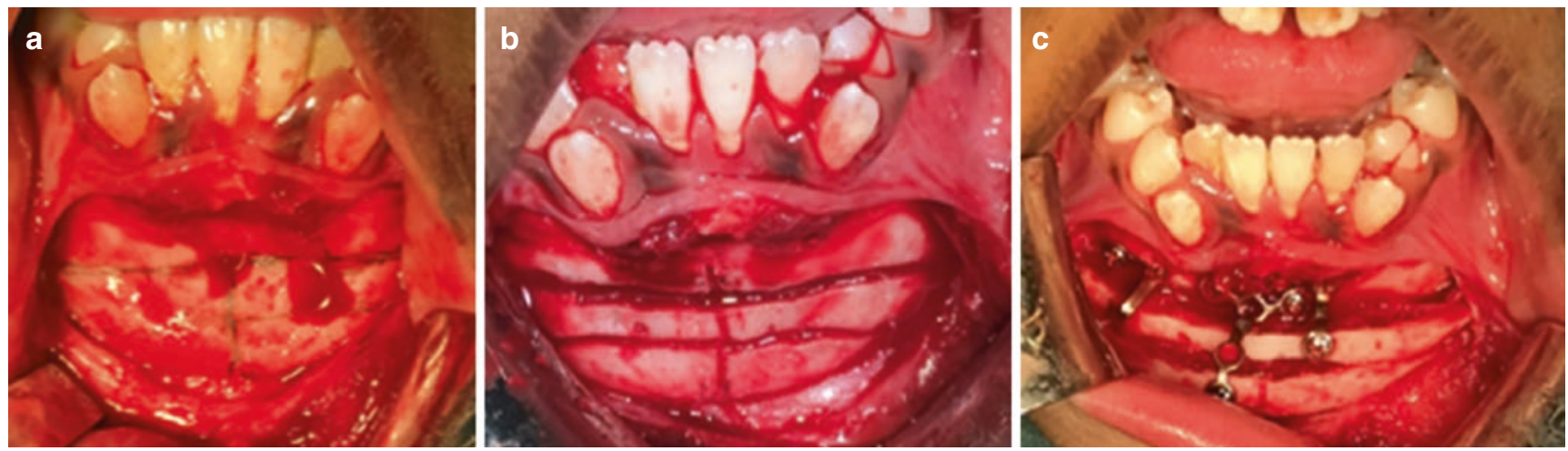

(CAssociation of Oral and Maxillofacial Surgeons of India

Fig. 78.42 (a-c) Intraoperative view of double sliding genioplasty done for the same patient as in Fig. 78.41. (a) Surgical exposure of the genium, (b) osteotomy design marked on the chin and (c) completion of genioplasty with fixation (also see Figs. 68.32 and 68.33 for use of double sliding genioplasty in other clinical situations) 

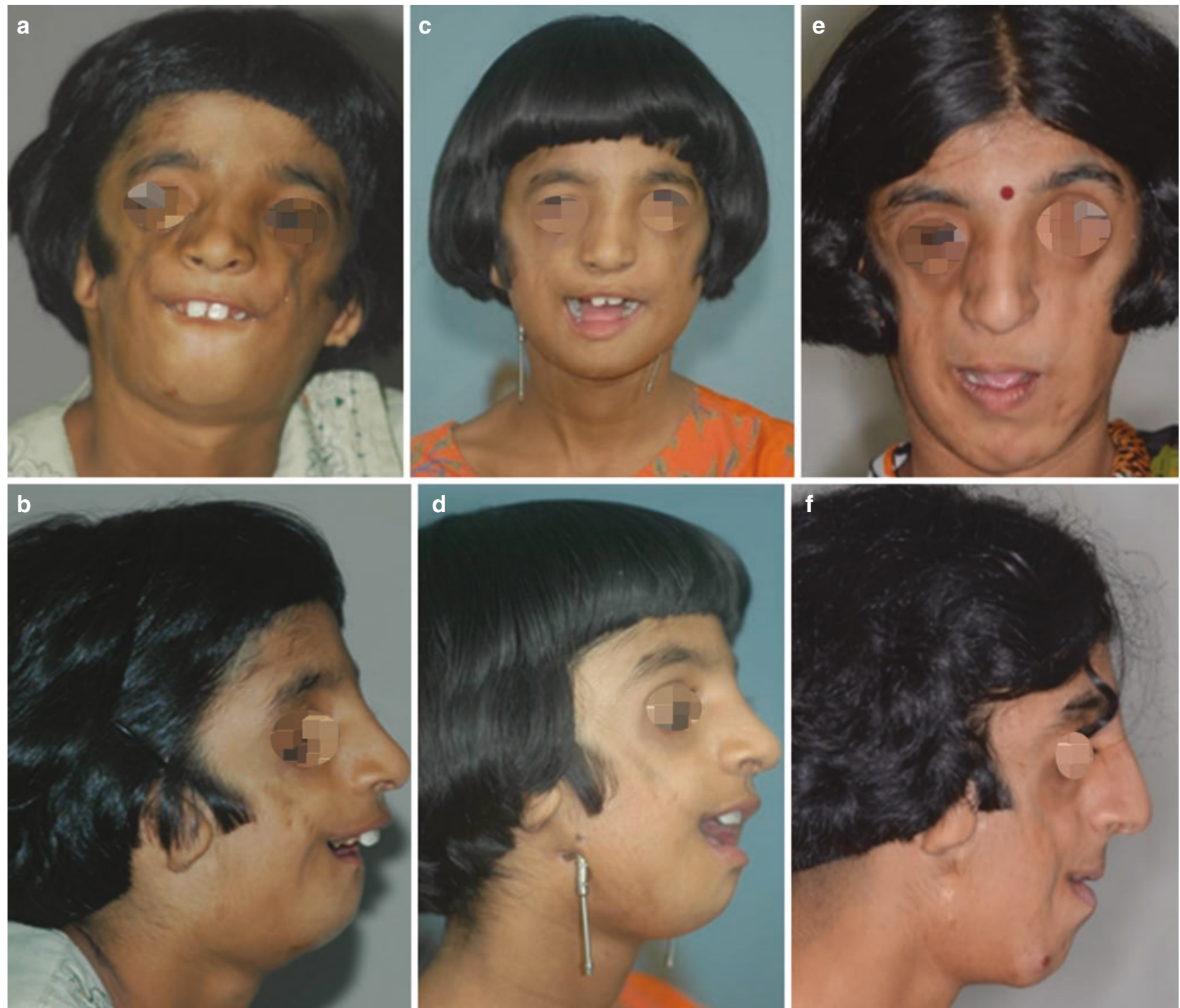

CAssociation of Oral and Maxillofacial Surgeons of India

Fig. 78.43 (a-f) Case of TCS who underwent early osteodistraction. (a, b) Pre-operative frontal and profile photos, (c, d) Frontal and profile photos post distraction with bilateral uni-directional distractors, $(\mathbf{e}, \mathbf{f})$ Frontal and profile views after five years follow-up

Type 2 defects: Defect consists of hypoplastic zygomatic body with a reduced zygomatic temporal process and a dysplastic or absent lateral orbital wall. This class of defect usually requires surgery to address the bony deficiency. Studies have established that a malar osteotomy offers better contour as compared to onlay bone autografting [66]. Though the malar osteotomy is aimed at correcting the width of the midface, it is difficult to augment anteroposterior projection by osteotomy only. It should be noted that this defect is characterized by a deficient vertical dimension as well. Thus, a zygomatic osteotomy is preferably combined with an onlay graft. The Mommaerts zygomatic osteotomy is favoured in some units because it does not alter orbital dimensions. Alloplastic materials [e.g. Medpore] can be very effective alternatives to the traditional onlays [67].

\section{Types 3 and 4}

The defects range from severe hypoplasia/dysplasia to complete absence of orbito-zygomatic bony complex. Patients belonging to these groups require bony augmentation. In adults, alloplastic augmentation with patient-specific implants can be considered as they provide optimal results.

In general, the zygomatico-maxillary-orbital bone complex can be reconstructed using an autologous free bone or regional pedicle graft. Non-vascularized autologous bone grafting for larger defects is increasingly prone to loss of graft due to infection and resorption if not fully covered by surrounding soft tissue. Studies have established that resorption occurs due to reduced vascularity and increased functional loads on the graft. Therefore, it is prudent to line the bone grafts by soft tissue on its inner side in the proximity of maxillary sinus and nasal cavity [68]. 
Calvarial bone grafts have been used for reconstruction of midface in various craniofacial deformities. Fullthickness calvarial grafting outcomes are more stable in the long term due to the dense cortical nature of the graft (Fig. 78.44a, b). Studies [69] have also established that dense membranous bone grafts [e.g. calvarial] are more effective than endochondral grafts [e.g. iliac crest] in the craniofacial skeleton. Calvarial bone grafts have become popular because of their low resorption rates and minimal donor site morbidity for orbito-zygomatic complex reconstruction [70].

\subsection{Conclusion}

Hemifacial microsomia and Treacher Collins syndrome are both congenital craniofacial anomalies that negatively impact the physiological and psychological wellbeing of an individual [71]. Due to multidimensional nature of the deformity, a multidisciplinary holistic approach is required with proper guidance and counselling of the patients at every level of treatment. However, with the advances in regenerative sciences and genetic engineering, diagnosis and management of such congenital deformities is becoming less challenging. Disclosure Authors have no financial conflicts to disclose.

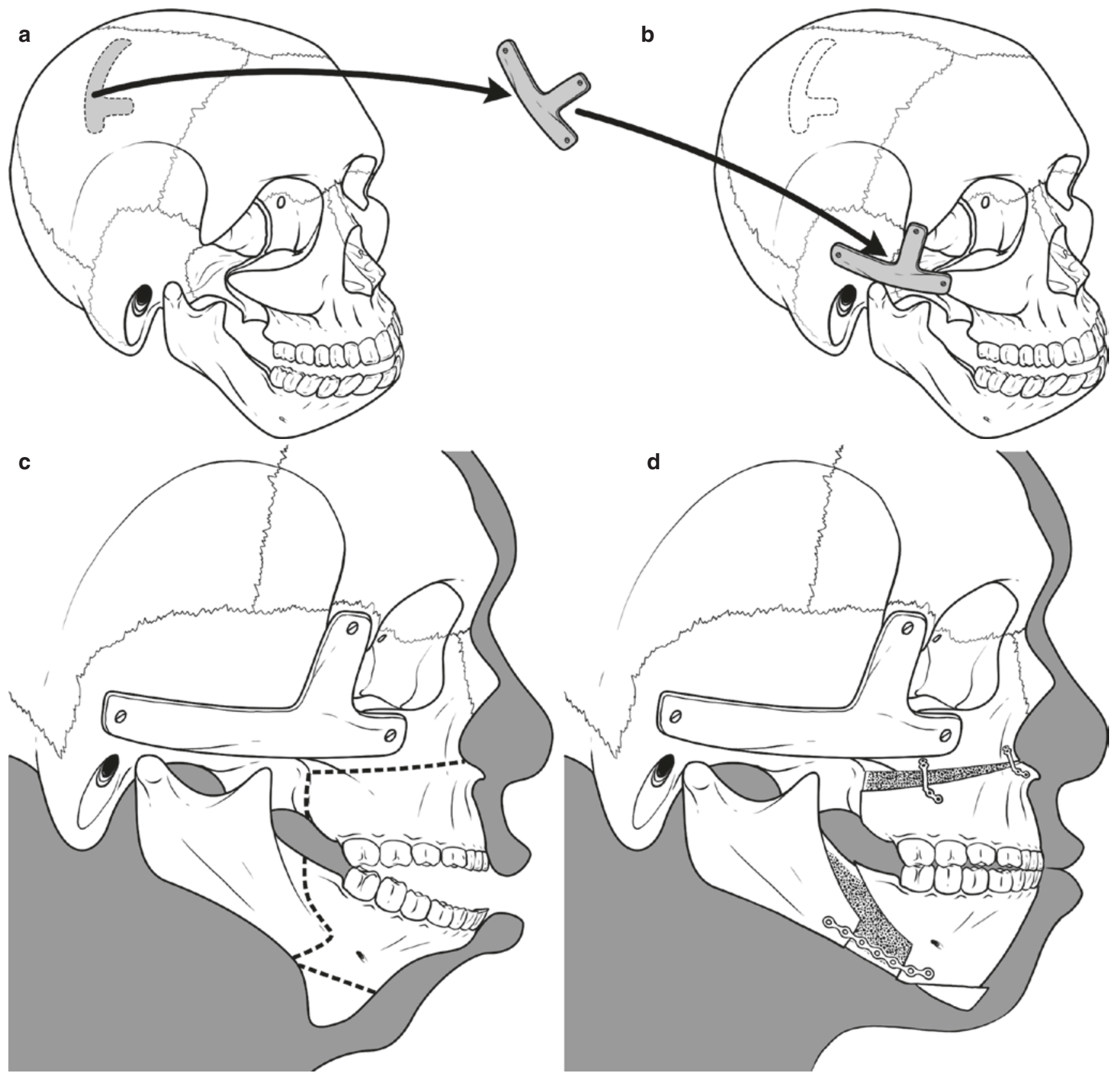

CAssociation of Oral and Maxillofacial Surgeons of India

Fig. 78.44 Skeletal correction for TCS. (a) Calvarial graft harvest for recsontruction of zygoma, (b) graft in place, (c) osteotomy design for orthognathic correction with bimaxillary surgery and genioplsty, (d) diagram showing post orthognathic final correction 


\subsection{Case Scenarios}

\section{Case 1: Treacher Collins Syndrome} (Fig. 78.43a-f)

Case of TCS who underwent early osteodistraction. Note the mandibular advancement using bilateral unidirectional distractors. Follow-up after 5 years. Patient is currently undergoing orthodontic treatment.
Case 2: Hemifacial Microsomia (Figs. 78.45a-e, 78.46a-c, 78.47a, b, 78.48a-c, 78.49a-c, 78.50a, b, $78.51,78.52 a-d, 78.53 a, b)$

Case of a 20-year-old girl having HFM, undergoing osteotomy for asymmetry correction. Preoperative photographs, radiographs and CT scans showing the extent of asymmetry. Pre-surgical orthodontics for levelling and alignment. Virtual planning to fabricate CAD-CAM splint. Final postoperative
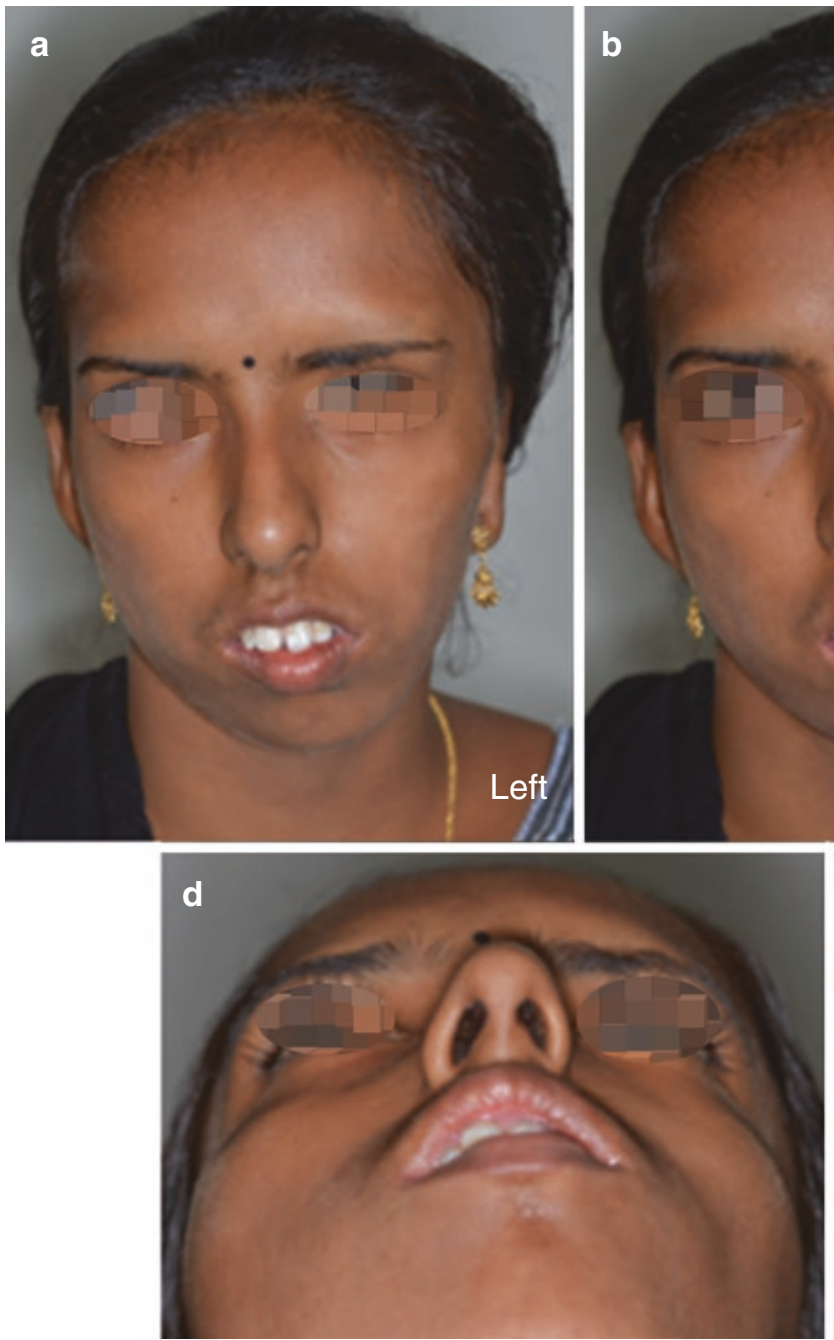
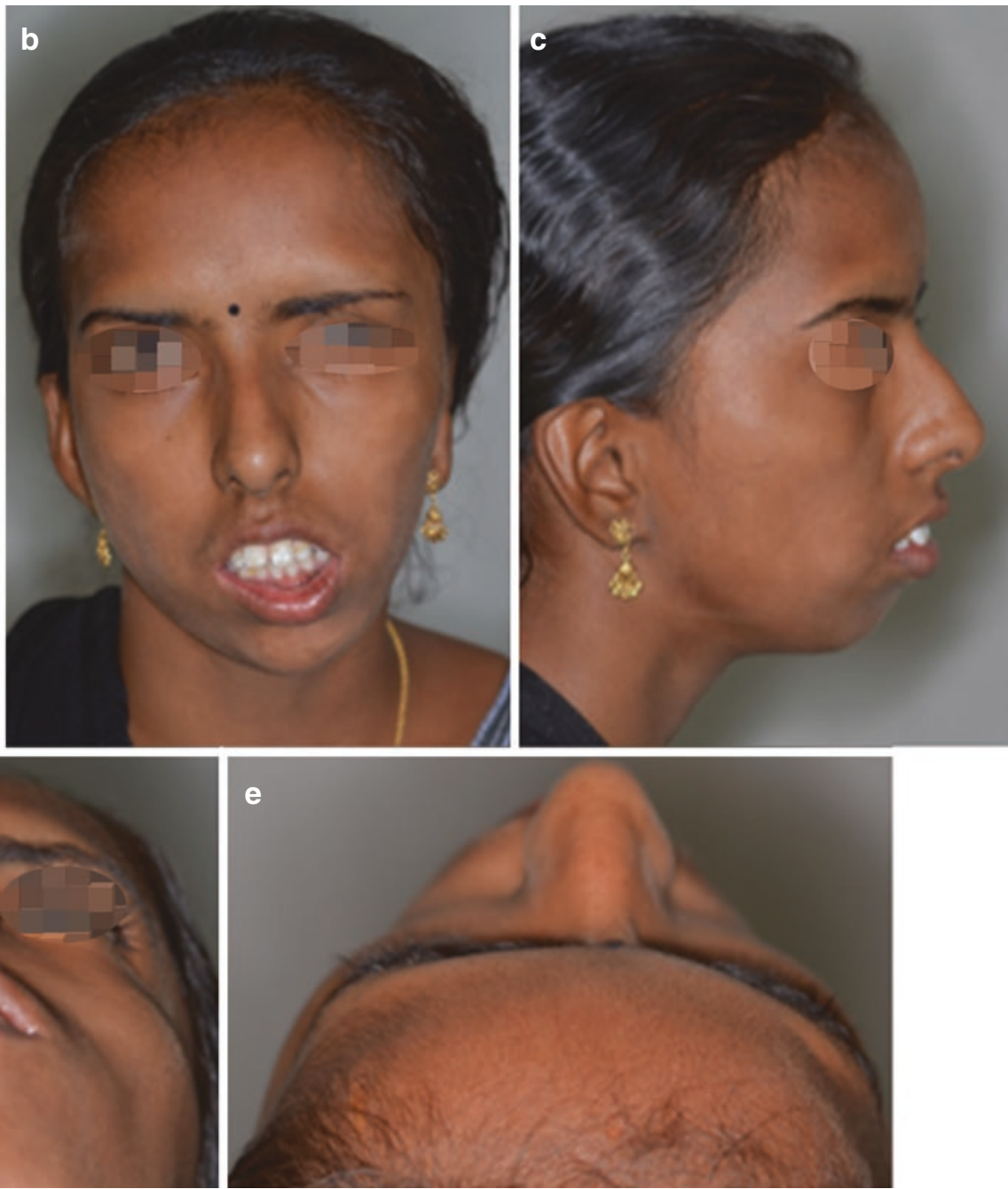

CAssociation of Oral and Maxillofacial Surgeons of India

Fig. 78.45 (a-e) Preoperative views of a female patient with facial asymmetry and deviation towards the left side
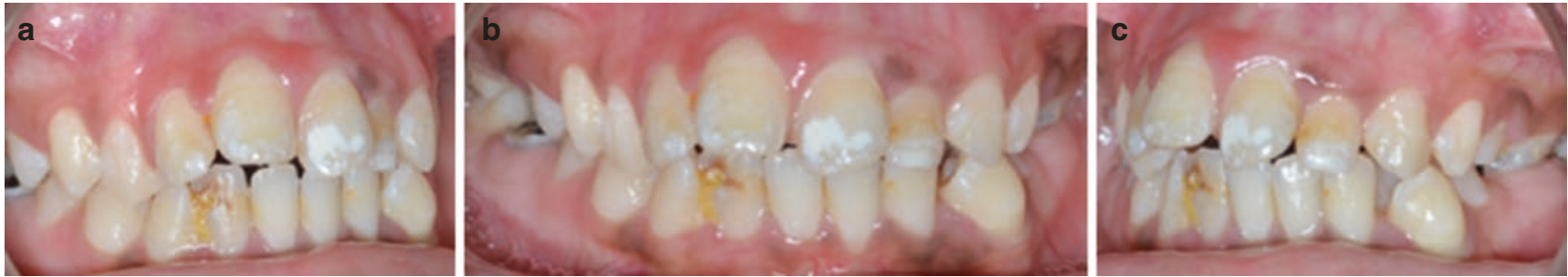

CAssociation of Oral and Maxillofacial Surgeons of India

Fig. 78.46 (a-c) Intraoral view showing malocclusion, crowding and midline deviation 

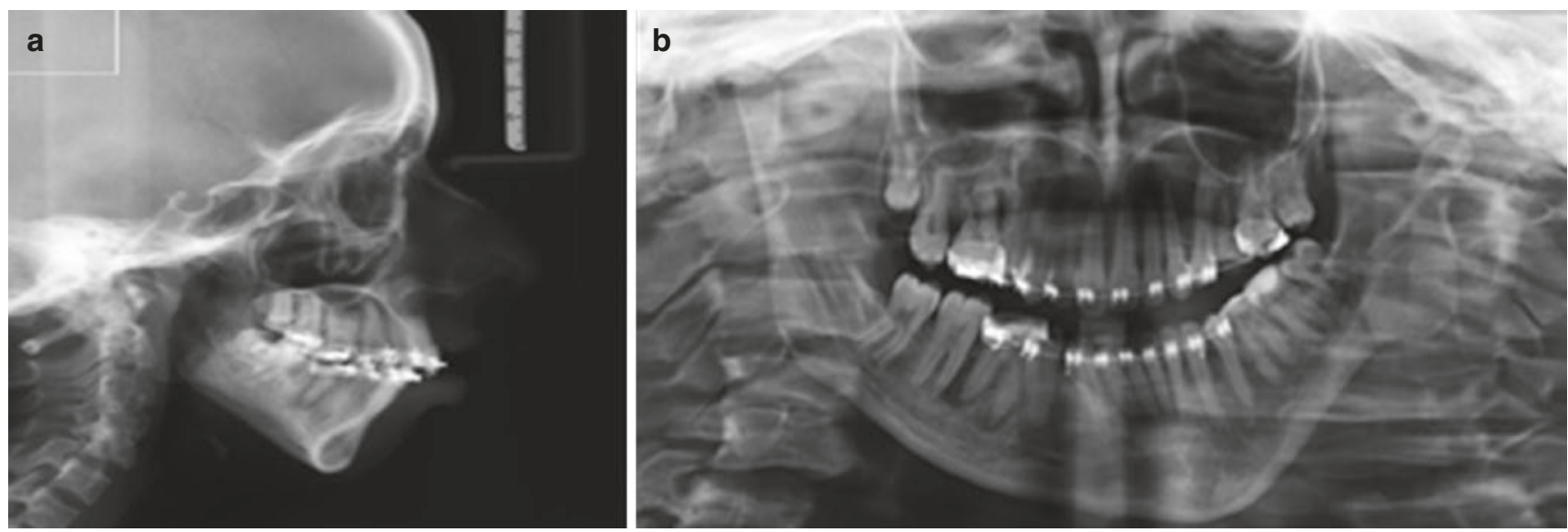

CAssociation of Oral and Maxillofacial Surgeons of India

Fig. 78.47 (a, b) Preoperative (a) lateral cephalogram and (b) OPG showing Class II skeletal profile with left-sided TMJ deformity
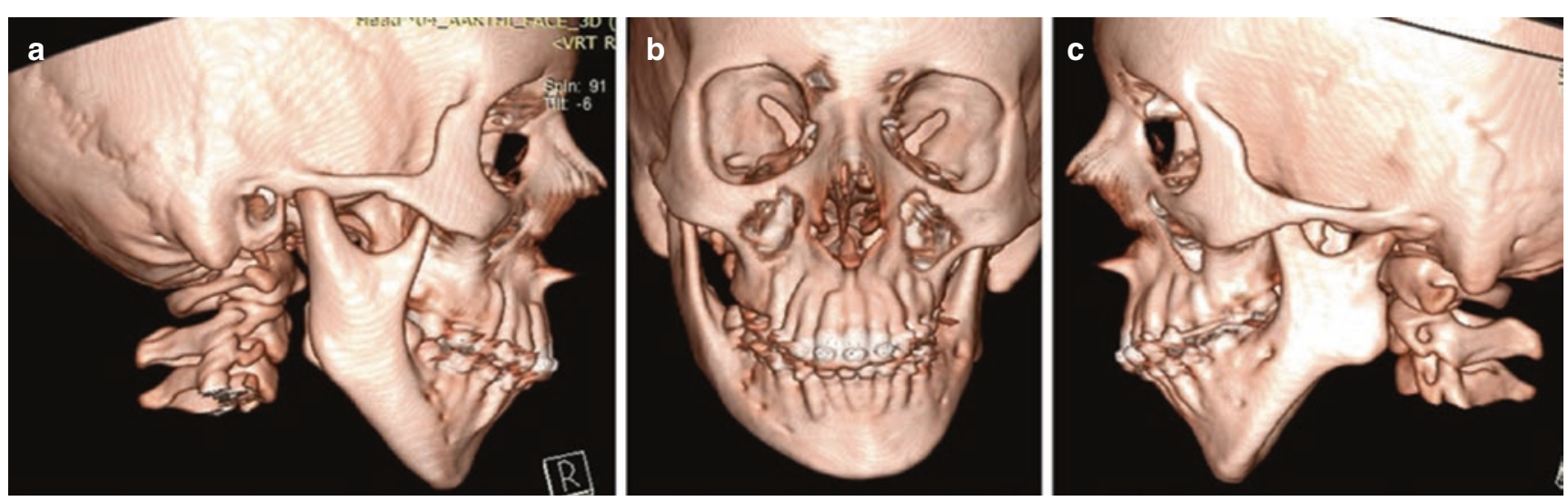

(C)Association of Oral and Maxillofacial Surgeons of India

Fig. 78.48 (a-c) Preoperative CT scans showing TMJ deformity on the left side
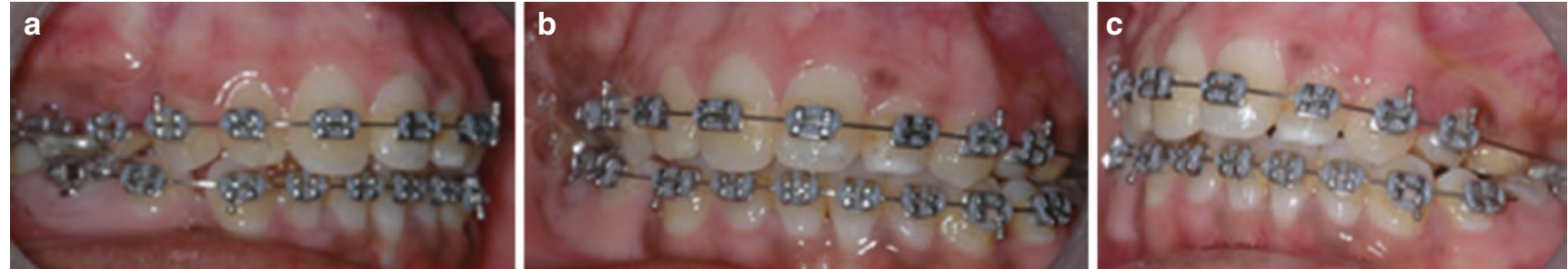

CAssociation of Oral and Maxillofacial Surgeons of India

Fig. 78.49 (a-c) Pre-surgical intermediate orthodontics treatment for alignment and levelling 

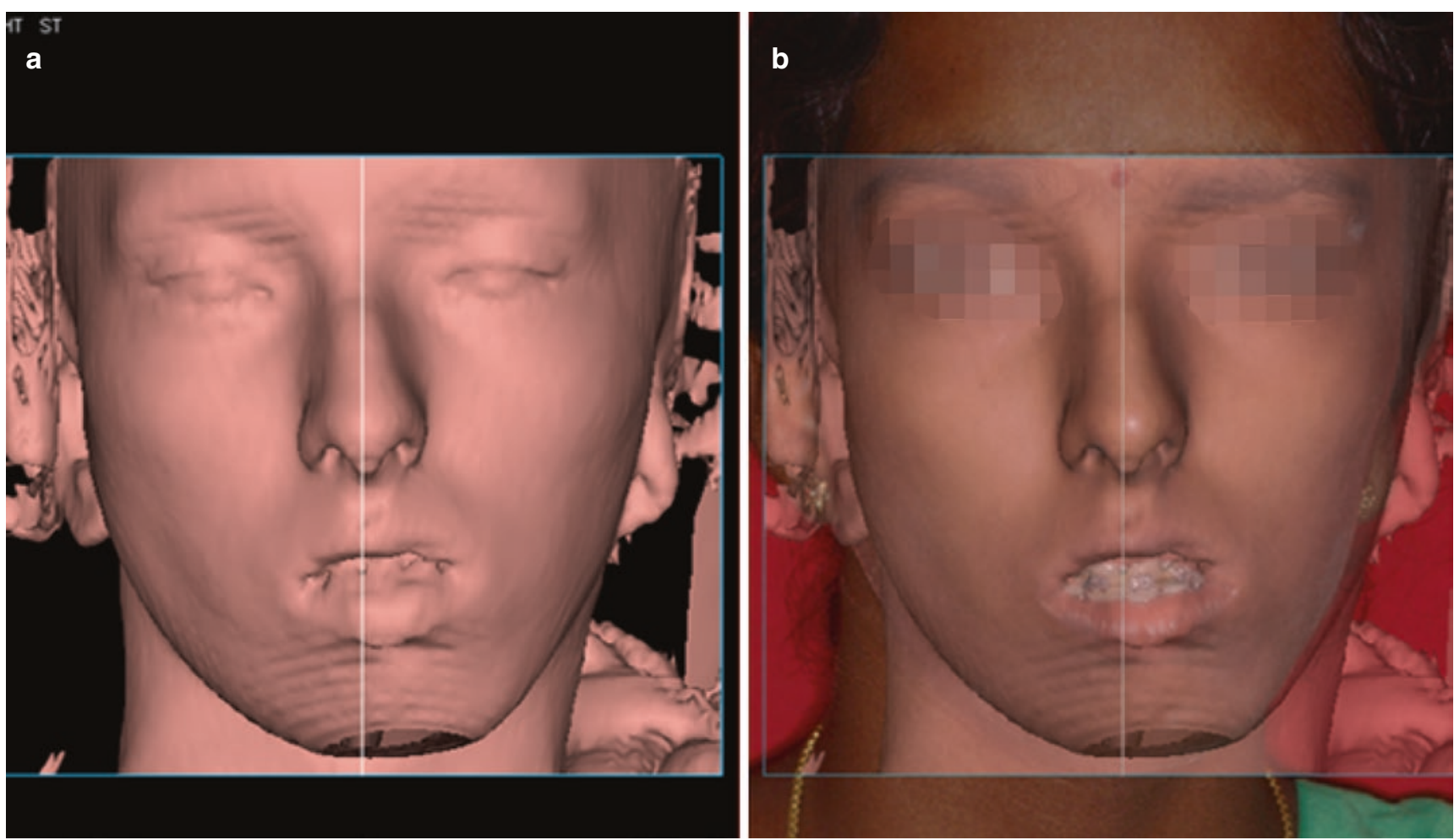

CAssociation of Oral and Maxillofacial Surgeons of India

Fig. 78.50 (a, b) Virtual planning using 3D photogrammetry. (a) soft tissue reconstruction from the CT data, (b) superimposition of the patients photograph on the CT model

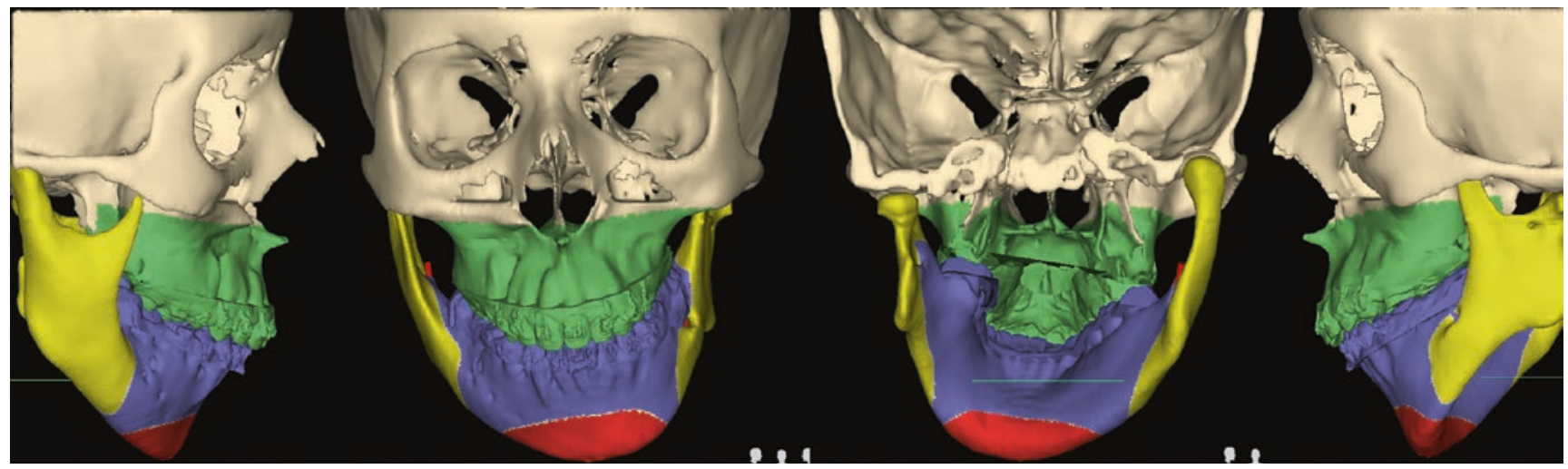

CAssociation of Oral and Maxillofacial Surgeons of India

Fig. 78.51 Virtual planning of orthognathic surgery to correct pitching, roll and yaw defect of the maxilla and mandible with genioplasty 

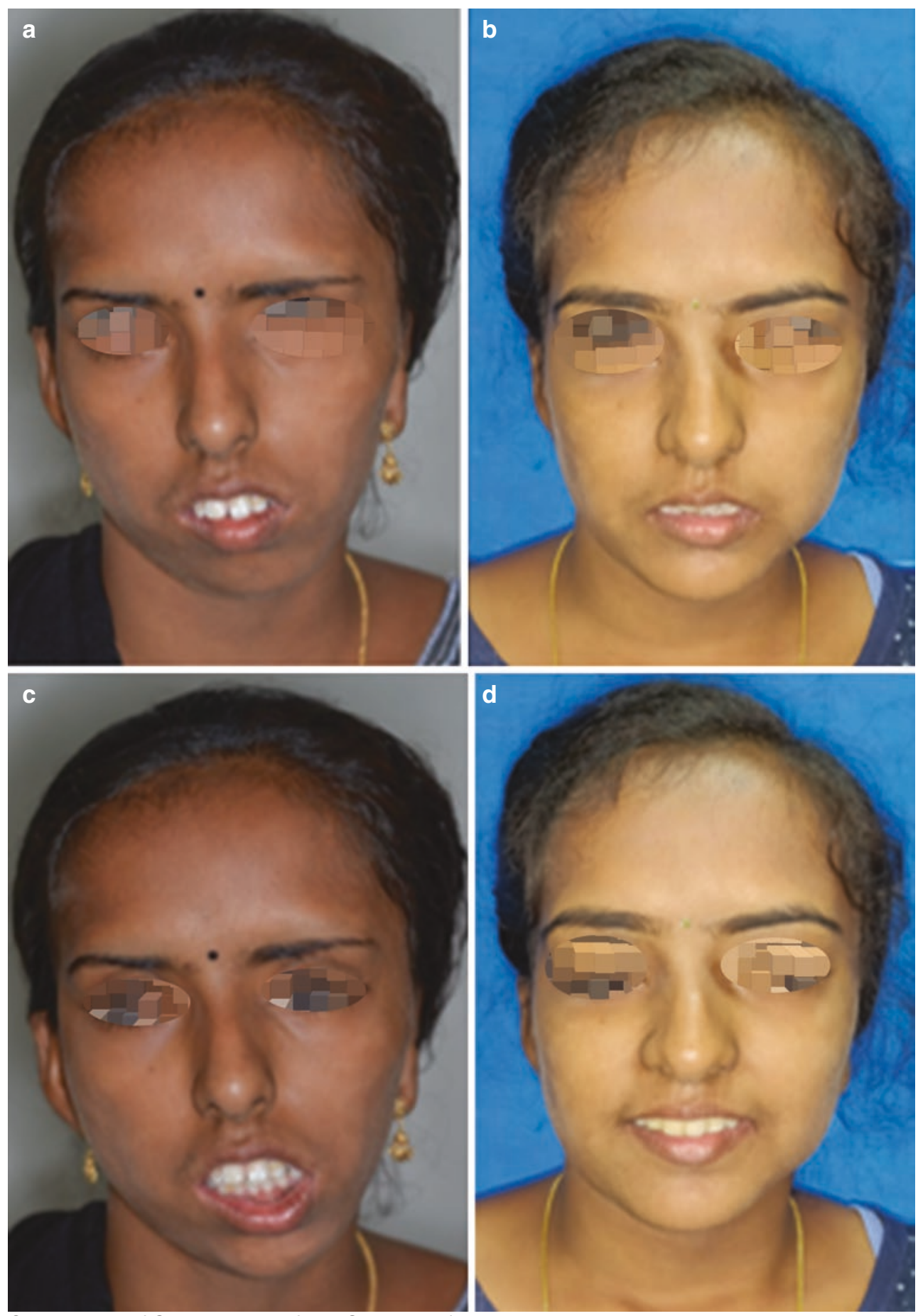

(C)Association of Oral and Maxillofacial Surgeons of India

Fig. 78.52 (a-d): Pre (a, c) and post operative $(\mathbf{b}, \mathbf{d})$ photograph showing correction of asymmetry in patient with HFM 

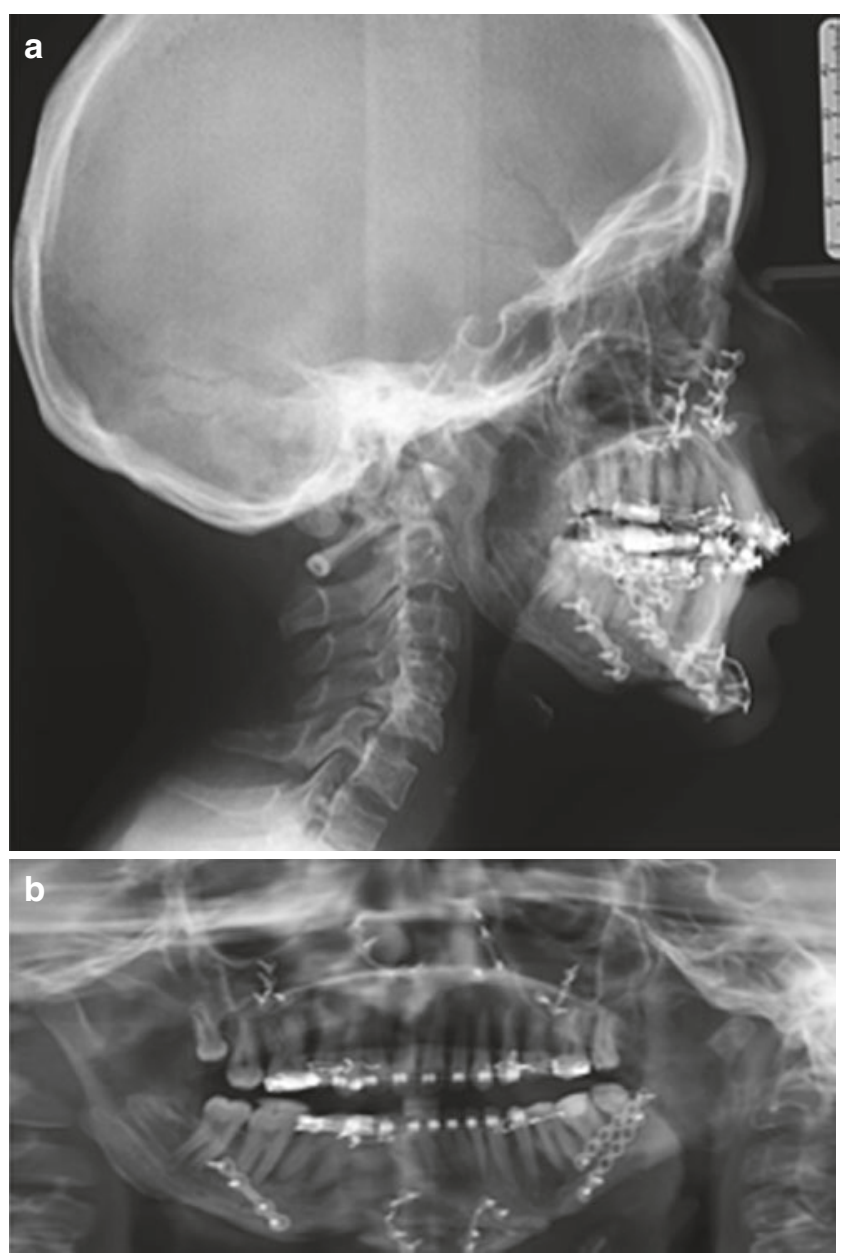

(CAssociation of Oral and Maxillofacial Surgeons of India

Fig. 78.53 (a, b) Postoperative (a) lateral cephalogram and (b) OPG showing correction of maxillomandibular relation. Refer to Fig. 78.47 for pre-operative xrays

photographs and radiographs showing correction of asymmetry.

\section{References}

1. Posnick JC. Hemifacial macrosomia: evaluation and treatment. Principles and practice of orthognathic surgery. St. Louis, Missouri: Elsevier; 2014.

2. Brandstetter KA, Patel KG. Craniofacial Microsomia. Facial Plast Surg Clin North Am 2016 Nov;24(4):495-515. Review.

3. Poswillo D. The aetiology and pathogenesis of craniofacial deformity. Development. 1988;103(Suppl):207-12.

4. Scambler PJ. The 22q11 deletion syndromes. Hum Mol Genet. 2000, Oct 1;9(16):2421-6.

5. Poswillo D. The pathogenesis of the first and second branchial arch syndrome. Oral Surg Oral Med Oral Pathol. 1973;35(3):302-28.
6. Werler MM, Sheehan JE, Hayes C, Mitchell AA, Mulliken JB. Vasoactive exposures, vascular events, and hemifacial microsomia. Birth Defects Res A Clin Mol Teratol. 2004;70(6):389-95.

7. Werler MM, Sheehan JE, Hayes C, Padwa BL, Mitchell AA, Mulliken JB. Demographic and reproductive factors associated with hemifacial microsomia. Cleft Palate Craniofac J. 2004;41(5):494-50.

8. Taysi K, Marsh JL, Wise DM. Familial hemifacial microsomia. Cleft Palate J. 1983;20(1):47-53.

9. Juriloff DM, Harris MJ, Froster-Iskenius U. Hemifacial deficiency induced by a shift in dominance of the mouse mutation far: a possible genetic model for hemifacial microsomia. J Craniofac Genet Dev Biol. 1987;7(1):27-44.

10. Poonawalla HH, Kaye CI, Rosenthal IM, Pruzansky S. Hemifacial microsomia in a patient with Klinefelter syndrome. Cleft Palate J. 1980;17(3):194-6.

11. David DJ, Mahatumarat C, Cooter RD. Hemifacial microsomia: a multisystem classification. Plast Reconstr Surg. 1987;80:525-35.

12. Vento AR, LaBrie RA, Mulliken JB. The O.M.E.N.S. classification of hemifacial microsomia. Cleft Palate Craniofac J 1991;28:68-76. discussion 77

13. Kaban LB, Mulliken JB, Murray JE. Three-dimensional approach to analysis and treatment of hemifacial microso- mia. Cleft Palate J. 1981;18:90-9.

14. Grabb WC. The first and second branchial arch syndrome. Plast Reconstr Surg. 1965;36(5):485-508.

15. Rollnick BR, Kaye CI. Hemifacial microsomia and variants: pedigree data. Am J Med Genet. 1983;15(2):233-53.

16. Stark RB, Saunders DE. The first branchial syndrome. The oralmandibular-auricular syndrome. Plast Reconstr Surg Transplant Bull. 1962;29:229-39.

17. Die MH. Missbildungen des ohres. In: Denker AK, editor. Handbuch der Spez Path Anatomie Histologie. Berlin: Springer; 1926. p. 131.

18. Meurman Y. Congenital microtia and meatal atresia; observations and aspects oftreatment. AMA Arch Otolaryngol. 1957;66:443-63.

19. Hollier LH, Rowe NM, Mackool RJ, Williams JK, Kim JH, Longaker MT, Grayson BH, JG MC. Controlled multiplanar distraction of the mandible. Part III: Laboratory studies of sagittal (anteroposterior) and horizontal (mediolateral) movements. J Craniofac Surg. 2000 Mar;11(2):83-95.

20. Fan WS, Mulliken JB, Padwa BL. An association between hemifacial microsomia and facial clefting. J Oral Maxillofac Surg. 2005;63:330-4.

21. Parameswaran A, Ramanathan M. Hemifacial microsomia. J Indian Orthodontic Soc. 2018 Jul 1;52(3):155.

22. Tahiri Y, Viezel-Mathieu A, Aldekhayel S, Lee J, Gilardino M. The effectiveness of mandibular distraction in improving airway obstruction in the pediatric population. Plast Reconstr Surg. 2014;133:352e-9e.

23. Nagy K, Kuijpers-Jagtman AM, Mommaerts MY. No evidence for long-term effectiveness of early osteodistraction in hemifacial microsomia. Plast Reconstr Surg. 2009;124:2061-71.

24. Mishra L, Misra SR, Kumar M, Tripathy R. Hemifacial microsomia: a series of three case reports. J Clin Diagn Res. 2013 Oct;7(10):2383-6.

25. Munro I. Hemifacial micorosmia: the skeletal correction. Oper Tech Plast Reconstr Surg. 1994;1:77-92.

26. Kaban LB, Moses MH, Mulliken JB. Correction of hemifacial microsomia in thegrowing child: a follow-up study. Cleft Palate J. 1986;23(Suppl 1):50. 
27. Kaban LB, Padwa BL, Mulliken JB. Surgical correction of mandibular hypoplasia in hemifacial microsomia: the case for treatment in early childhood. J Oral Maxillofac Surg. 1998;56:628-38.

28. Ohtani J, Hoffman WY, Vargervik K, Oberoi S. Team management and treatment outcomes for patients with hemifacial microsomia. Am J Orthod Dentofac Orthop. 2012;141(4 Suppl):S74-81.

29. Silvestri A, Natali G, Iannetti G. Functional therapy in hemifacial microsomia: therapeutic protocol for growing children. J Oral Maxillofac Surg. 1996;54:271-8. discussion 278-80

30. Zanardi G, Parente EV, Esteves LS, Louro RS, Capelli J Jr. Orthodontic and surgical treatment of a patient with hemifacial microsomia. Am J Orthod Dentofac Orthop. 2012;141(4 Suppl):S130-9.

31. Tahiri Y, Chang CS, Tuin J, Paliga JT, Lowe KM, Taylor JA, et al. Costochondral grafting in craniofacial microsomia. Plast Reconstr Surg. 2015;135:530-41.

32. Murra JE, Mulliken JB, Kaban IB. Twenty-year experience in maxillofacial surgery: an evaluation of early surgery on growth function and body image. Ann Surg. 1979;190:320.

33. Ongkosuwito EM, van Vooren J, van Neck JW, Wattel E, Wolvius $\mathrm{EB}$, van Adrichem LN, et al. Changes of mandibular ramal height, during growth in unilateral hemifacial microsomia patients and unaffected controls. J Craniomaxillofac Surg. 2013;41:92-7.

34. Ortiz Monasterio F, Molina F, Andrade L, Rodriguez C, Sainz AJ. Simultaneous mandibular and maxillary distraction in hemifacial microsomia in adults: avoiding occlusal disasters. Plast Reconstr Surg. 1997;100:852-6.

35. Suh J, Choi TH, Baek SH, Kim JC, Kim S. Mandibular distraction in unilateral craniofacial microsomia: longitudinal results until the completion of growth. Plast Reconstr Surg. 2013;132:1244-52.

36. Salins PC, Venkatraman B, Kavarody M. Morphometric basis for orthomorphic correction of mandibular asymmetry. J Oral Maxillofac Surg. 2008 Jul;66(7):1523-31.

37. Weichman KE, Jacobs J, Patel P, Szpalski C, Shetye P, Grayson B, et al. Early distraction for mild to moderate unilateral craniofacial microsomia: long-term follow-up, outcomes, and recommendations. Plast Reconstr Surg. 2017;139:941e-53e.

38. Cassi D, Battistoni G, Magnifico M, et al. Three-dimensional evaluation of facial asymmetry in patients with hemifacial microsomia using stereophotogrammetry. J Craniomaxillofac Surg. 2019;47(1):179-84.

39. Peacock ZS, Tricomi BJ, Faquin WC, et al. Bilateral continuous automated distraction osteogenesis: proof of principle. J Craniofac Surg. 2015;26(8):2320-4.

40. Yamada Y, Ueda M, Hibi H, Nagasaka T. Translational reseach for injectable tissue-engineered bone regeneration using mesenchymal stem cells and platelet-rich plasma: from basic research to clinical application. Cell Transplant. 2004;13:343-55.

41. Gorlin RJ, Cohen MM Jr, Levin LS. Syndromes of the head and neck. 3rd ed. New York: Oxford University Press; 1990. p. 649-52.

42. Franceschetti A, Klein D. The mandibulofacial dysostosis; a new hereditary syndrome. Acta Ophthalmol. 1949;27(2):143-224.

43. Rogers BO. Berry-treacher collins syndrome: a review of 200 cases (mandibulo-facial dysostosis; franceschetti-zwahlen-klein syndromes). Br J Plast Surg. 1964 Apr;17:109-37. Pubmed pmid: 14150863

44. Jones KL, Smith DW, Harvey MAS, Hall BD, Quan L. Older paternal age and fresh gene mutation: data on additional disorders. J Pediatr. 1975;86:84-8.

45. Posnick JC, Ruiz RL. Treacher Collins syndrome: current evaluation, treatment, and future directions. Cleft Palate Craniofac J. 2000;37:434.
46. Sulik KK, Johnston MC, Smiley SJ, Speight HS, Jarvis BE. Mandibulofacial dysostosis (Treacher Collins syndrome): a new proposal for its pathogenesis. Am J Med Genet. 1987;27:359-72.

47. Dauwerse JG, Dixon J, Seland S, Ruivenkamp CA, van Haeringen A, Hoefsloot LH, et al. Mutations in genes encoding subunits of RNA polymerases I and III cause Treacher Collins syndrome. Nat Genet. 2011;43:20-2.

48. Andrade EC, Júnior VS, Didoni AL, Freitas PZ, Carneiro AF, Yoshimoto FR. Treacher Collins syndrome with choanal atresia: a case report and review of disease features. Braz J Otorhinolaryngol. 2005;71:107-10.

49. Nikkhah D, Ponniah A, Ruff C, Dunaway D. Planning surgical reconstruction in Treacher-Collins syndrome using virtual simulation. Plastic Reconstr Surg. 2013;132:790e-805e.

50. Marszalek B, Wójcicki P, Kobus K, Trzeciak WH. Clinical features, treatment and genetic background of Treacher Collins syndrome. J Appl Genet. 2002;43:223-33.

51. Shete P, Tupkari J, Benjamin T, Singh A. Treacher Collins syndrome. J Oral Maxillofac Pathol. 2011;15:348-51.

52. Waitzman AA, Posnick JC, Armstrong DC, Pron GE. Craniofacial skeletal measurements based on computed tomography: part II. Normal values and growth trends. Cleft Palate Craniofac J. 1992, Mar 01;29(2):118-28.

53. Trainor PA, Dixon J, Dixon MJ. Treacher Collins syndrome: etiology, pathogenesis and prevention. Eur $\mathrm{J}$ Hum Genet. 2009; 17:275-83.

54. Sher AE. Obstructive sleep apnea syndrome: a complex disorder of the upper airway. Otolaryngol Clin N Am. 1990;23(4):593-608.

55. Hoeve LJ, Pijpers M, Joosten KF. OSAS in craniofacial syndromes: an unsolved problem. Int J Pediatr Otorhinolaryngol. 2003;67.

56. Rachmiel A, Emodi O, Aizenbud D. Management of obstructive sleep apnea in pediatric craniofacial anomalies. Ann Maxillofac Surg. 2012;2:111-5.

57. Ellis DS, Potluri PK, O'Flaherty JE, et al. Difficult airway management in the neonate: a simple method of intubating through a laryngeal mask airway. Paediatr Anaesth. 1999;9:460-2.

58. Morovic CG, Monasterio L. Distraction osteogenesis for obstructive apneas in patients with congenital craniofacial malformations. Plast Reconstr Surg. 2000;105:2324-30.

59. Rachmiel A, Emodi O, Rachmiel D, Aizenbud D. Internal mandibular distraction to relieve airway obstruction in children with severe micrognathia. Int J Oral Maxillofac Surg. 2014;43:1176-81.

60. Diner PA, Kollar E, Martinez H, Vazquez MP. Submerged intraoral device for mandibular lengthening. J Craniomaxillofac Surg. 1997;25:116-23.

61. Hwang DW, Jung KJ, Kim SY, Kim JH. Usefulness of videofluoroscopic swallow study in treacher Collins syndrome with cleft palate: a case report. Ann Rehabil Med 2014 Oct;38(5):707-11.

62. da Silva Dalben G, Teixeira das Neves L, Ribeiro Gomide M. Oral health status of children with treacher Collins syndrome. Spec Care Dentist 2006 Mar-Apr; 26 (2):71-75. quiz 85-7.

63. Okada R, Kuroda T. Orthodontic treatment for a patient with Treacher-Collins syndrome: a case report. World J Orthod 2008 Winter; 9 (4):e37-e47. PubMed PMID:19641756.

64. Hylton JB, Leon-Salazar V, Anderson GC, De Felippe NL. Multidisciplinary treatment approach in Treacher Collins syndrome. J Dent Child (Chic) 2012 Jan-Apr; 79 (1):15-21. Review. PubMed PMID: 22449504.

65. Lim AA, Fan K, Allam KA, et al. Autologous fat transplantation in the craniofacial patient: the UCLA experience. J Craniofac Surg 2012;23(4):1061e6 [Epub 2012/07/11]. 
66. Posnick JC, Goldstein JA, Waitzman AA. Surgical correction of the Treacher Collins malar deficiency: quantitative CT scan analysis of long-term results. Plast Reconstr Surg. 1993;92(1):12-22.

67. Mommaerts MY, Nadjmi N, Abeloos JV, Neyt LF. Six year's experience with the zygomatic "sandwich" osteotomy for correction of malar deficiency. J Oral Maxillofac Surg Off J Am Assoc Oral Maxillofac Surg 1999;57(1):8e13. discussion 4e5. Epub 1999/01/23.

68. Smolka W, Eggensperger N, Kollar A, Iizuka T. Midfacial reconstruction using Calvarial Split bone grafts. Arch Otolaryngol Head Neck Surg. 2005;131(2):131-6.
69. Freihofer HP. Variations in the correction of Treacher Collins syndrome. Plast Reconstr Surg 1997;99(3):647e57.

70. Marsh JL, Celin SE, Vannier MW, Gado M. The skeletal anatomy of mandibulofacial dysostosis (Treacher Collins syndrome). Plast Reconstr Surg 1986;78(4):460e70. [Epub 1986/10/01].

71. Murray JE, Kaban LB, Mulliken JB. Analysis and treatment of hemifacial microsomia. J Craniofac Surg. 1985;33:377.

Open Access This chapter is licensed under the terms of the Creative Commons Attribution 4.0 International License (http://creativecommons. org/licenses/by/4.0/), which permits use, sharing, adaptation, distribution and reproduction in any medium or format, as long as you give appropriate credit to the original author(s) and the source, provide a link to the Creative Commons license and indicate if changes were made.

The images or other third party material in this chapter are included in the chapter's Creative Commons license, unless indicated otherwise in a credit line to the material. If material is not included in the chapter's Creative Commons license and your intended use is not permitted by statutory regulation or exceeds the permitted use, you will need to obtain permission directly from the copyright holder. 